UNIVERSIDADE DE SÃO PAULO

ESCOLA DE ENFERMAGEM

LARA SIMONE MESSIAS FLORIANO

\title{
POLÍTICAS PÚBLICAS DE DESINSTITUCIONALIZAÇÃO NO ESTADO DE SÃO PAULO E AS RECOMENDAÇÕES DO CENSO
} PSICOSSOCIAL (2008) DE MORADORES DE HOSPITAIS PSIQUIÁTRICOS

SÃO PAULO 


\title{
POLÍTICAS PÚBLICAS DE DESINSTITUCIONALIZAÇÃO NO ESTADO DE SÃO PAULO E AS RECOMENDAÇÕES DO CENSO PSICOSSOCIAL (2008) DE MORADORES DE HOSPITAIS PSIQUIÁTRICOS
}

\author{
Versão corrigida Tese apresentada ao \\ Programa Interunidades de Doutoramento em \\ Enfermagem da Escola de Enfermagem da \\ Universidade de São Paulo e Escola de \\ Enfermagem de Ribeirão Preto, para a \\ obtenção do título de Doutora em Ciências. \\ Área de Concentração: Enfermagem \\ Linha de pesquisa: Prática Social e \\ Profissional em Saúde \\ Orientad ora: Prof. ${ }^{a}$ Dr. ${ }^{a}$ Sônia Barros
}

\section{VERSÃO CORRIGIDA}

A versão original encontra-se disponível na Biblioteca da Escola de Enfermagem da Universidade de São Paulo e na Biblioteca Digital de Teses e Dissertações da Universidade de São Paulo

\section{SÃO PAULO}


AUTORIZO A REPRODUÇÃO E DIVULGAÇÃO TOTAL OU PARCIAL DESTE TRABALHO, POR QUALQUER MEIO CONVENCIONAL OU ELETRÔNICO, PARA FINS DE ESTUDO E PESQUISA, DESDE QUE CITADA A FONTE.

Assinatura:

Data:

\section{Catalogação na Publicação (CIP) \\ Biblioteca "Wanda de Aguiar Horta" \\ Escola de Enfermagem da Universidade de São Paulo}

Floriano, Lara Simone Messias

Políticas públicas de desinstitucionalização no estado de São Paulo e as recomendações do censo psicossocial (2008) de moradores de hospitais psiquiátricos / Lara Simone Messias Floriano. São Paulo, 2019.

$167 \mathrm{p}$.

Tese (Doutorado) - Escola de Enfermagem da Universidade de São Paulo.

Orientadora: Prof. ${ }^{a}$ Dr. ${ }^{a}$ Sônia Barros

Programa Interunidades de Doutoramento em Enfermagem da EEUSP e EERPUSP

1. Hospitais psiquiátricos. 2. Censos. 3. Saúde mental. 4. Enfermagem. I. Título.

Ficha cata lográfica elaborada por Fabiana Gulin Longhi Palacio (CRB-8: 7257) 
Nome: Lara Simone Messias Floriano

Título: Políticas públicas de desinstitucionalização no estado de São Paulo e as recomendações do censo psicossocial (2008) de moradores de hospitais psiquiátricos.

Tese apresentada ao Programa Interunidades de Doutoramento em Enfermagem da Escola de Enfermagem da Universidade de São Paulo e Escola de Enfermagem de Ribeirão Preto, para a obtenção do título de Doutora em Ciências.

Aprovado em:

\section{BANCA EXAMINADORA}

Orientador: Prof. ${ }^{a}$ Dr. ${ }^{a}$ Sônia Barros

Instituição: EEUSP

Assinatura:

Prof. ${ }^{(a)}$ Dr. ${ }^{(a)}$

Instituição:

Julgamento:

Assinatura:

Prof. ${ }^{(a)}$ Dr. ${ }^{(a)}$

Instituição:

Julgamento:

Assinatura:

Prof. ${ }^{(a)}$ Dr. ${ }^{(a)}$

Instituição:

Julgamento:

Assinatura: 


\section{DEDICATÓRIA}

A Deus, pela minha vida.

Aos meus amados pais, José e Elisabete, por serem minha fortaleza e a quem dedico todas as minhas vitórias!

Ao meu marido, Dori Edson, por me esperar sempre e saber que não vou parar!

Aos meus filhos, Davi Antonio, Yuri Daniele Anie Lisa, meus amores, desejo apenas que façam a diferença! 


\section{AGRADECIMENTOS}

A minha Orientadora, Prof. ${ }^{a} \mathcal{D} r .{ }^{a}$ Sônia Barros, por ser o exemplo, a pessoa mais competente que conheci, por ter me dado a oportunidade no momento em que mais precisei profissionalmente, serei sempre grata pelos ensinamentos.

Às queridas amigas Anaísa e Laís, que me acompanharam nessa trajetória, pelos sorrisos, momentos de descontração e apoio incondicional.

A amiga Jussara, pelo suporte e palavras de carinfo; seremos sempre parceiras.

À Professora Dr. ${ }^{a}$ Márcia de Oliveira, querida por todos e por estar sempre pronta a colaborar com seu jeito simples de ser.

Aos colegas do Grupo de Pesquisa "Enfermagem e as Políticas de Saúde Mental", por proporcionarem muito aprendizado.

A Lucélia, Gorete e Clarice, pela bondade e dedicação no cuidado aos meus filhos, enquanto eu estava distante.

Ao Programa "Interunidades de Doutoramento em Enfermagem", da Escola de Enfermagem da Universidade de São Paulo, pela oportunidade de aprendizado de excelência.

Ao amigo Paulo, da Biblioteca da Escola de Enfermagem da USP, pelas gentilezas e pronto auxílio.

À Secretaria de Estado da Saúde de São Paulo, pela autorização institucional para coleta de dados.

Aos sujeitos participantes de minha pesquisa de doutoramento, pelo aceite e disponibilidade. 
Aos membros da banca de exame de qualificação e defesa da tese de doutoramento, pelas valiosas contribuições.

À Fundação de Apoio ao Desenvolvimento Científico e Tecnológico do Paraná, pelo apoio financeiro à realização desta pesquisa.

A minha segunda casa, Universidade Estadual de Ponta Grossa, instituição pública, gratuita e de qualidade, pelo suporte incondicional em minha carreira docente.

Ao Vice-Reitor da Vniversidade Estadual de Ponta Grossa, Dr. Everson Augusto Krum, pelo acolfimento no retorno às minhas atividades docentes e pela confiança com a coordenação do Programa "VEPG Abraça".

A amiga, enfermeira Luciane Cabral, pela simplicidade, pela confiança no meu trabalfo e por me dar oportunidades.

Às colegas professoras Carla, Clóris, Juliana e Lídia, do Departamento de Enfermageme Saúde Pública da Universidade Estadual de Ponta Grossa, por terem assumido minhas obrigações docentes durante meu afastamento.

À equipe do Programa "UEPG Abraça", pela paciência e às enfermeiras Caroline e Alessandra, pelo pronto auxílio.

A todos os usuários de Saúde Mental que são a minha inspiração em cuidar desde o início da minha carreira profissional.

Minha gratidão! 
Art. 5: "Todos são iguais perante a lei, sem distinção de qualquer natureza, garantindo-se aos 6 rasileiros e aos estrangeiros residentes no País a inviolabilidade do direito à vida, à liberdade, à igualdade, à segurança e à propriedade".

Constituição da República Federativa do Brasih de 1988. 
FLORIANO, Lara Simone Messias. Políticas Públicas de Desinstitucionalização no Estado de São Paulo e as Recomendações do Censo Psicossocial (2008) de Moradores de Hospitais Psiquiátricos. [tese]. São Paulo: Escola de Enfermagem, Universidade de São Paulo; 2019.

\section{RESUMO}

Introdução: Apesar do cenário de avanços no processo da Reforma Psiquiátrica Brasileira e das estratégias de desinstitucionalização da Rede de Atenção Psicossocial, no interstício de 1990 a 2014, o Brasil ainda conta com um grande número de leitos em hospitais psiquiátricos. O $1^{\circ}$ Censo Psicossocial dos Moradores dos Hospitais Psiquiátricos do Estado de São Paulo (2008) tornou possível a identificação de ações estratégicas para a desinstitucionalização de pessoas que foram excluídas do convívio social, sendo que tais ações foram descritas em um conjunto de recomendações, que deveriam ser diretrizes à construção de políticas públicas que possibilitam direitos, a inclusão social, a reabilitação psicossocial e o resgate da cidadania dessas pessoas. Objetivo Geral: Analisar as políticas públicas de saúde mental relacionadas aos direitos, cidadania e à reabilitação psicossocial dos sujeitos com transtornos mentais, derivadas do conjunto de recomendações propostas na obra resultante do Censo Psicossocial dos moradores em hospitais psiquiátricos (2008), para contribuir com a (re)formulação das políticas públicas de direitos, cidadania e reabilitação psicossocial. Objetivos Específicos: Identificar as ações propostas e implementadas pela Secretaria de Estado da Saúde de São Paulo para efetivar políticas públicas de desinstitucionalização, após o Censo Psicossocial (2008) de moradores em hospitais psiquiátricos do Estado de São Paulo e; Caracterizar as políticas públicas de desinstitucionalização das pessoas com transtornos mentais internadas em hospitais psiquiátricos no Estado de São Paulo. Material e Método: Teoria da Intervenção Práxica da Enfermagem em Saúde Coletiva (TIPESC), proposta por Egry (1996), realizando-se abordagem qualitativa, pesquisa documental e entrevista semi estruturada. Os sujeitos participantes do estudo foram os responsáveis pela formulação, execução e controle da Política Estadual de Saúde e de suas diretrizes e citados pelos entrevistados que puderam revelar contradições no processo de construção de políticas públicas de desinstitucionalização no Estado, com base nas recomendações do Censo Psicossocial (2008). A análise temática da pesquisa documental e das entrevistas foram realizadas e todos os aspectos éticos foram respeitados. Resultados: A corresponsabilização e a articulação entre os responsáveis pela formulação, execução e controle das ações desinstitucionalizantes de Saúde Mental no Estado de São Paulo, culminou em fragilidades e barreiras que impedem que as recomendações propostas pelo Censo Psicossocial (2008) sejam efetivadas na sua totalidade, permitindo que o espaço para hospitais psiquiátricos ainda esteja presente e persistente. Considerações finais. Há mais de uma década após a realização do $1^{\circ}$ Censo Psicossocial de moradores em hospitais psiquiátricos do Estado de São Paulo (2008), o cenário pouco mudou e o processo de desinstitucionalização das pessoas com transtornos mentais de longa internação se estagnou após 2014. Portanto, se faz necessário que medidas pautadas nas recomendações já estabelecidas sejam tomadas para romper com o padrão biologicista, o monitoramento das novas internações involuntárias e compulsórias, o fortalecimento da RAPS com fomento suficiente destinado à implementação de SRT e CAPS, à apuração de curatela e punição para os que praticam corrupção e demais ações que fortaleçam a reinserção dos sujeitos com transtornos mentais na sociedade para efetivação de sua cidadania e reabilitação psicossocial.

Descritores: Hospitais Psiquiátricos. Censos. Desinstitucionalização. Saúde Mental. 
FLORIANO, Lara Simone Messias. Public Policies of Deinstitutionalization in the State of São Paulo and the Recommendations of the Psychosocial Census (2008) of Residents in Psychiatric Hospitals. [thesis]. São Paulo: Nursing School, University of São Paulo; 2019.

\begin{abstract}
Introduction: Although the advances in the scenario in the process of the Brazilian Pschiatry Reform and strategies of deinstitutionalization of the Psychosocial Care Network, in the interstice from 1990 to 2014, Brazil still has a large number of beds in psychiatric hospitals. The $1^{\text {st }}$ Psychosocial Census of Residents in Psychiatric Hospitals in the State of São Paulo (2008) made it possible to identify strategic actions for the deinstitutionalization of people who were excluded from social life, such actions were described in a set of recommendations, that should be guidelines for the construction of public policies that enable rights, social inclusion, psychosocial rehabilitation and the rescue of the citizenship of these people. General Objective: Analyze mental health public policies related to rights, citizenship and psychosocial rehabilitation of subjects with mental disorders, derived from the set of recommendations proposed in the work resulting from the Psychosocial Census of Residents in Psychiatric Hospitals (2008), to contribute to (re)formulation of public policies on rights, citizenship and psychosocial rehabilitation. Specific Objectives: Identify the proposed and implemented actions by the São Paulo State Department of Health to implement deinstitutionalization public policies, after the Psychosocial Census (2008) of Residents in Psychiatric Hospitals in the State of São Paulo and; Characterize the deinstitutionalization public policies of people with mental disorders admitted to psychiatric hospitals in the State of São Paulo. Material and Method: Theory of Practical Intervention of Collective Health Nursing (TPICHN), proposed by Egry (1996), using a qualitative approach, documentary research and semi-structured interview. The participating subjects in the study were responsible for the formulation, execution and control of the State Health Policy and its guidelines, and cited by the interviewees who could reveal contradictions in the process of building public policies for deinstitutionalization in the state, based on the recommendations of the Psychosocial Census. (2008). The thematic analysis of documentary research and interviews were conducted and all ethical aspects were respected. Results: The coresponsibility and articulation between those responsible for the formulation, execution and control of deinstitutionalizing actions of Mental Health in the State of São Paulo, have culminated in weaknesses and barriers that prevent the recommendations proposed by the Psychosocial Census (2008) from being fully implemented, allowing that the space for psychiatric hospitals still be present and persistent. Final considerations: More than a decade after the $1^{\text {st }}$ Psychosocial Census of Residents in Psychiatric Hospitals in the State of São Paulo (2008), the scenario has changed a little and the process of deinstitutionalization of people with long-term mental disorders stagnated after 2014. Therefore, it is necessary that measures based on the recommendations already established be taken to break with the biologicist standard, the monitoring of the new involuntary and compulsory admissions strengthening RAPS with sufficient support for the implementation of SRT and CAPS, the determination of curatela and punishment for those who practice corruption and other actions that strengthen the reinsertion of subjects with mental disorders in society for the realization of their citizenship and psychosocial rehabilitation.
\end{abstract}

Keywords: Psychiatric Hospitals. Census. Deinstitutionalization. Mental Health. 


\section{LISTA DE FIGURAS}

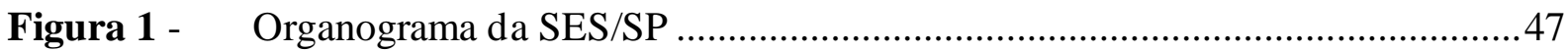

Figura 2 - Estado de São Paulo segundo Departamentos de Saúde, 2012........................48

Figura 3 - Taxa de Cobertura de CAPS pelas Regiões de Saúde, Estado de São Paulo, 2012.

Figura 4 - Taxa de Cobertura de CAPS pelas Regiões de Saúde, Estado de São Paulo, 2015

Figura 5 - Taxa de Cobertura de CAPS pelas Regiões de Saúde, Estado de São Paulo, 2016 .

Figura 6 - Página inicial da Base de Dados de Legislação em Saúde 75 


\section{LISTA DE QUADROS}

Quadro 1 - Instituições da SES/SP

Quadro 2 - Legislação nacional, estadual, municipal e informações relacionadas a nosso objeto de estudo

Quadro 3 - Objetivos e Metas do Eixo II do PES/SP quadriênio 2016-2019..... 94

Quadro 4 - Quadro demonstrativo da análise das ações relatadas por documentos e entrevistados frente às recomendações propostas pelo Censo Psicossocial (2008) de moradores em hospitais psiquiátricos do Estado de São Paulo 


\section{LISTA DE TABELA}

Tabela 1 - Hospitais Psiquiátricos do Estado de São Paulo/SP........................................59

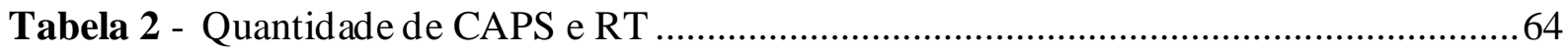




\section{LISTA DE SIGLAS}

ABP Associação Brasileira de Psiquiatria

AIH Autorizações de Internação Hospitalar

BPC Benefício de Prestação Continuada

BVS Biblioteca Virtual em Saúde

CAF Coordenadoria de Assistência Farmacêutica

CAO Centro de Apoio Operacional Cível e de Tutela Coletiva

CAPS Centro de Atenção Psicossocial

CCD Coordenadoria de Controle de Doenças

CCTIES Coordenadoria de Ciência, Tecnologia e Insumos Estratégicos de Saúde

CES Conselho Estadual de Saúde

CGA Coordenadoria Geral de Administração

CGCSS Coordenadoria de Gestão de Contratos de Serviços de Saúde

CGOF Coordenadoria de Gestão Orçamentária e Financeira

CIB Comissão Intergestores Bipartite

COSEMS/SP Conselho de Secretários Municipais de Saúde do Estado de São Paulo

CPS Coordenadoria de Planejamento de Saúde

CRATOD Centro de Referência de Álcool, Tabaco e Outras Drogas

CRH Coordenadoria de Recursos Humanos

CRS Coordenadoria de Regiões de Saúde

CRT/AIDS Centro de Referência e Treinamento DST/AIDS

CSS Coordenadoria de Serviços de Saúde

CVE Centro de Vigilância Epidemiológica

CVS Centro de Vigilância Sanitária

DRS Departamentos Regionais de Saúde

EEUSP Escola de Enfermagem da Universidade de São Paulo

FOSP Fundação Oncocentro de São Paulo

FURP Fundação para o Remédio Popular

GTAE Grupo Técnico de Ações Estratégicas

IAL Instituto Adolfo Lutz 
IPI internações psiquiátricas involuntárias

IPV internações psiquiátricas voluntárias

IPVI internações psiquiátricas voluntárias e involuntárias

LOAS Lei Orgânica da Assistência Social

MPF Ministério Público Federal

MPSP Ministério Público Estadual de São Paulo

MS Ministério da Saúde

NOAS Norma Operacional de Assistência em Saúde

NOB Norma Operacional Básica

PES Plano Estadual de Saúde

PNASH Programa Nacional de Avaliação dos Serviços Hospitalares

PTS Projeto Terapêutico Singular

PVC Programa "De Volta para Casa"

RAPDS Rede Protetiva de Direitos Sociais

RAPS Rede de Atenção Psicossocial

RRAPS Redes Regionais de Atenção Psicossocial

SES-SP Secretaria de Estado da Saúde de São Paulo

Sisnad Sistema Nacional de Políticas Públicas sobre Drogas

SRT Serviço Residencial Terapêutico

SUCEN Superintendência de Controle de Endemias

SUS S Sistema Único de Saúde

TAC Termo de Ajustamento de Conduta

TCLE Termo de Consentimento Livre e Esclarecido

TIPESC Teoria da Intervenção Práxica da Enfermagem em Saúde Coletiva 


\section{SUMÁRIO}

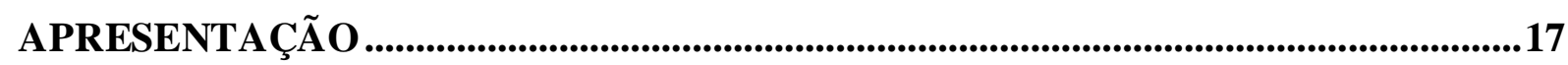

1 INTRODUÇÃ

1.1 REVISÃO DE LITERATURA E PROBLEMA DE PESQUISA ….........................32

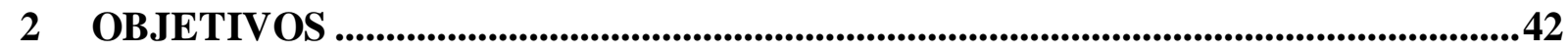

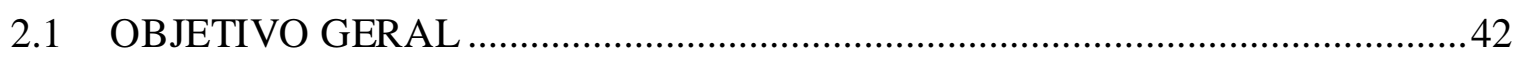

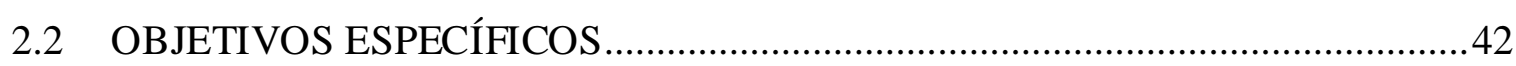

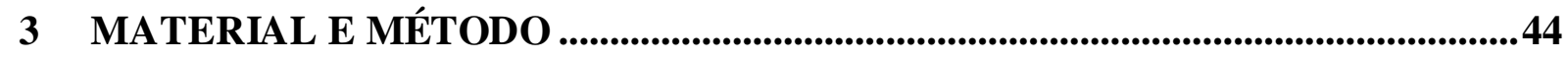

3.1 BASE TEÓRICO-METODOLÓGICA DO ESTUDO …..........................................44

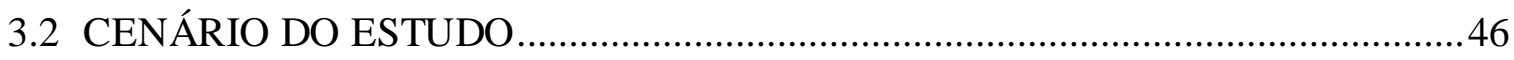

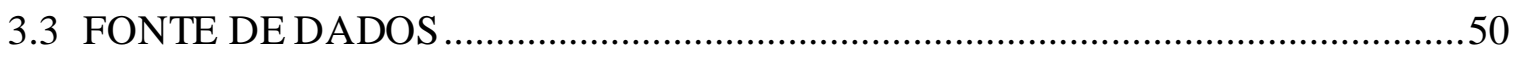

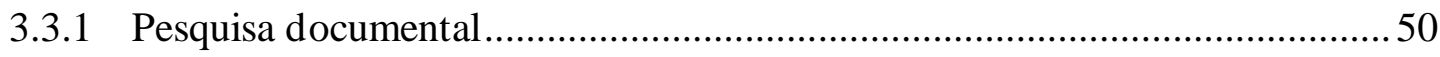

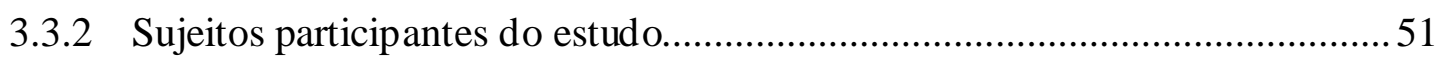

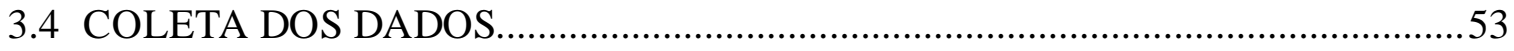

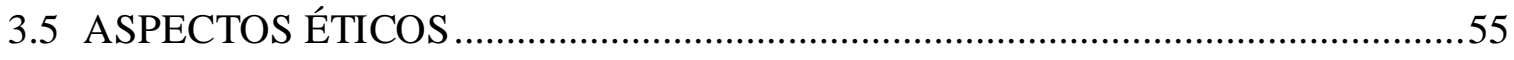

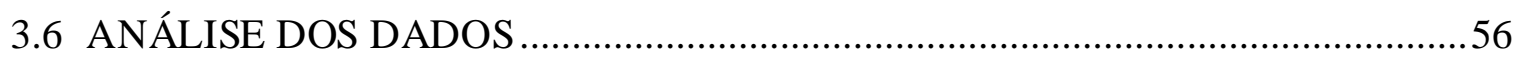

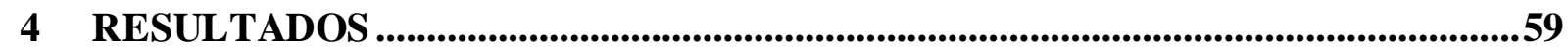

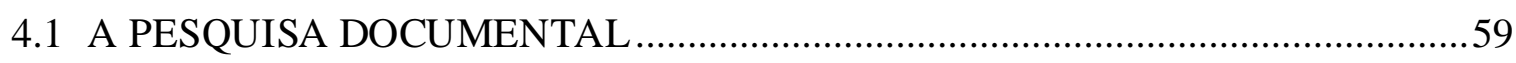

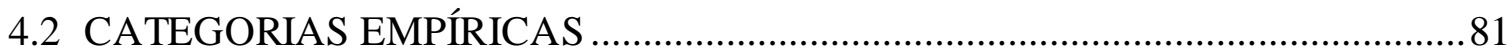

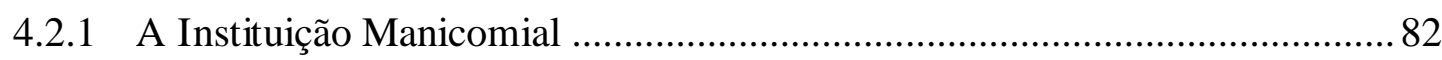

4.2.2 A Desinstitucionalização no Estado de São Paulo ....................................... 87

4.2.3 Redes de Atenção Psicossocial (RAPS) do Estado de São Paulo: A Desinstitucionalização .......................................................................... 100

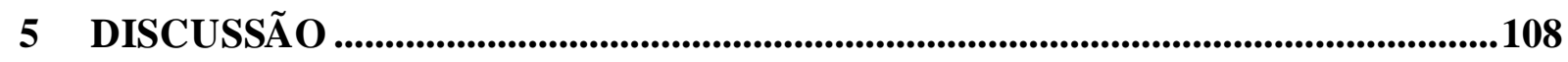

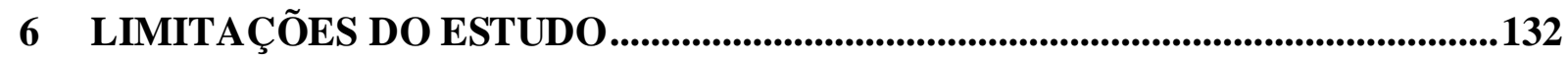

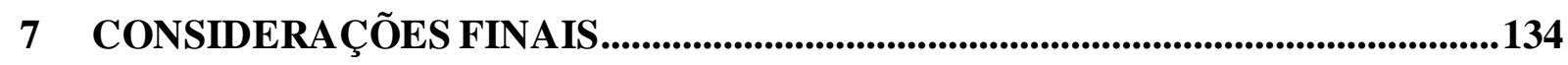

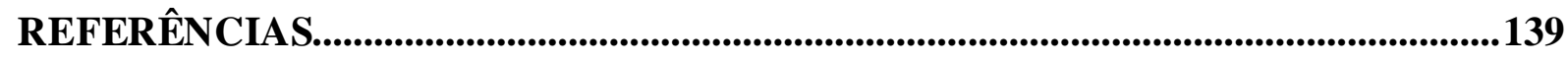

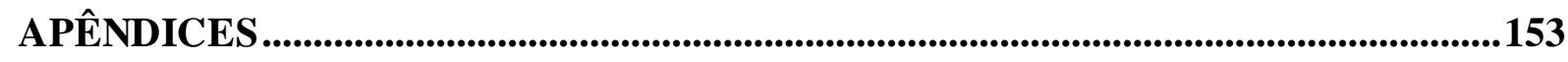

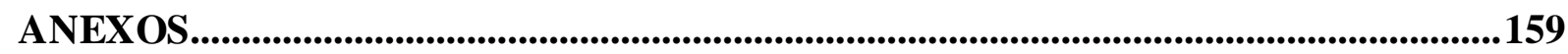


APRESENTACÃO = 


\section{APRESENTAÇÃO}

Era o ano de 2016 quando eu, enfermeira, professora de uma universidade estadual pública do interior do Paraná e doutoranda do Programa Interunidades de Doutoramento em Enfermagem, da Escola de Enfermagem da Universidade de São Paulo e da Escola de Enfermagem de Ribeirão Preto, me deparei pela primeira vez com um livro intitulado: Desafios para a Desinstitucionalização: Censo Psicossocial dos moradores em Hospitais Psiquiátricos do Estado de São Paulo (2008), organizado pela Dr. ${ }^{a}$ Sônia Barros, minha orientadora, e por Regina Bichaff.

No começo da leitura, imaginei que o Censo Psicossocial realizado no Estado de São Paulo também poderia ser realizado no meu Estado, já que até aquele ano (até hoje também) não tínhamos nenhum estudo ou relatório daquela magnitude, que apresentasse um diagnóstico situacional de uma população moradora há mais de um ano em hospitais psiquiátricos, pesquisa essa apoiada pela Secretaria Estadual de Saúde de São Paulo.

No entanto, quando percebi, já estava impressionada com os primeiros resultados apontados no referido Censo Psicossocial, “a população moradora há mais de um ano em hospitais psiquiátricos [era] composta por 3.930 (três mil, novecentos e trinta) homens e 2.419 (duas mil, quatrocentas e dezenove) mulheres" (Barros, Bichaff, 2008, p. 114), ou seja, 6.349 (seis mil, trezentos e quarenta e nove) estavam hospitalizados e dependiam de políticas públicas que definissem instrumentos e estratégias que permitiriam a viabilização da reinserção social desses sujeitos à comunidade.

Esse universo de pessoas esquecidas, ignoradas, diante da própria sorte e que na sua grande maioria, 4.133 (quatro mil cento e trinta e três), estavam lá internadas há mais de dez anos. O Censo Psicossocial (2008) apontou pessoas que internaram quando eram crianças, pessoas pobres, negras, analfabetas, sem diagnóstico algum ou com mais de um diagnóstico, pessoas sem registro ou data de nascimento, metade delas com ausência total ou parcial dos dentes (42,21\%), entre tantos outros dados. O Censo Psicossocial detectou que 64,06\% desses pacientes contavam com família localizada e comprovada com endereço.

Assim, perplexa com tamanha exclusão social, ao final do livro, especificamente na página 123, li as dezessete recomendações propostas pelos organizadores do Censo Psicossocial para a Secretaria de Estado da Saúde de São Paulo, no que tange a desinstitucionalização dos moradores nos hospitais psiquiátricos do Estado. 
As recomendações propostas pelo Censo Psicossocial (2008) representam as ações, articulações, diretrizes e avanços à construção de políticas públicas de desinstitucionalização, sejam, as políticas de cidadania, direitos e de reabilitação psicossocial, para as pessoas com transtornos mentais institucionalizadas em hospitais psiquiátricos, ou seja, as recomendações são as chaves que abrem as portas dos manicômios e representam a liberdade para os excluídos - as pessoas com transtornos mentais - chaves para a reabilitação psicossocial.

A partir de minhas inquietações em relação ao que aconteceu com aquelas pessoas e diante das recomendações propostas pelo Censo Psicossocial (2008), propostas que são viáveis de implementação pelos gestores e envolvidos no campo da Saúde Mental para fortalecer e ampliar a inclusão das pessoas com transtornos mentais na rede de atenção de base comunitária e territorial, promovendo a reintegração social e a cidadania desses sujeitos, resolvi desenvolver este estudo e aqui apresento, onze anos depois, uma análise das políticas públicas de Saúde Mental relacionadas aos direitos, cidadania e reabilitação psicossocial efetivamente implementadas no Estado, derivadas do conjunto de recomendações propostas na obra resultante do Censo Psicossocial (2008), para contribuir com a (re)formulação das políticas públicas de direitos, cidadania e reabilitação psicossocial. 


\section{INTRODUCÃO}




\section{INTRODUÇÃO}

O Brasil é um país historicamente marcado pelas injustiças e desigualdades sociais, mas também por muitas lutas. No caso da trajetória da saúde mental, não foi diferente. Durante anos, as pessoas com transtornos mentais vivenciaram situações injustas e desumanas atrás dos portões dos hospitais psiquiátricos, os quais sofreram a discriminação, o preconceito, a estigmatização e a marginalização.

Após duas décadas do processo da Reforma Psiquiátrica e de doze anos de tramitação, em 06 de abril de 2001 foi aprovada a Lei da Reforma Psiquiátrica Brasileira $n^{\circ} 10.216$, que dispõe sobre a proteção e os direitos das pessoas com transtornos mentais e, redireciona o modelo assistencial em saúde mental (Brasil, 2001).

A Lei da Reforma traz em seu bojo o princípio de desinstitucionalização que, de acordo com Rotelli, et al. (1990, p. 33), “é sobretudo um trabalho terapêutico, voltado para a reconstituição das pessoas, enquanto pessoas que sofrem, como sujeitos", uma vez que mudase o paradigma centrado na institucionalização da doença, na cura, no tratamento, na objetificação do sujeito, para o entendimento de que "cuidar significa ocupar-se, aqui e agora, de fazer com que se transformem os modos de viver e sentir o sofrimento do 'paciente' e que, ao mesmo tempo, se transforme sua vida concreta e cotidiana, que alimenta este sofrimento".

Ocorre uma transformação nas relações de poder entre os hospitais psiquiátricos, local de institucionalização da doença e o sujeito em seu processo de historicização de vida, de recriação de vínculos e laços afetivos familiares, na comunidade, em seu território, longe do isolamento ${ }^{1}$

$\mathrm{Na}$ base do processo de Reforma Psiquiátrica tem-se a noção de que a desinstitucionalização introduz novos sujeitos de direitos, com o estabelecimento de avanços nas relações sociais e na qualidade de vida desses sujeitos para além da questão puramente biológica, por meio de projetos que contemplem questões relacionadas à moradia, trabalho, lazer, aos projetos individuais, as suas histórias de vida enquanto seres humanos (Yasui, 2010).

É oportuno destacar que pautamos a presente investigação no conceito de homem proposto por Egry e Shima (1992, p. 108), “ser biológico e social, com integridade, inserido

\footnotetext{
$1 \mathrm{Na}$ busca de "resgatar/construir laços sociais; reconstruir o direito e a capacidade de palavra; restituir os direitos civis eliminando a coação, as tutelas jurídicas e o estatuto de periculosidade; reconstruir o direito e a capacidade de uso dos objetos pessoais; produzir relações, espaços e objetos de interlocução, liberar os sentimentos; reativar uma base de rendimentos para poder ter acesso a os intercâmbios sociais" (Rotelli et al., 1990,p. 33).
} 
em uma sociedade historicamente determinada", sendo que, "é um ser histórico porque, transformando-se, transforma a sociedade: é produto e produtor da vida social”, mais ainda, "o que o homem faz, pensa e sente não está isolado dos demais homens, mas sim intimamente relacionado e determinado pela ação e realização de cada um, da natureza e da sociedade em que se insere".

Levando-se em conta essa concepção de homem, a pessoa com transtorno mental institucionalizada, isolada, afastada do convívio em sociedade, impedida de se relacionar, de produzir, torna-se um sujeito a-histórico e é nesse contexto, que o processo de desinstitucionalização e de reabilitação psicossocial dessas pessoas tornam-se fundamental para lhes devolver a condição, além de sujeito, a de homem e a de ser social.

Mesmo que a referida Lei tenha recebido críticas por não trazer de forma enfática a extinção dos manicômios, representa no país, um avanço no processo de regulamentação das instituições, visando a garantir aos cidadãos, o tratamento preferencial em serviços comunitários, bem como a internação, ser a última alternativa, nos casos que forem insuficientes os recursos extra-hospitalares (Amarante et al., 2016).

A criação de serviços substitutivos extra-hospitalares tem nos Centros de Atenção Psicossocial (CAPS) a sua figura emblemática, tornando-se o modelo de assistência para todo o país, estabelecendo as diretrizes de assistência em saúde mental e as normas para o cuidado ambulatorial (Brasil, 2002a).

Em continuidade à Política de Reforma, surgiram várias normatizações e Portarias do Ministério da Saúde que criou programas específicos para a desinstitucionalização, tais como os Serviços Residenciais Terapêuticos (SRT), por meio da Portaria $n^{\circ} .106$ de 11 de fevereiro de 2000 (que introduz os SRT no SUS para egressos de longas internações), a Portaria n. ${ }^{\circ}$ 1.220 de 07 de novembro de 2000, que regulamenta a portaria 106/2000, para fins de cadastro e financiamento no SIA/SUS e o Programa "De Volta Para Casa", segundo critérios definidos na Lei $\mathrm{n}^{\mathrm{o}} 10.708$, de 31 de julho de 2003, que tem como parte integrante o pagamento do auxílio-reabilitação psicossocial (Brasil, 2000, 2003).

Ainda, levando em consideração a necessidade de garantir a qualidade assistencial mínima às pessoas com transtornos mentais, bem como aquelas que fazem uso de álcool e outras drogas que se encontram em situação de internação em hospitais psiquiátricos, foi instituído em 2002, pelo Ministério da Saúde, o Programa Nacional de Avaliação dos Serviços Hospitalares (PNASH/Psiquiatria) que estabelece diretrizes e normas para a assistência hospitalar em psiquiatria, e no ano de 2004, considerando a urgência de se estabelecer critérios racionais para a reestruturação do financiamento e remuneração dos 
procedimentos de atendimento em hospital psiquiátrico, foi instituído o "Programa Anual de Reestruturação da Assistência Psiquiátrica Hospitalar no SUS - 2004" com a Portaria $n^{\circ}$ 52, de 20 de janeiro de 2004, que tem como finalidade, "processo de mudança do modelo assistencial que deve ser conduzido de modo a garantir uma transição segura, onde a redução dos leitos hospitalares possa ser planificada e acompanhada da construção concomitante de alternativas de atenção no modelo comunitário" (Brasil, 2002b, 2004).

Nesse contexto, à luz de dados do Informativo do Ministério da Saúde, Saúde Mental em Dados - 8 (Brasil, 2011a), ocorreu uma ampliação no número de CAPS de 148 para 1620 unidades entre dezembro de 1998 até dezembro de 2010, sendo que a cobertura em saúde mental teve uma expansão de 21\% em 2002, para 66\% em 2010 no Brasil.

Evidencia-se, também, a expansão e a consolidação dos Serviços Residenciais Terapêuticos (SRT), de 85 SRT em 2002 para 570 SRT em 2010, visto que essa era uma das principais preocupações do processo de desinstitucionalização de pessoas internadas com longa permanência nos últimos anos, no entanto, ainda era baixa diante das dificuldades técnicas, políticas e socioculturais dos processos de desinstitucionalização ao processo de reintegração de pacientes de longa permanência (Brasil, 2011a).

Quanto ao Programa "De Volta para Casa", em dezembro de 2003 eram 206 beneficiários do auxílio-reabilitação psicossocial para egressos de longas internações psiquiátricas, expandindo para 3.635 em dezembro de 2010 (Brasil, 2011a).

Mesmo sendo um programa fundamental para o processo de desinstitucionalização no Brasil, de acordo com os dados do Ministério da Saúde (Brasil, 2011a, p. 13), "o número de beneficiários do Programa "De Volta para Casa" ainda é muito baixo - apenas 1/3 do número estimado de pessoas internadas com longa permanência hospitalar no Brasil recebe o benefício", demonstrando a existência de "grande dificuldade para a desinstitucionalização da população moradora de Hospitais Psiquiátricos” (Brasil, 2011a, p. 4).

É nesse contexto de transformação, com o objetivo de acolher e atender às diversas demandas de saúde mental, levando em consideração o reconhecimento da singularidade e a autonomia dos sujeitos nesse processo, que ocorre a implantação da Rede de Atenção Psicossocial (RAPS), em 28 de junho de 2011, formada por sete componentes: I - Atenção Básica em Saúde; II - Atenção Psicossocial Especializada; III - Atenção de Urgência e Emergência; IV - Atenção Residencial de Caráter Transitório; V - Atenção Hospitalar; VI Estratégias de Desinstitucionalização; e VII - Reabilitação Psicossocial (Brasil, 2011a).

A partir de 2011, a Portaria $n^{\circ} 106 / 2000$ foi alterada pela Portaria $n^{\circ} 3090$ de 23 de dezembro de 2011, que dispõe sobre o repasse de recursos e incentivo de custeio mensal para 
implantação e/ou funcionamento dos SRT, acrescendo no artigo $2^{\circ}$ da Portaria $n^{\circ} 106$ que os serviços deverão acolher "pessoas com internação de longa permanência (dois anos ou mais ininterruptos) egressas de hospitais psiquiátricos e hospitais de custódia". Também define que as STRs são "unidades de moradia, inseridas na comunidade, devendo estar fora dos limites de unidades hospitalares gerais ou especializadas, estando vinculadas à rede pública de serviços de saúde" (Brasil, 2011b).

Ainda, em relação ao caráter essencial do SRT caracteriza-o por "ser um espaço de moradia que garanta o convívio social, a reabilitação psicossocial e o resgate da cidadania do sujeito, promovendo os laços afetivos, a reinserção no espaço da cidade e a reconstrução das referências familiares", podendo ser constituídos na modalidade Tipo I, para "pessoas com transtorno mental em processo de desinstitucionalização" ou do Tipo 2, para "pessoas com transtorno mental e acentuado nível de dependência, especialmente em função do seu comprometimento físico, que necessitam de cuidados permanentes específicos" (Brasil, 2011b).

De acordo com Informativo do Ministério da Saúde, Saúde Mental em Dados - 12, a estruturação da Rede de Atenção Psicossocial resultou em um aumento de 1620 CAPS em dezembro de 2010 para 2209 CAPS em dezembro de 2014 (Brasil, 2015). Também de acordo com os dados do Ministério da Saúde (Brasil, 2015), um aumento nos Serviços Residenciais Terapêuticos, para 610 SRT em funcionamento e cadastrados em 2014, dos quais 289 eram habilitados, que recebem repasses de recursos federais de custeio mensal e também para implantação, resultando em um total de 3.475 moradores nesses serviços.

O Programa "De Volta para Casa" (PVC) alcançou nesse mesmo período 4.349 beneficiários cadastrados, sendo que havia previsões de aumento significativo na medida em que se avancem os processos de desinstitucionalização, entretanto, observa-se que apenas 22 unid ades da federação possuem municípios cadastrados no PVC (Brasil, 2015).

Apesar do cenário de avanços no processo da Reforma, mesmo após a Portaria $\mathrm{n}^{\circ}$ 2.840, de 29 de dezembro de 2014, que "cria o Programa de Desinstitucionalização integrante do componente Estratégias de Desinstitucionalização da Rede de Atenção Psicossocial (RAPS), no âmbito do Sistema Único de Saúde (SUS), e institui o respectivo incentivo financeiro de custeio mensal", visto que, conforme seu artigo $2^{\circ}$, este componente é “constituído por iniciativas que visam a garantir às pessoas com sofrimento ou transtorno mental, e com necessidades decorrentes do uso de crack, álcool e outras drogas, em situação de internação de longa permanência", buscando-se "o cuidado integral por meio de estratégias substitutivas, na perspectiva da garantia de direitos com a promoção de autonomia e o 
exercício de cidadania, buscando-se sua progressiva inclusão social” o Brasil ainda conta com um grande número de leitos psiquiátricos em hospitais especializados (Brasil, 2014).

Em relação ao Programa Nacional de Avaliação dos Serviços Hospitalares PNASH/Psiquiatria, no decorrer dos anos de 2012, 2013 e 2014, as equipes de vistorias do PNASH, formadas por representantes das Secretarias Estaduais e Municipais de Saúde e da Vigilância Sanitária, vistoriaram 143 hospitais psiquiátricos públicos e privados conveniados ao SUS (exceto o Estado do Rio de Janeiro e Juiz de Fora (MG) que não realizaram o PNASH). O resultado desse processo foi publicado por meio da Portaria GM/MS n 1727 , de 24 de novembro de 2016, indicando o descredenciamento de 27 hospitais que obtiveram índice inferior a $40 \%$ na avaliação técnica e os que não alcançaram o índice mínimo de $61 \%$ do PNASH, levando-se em consideração a avaliação do usuário (Brasil, 2016a).

O processo de desinstitucionalização brasileiro, mesmo sendo considerado como modelo para outros países, ainda é gradual e marcado por desigualdades regionais no tratamento da questão, mesmo pela oposição de grupos contrários à Reforma Psiquiátrica, que defendem a medicalização da loucura, o isolamento e o afastamento do "louco" da sociedade até que este esteja apto a conviver dentro de um padrão definido como de normalidade, criando um embate político e de poder. ${ }^{2}$

Cabe destacar que, nosso foco de pesquisa situa-se especificamente no Estado de São Paulo. De acordo com Barros e Bichaff (2008, p. 26), assim como no contexto nacional, a rede de atenção à saúde era insuficiente para atender a demanda existente no Estado de São Paulo, sendo que cerca de 50\% dos leitos psiquiátricos eram ocupados por pacientes institucionalizados há mais de um ano, considerados "moradores", de longa duração, e que "só medidas pontuais eram tomadas por alguns hospitais da rede própria, no sentido de buscar a inclusão destas pessoas na sociedade".

Assim, para Barros e Bichaff (2008, p. 26) não se verificava em São Paulo, "política que definisse projetos para a Reabilitação Psicossocial desses pacientes". Todo esse quadro de elevado índice de ocupação dos leitos psiquiátricos por pacientes de longa permanência era agravado pela precariedade "nas condições técnico-assistenciais de vários hospitais psiquiátricos" (Barros, Bichaff, 2008, p. 26).

$\mathrm{Na}$ busca de respostas efetivas a esses cidadãos, bem como, seguindo as diretrizes do Plano Estadual de Saúde (PES) na área de Saúde Mental para o quadriênio 2008-2011, o

\footnotetext{
${ }^{2}$ Como afirma Guljor (2016, p. 1): “a Reforma Psiquiátrica não é dada pelos gestores, pela gestão central. Ela é fruto de mobilização, de pressão, de conquista. Como a Reforma Sanitária. Elas estão articuladas. E essa luta, hoje, pela garantia do SUS é a luta pela garantia também da Reforma Psiquiátrica”.
} 
Grupo Técnico de Ações Estratégicas (GTAE) da Secretaria Estadual de Saúde de São Paulo (SES-SP), organizou um grupo de trabalho por meio da Resolução SS-294 de 29 de agosto de 2007, sob a coordenação do GTAE, e realizou o $1^{\circ}$ Censo Psicossocial dos Moradores dos Hospitais Psiquiátricos do Estado de São Paulo (Barros, Bichaff, 2008).

O referido Censo propôs acompanhar, coordenar e elaborar diagnóstico situacional das pessoas institucionalizadas há mais de um ano, em 58 hospitais psiquiátricos, localizados em 38 municípios de 15 Departamentos Regionais de Saúde (DRS) do Estado, com o objetivo de tornar as pessoas com transtornos mentais institucionalizadas em hospitais psiquiátricos por longo tempo, objetos de política pública específica e para construção de proposta de desinstitucionalização (Barros, Bichaff, 2008).

Os dados apresentados pelo Censo Psicossocial de 2008 indicavam, entre outros resultados, o que se segue:

- A presença do expressivo número de 6.349 pessoas há longo tempo internadas;

- Que $70 \%$ destes foram internad os há mais de dez anos nos hospitais psiquiátricos;

- No recorte raça/cor/etnia de acordo com dados do IBGE (2000), a população de pretos e pardos de São Paulo era de $27,4 \%$ e na população de moradores de hospitais psiquiátricos o Censo apontou $38,36 \%$ do total de pessoas pretas e pardas;

- 1312 pessoas estavam sem registro ou data de nascimento;

- 28 crianças e adolescentes foram excluídos do convívio familiar e social por estarem um longo tempo internadas;

- $\quad 62.07 \%$ das pessoas não eram alfabetizadas, apenas aproximadamente $9 \%$ eram capazes de escrever o próprio nome (Barros, Bichaff, 2008).

Ou seja, o Censo Psicossocial apontou institucionalização, exclusão, abandono, subordinação, despertencimento, das 6.349 pessoas de longa internação (Barros, Bichaff, 2008). O $1^{\circ}$ Censo Psicossocial (2008) foi sistematizado e publicado no livro "Desafios para a desinstitucionalização: Censo Psicossocial dos moradores em hospitais psiquiátricos do Estado de São Paulo" (Barros, Bichaff, 2008).

Após apresentação e análise de todos os dados coletados no trabalho de campo, que possibilitou a caracterização da população e o levantamento dos seus dados psicossociais, foi possível dar visibilidade àqueles que durante muito tempo foram excluídos e cerceados de seus direitos mais básicos, e ao final, traz uma série de recomendações, entre as páginas 124 
a130 da obra que devido a sua importância no contexto desta pesquisa são transcritas literalmente a seguir.

1. A articulação entre os três níveis de gestão do SUS para a construção do conjunto de condições sanitárias, institucionais, técnicas, econômicas, jurídicas, políticas - para a efetivação da desinstitucionalização das pessoas moradores de hospitais psiquiátricos do Estado de São Paulo assegurando o direito a moradia e a garantia de cuidado e de reabilitação psicossocial nas redes locais de atenção psicossocial.

2. A criação de incentivo estadual para os municípios que acolheram os moradores desinstitucionalizados visando a apoiar a implementação de SRT, O desenvolvimento de projetos de reabilitação psicossocial e a criação e/ou ampliação/consolidação dos serviços e das ações de base comunitária/territorial das redes locais de atenção psicossocial.

3. A inclusão, em curto prazo, do debate sobre a situação das pessoas moradoras de hospitais psiquiátricos do Estado de São Paulo na pauta da reunião da Câmara Técnica de Saúde Mental do Conselho Estadual de Saúde.

4. A inclusão, em curto prazo, do debate sobre a situação das pessoas moradoras de hospitais psiquiátricos do Estado de São Paulo na pauta de reunião da Comissão Intergestores Bipartite (CIB) visando a pactuação de ações e metas para a implementação e o desenvolvimento de projetos de desinstitucionalização das pessoas internadas há mais de um ano nos hospitais psiquiátricos do Estado, considerando as necessidades de investimentos e de articulação, dentre as quais:

- A necessidade de pactuação de transferência dos recursos financeiros referentes ao fechamento de leitos ocupados por moradores para os tetos dos municípios que acolherem os usuários egressos de hospitais psiquiátricos, a serem destinados à criação e/ou expansão de serviços de saúde mental de base comunitária/territorial, à criação e/ou ampliação de moradias assistidas (SRT), à criação e/ou fortalecimento de projetos intersetoriais no campo da educação, cultura, e trabalho, contemplando, dessa forma, as demandas de atenção e reabilitação psicossocial. É importante destacar, que, considerando que $69 \%$ do total de moradores encontra-se em hospitais psiquiátricos sob gestão estadual, e $31 \%$ em hospitais psiquiátricos sob gestão municipal, serão necessários repasses da gestão estadual para gestões municipais e entre gestões municipais;

- A implantação de SRT para as pessoas egressas de internações psiquiátricas de longa permanência que não possuem suporte social e laços familiares, conforme 
regulamentação da Portaria GM n. 106/2000. Considerando que a referida Portaria define, no máximo, 08 moradores/SRT, certamente será necessária a criação de cerca de 180 moradias assistidas para responder às demandas imediatas de um grupo de aproximadamente $26 \%$ dos moradores, uma vez que a informação sobre familiares não estava disponível quando da realização da coleta de dados do Censo:

- Por outro lado, para os moradores para os quais foi identificada a existência de presença de contatos de familiares/pessoas da rede social, destaca-se que não necessariamente essa presença é equivalente à possibilidade de moradia em conjunto, considerando, sobretudo, que $65 \%$ da população moradora encontra-se internada há mais de dez anos. Portanto, é possível indicar que a necessidade de criação de SRT abrangerá, também, diversas pessoas desse grupo, não obstante as possibilidades de serem ativados processos de reabilitação psicossocial com familiares/pessoas da rede social, e nos projetos de articulação e parceria com outras políticas públicas como às dirigidas às pessoas com deficiência;

- A expansão, de acordo com as necessidades dos contextos locais, da rede substitutiva em saúde mental e dos projetos intersetoriais, em particular CAPS I, II, e III, CAPS Infantil e CAPS AD, inserção de atenção em saúde mental na atenção básica, leitos psiquiátricos em hospitais gerais, centros de convivência, projetos de geração de renda e inserção no trabalho, projetos de alfabetização e de acesso aos bens culturais, visando a assegurar o acesso ao cuidado e à reabilitação psicossocial das pessoas desinstitucionalizadas, considerando que, com base na atual cobertura de 0,43 CAPS/100.000 habitantes no Estado de São Paulo, trata-se de rede ainda restrita frente às necessidades da demanda;

- A habilitação de municípios no Programa de Volta para Casa conforme a Portaria GM n. 2077/2003 que regulamenta a Lei 10.708/2003 nos Termos de seu Artigo $8^{\circ}$ (Brasil, 2003);

- A elaboração e implementação de processos formativos de educação permanente, em parcerias com as universidades, que visem à qualificação das equipes dos serviços de saúde e de saúde mental de base comunitária/territorial, de apoiadores/cuidadores de SRT, e de participantes de projetos intersetoriais para ampliação e potencialização da capacidade de atenção e de reabilitação psicossocial de pessoas com histórico de institucionalização em hospitais psiquiátricos. 
5. A realização do "Projeto Cidadania", visando à recuperação da documentação original ou à obtenção da Certidão Tardia de Nascimento dos 1.312 moradores denominados “ignorados”, operando no resgate de histórias, identidades e vínculos e promovendo as condições para o acesso aos benefícios e aos direitos previstos na legislação. Com esse objetivo, indica-se o envolvimento das equipes dos hospitais psiquiátricos, dos articuladores de saúde mental dos respectivos DRS, das equipes das redes municipais de atenção psicossocial, do Ministério Público e da Ordem dos Advogados do Brasil, e o desenvolvimento das seguintes medidas:

- Junto aos hospitais psiquiátricos próprios e conveniados: encaminhamento das informações sobre as iniciativas já realizadas ou em andamento para a obtenção de Certidões de Nascimento dos moradores denominados ignorados;

- Junto aos moradores com naturalidade e endereço familiar conhecido: a equipe técnica realizará busca de documentação original, apresentando listagem nominal;

- Junto aos moradores sobre os quais não estão disponíveis as informações sobre naturalidade e localização familiar é necessário realizar levantamento detalhado no prontuário e com o próprio morador e, no caso de novas informações, proceder à busca de documentação original. Esgotadas as possibilidades, indica-se o encaminhamento para o Ministério Público/OAB de solicitação de Certidão Tardia, através da elaboração de relatório, com as providências preliminares e a indicação do Nome, de acordo com a escolha do morador;

- O GT (Resolução SS 327/2007) propõe a criação de um novo GT, para conduzir as ações citadas, de maneira a orientar e acompanhar a obtenção das 1312 certidões de nascimento, tardias ou não.

6. Que, no desenvolvimento de projetos de desinstitucionalização orientados para a reabilitação psicossocial e nos percursos de implementação de SRT, sejam observados a Portaria GM n. 106/2000 e os seguintes princípios:

- o habitar como um dos eixos centrais nos percursos de reabilitação como cidadania que visem à ampliação de contratualidade (Saraceno, 1996, 1999);

- a produção de processos de desinstitucionalização pautados na validação dos moradores, no reconhecimento de seus saberes, capacidades, e direitos, e orientados para o fortalecimento do poder contratual, a potencialização de redes sociais, e a criação de condições para novas possibilidades de vida;

- a efetiva participação dos moradores na escolha da cidade na qual irá residir, considerando sua naturalidade, a última cidade de residência antes da internação 
atual, o município de residência do familiar, e as alternativas concretas existentes; cabe destacar a necessidade de propiciar as alternativas possíveis na singular situação de moradores de outros Estados e países;

- o respeito às interações e aos vínculos afetivos construídos entre moradores para a composição de grupos que irão habitar uma moradia assistida;

- o direito ao auxílio-reabilitação psicossocial (PVC) que, conforme a regulamentação da Lei 10.708/2003, poderá ser acessado por $81 \%$ dos moradores, isto é, aproximadamente 5.100 moradores;

- a garantia de Benefício de Prestação Continuada (BPC) da Lei Orgânica da Assistência Social (LOAS) nas situações indicadas;

- a compreensão dos SRT como moradias destinadas a cuidar de pessoas com transtornos mentais egressas de internação psiquiátrica de longa permanência, que não possuam suporte social e laços familiares, atuando como unidade de suporte, e que viabilizem sua reinserção na vida comunitária (Brasil, 2004). Dessa forma, diferente de um espaço sanitário, trata-se de implementar práticas e estratégias operativas de apoio e suporte que visem a promover o protagonismo das pessoas na vida cotidiana, a autonomia, a reapropriação do habitar, e de suas diferentes formas, e as possibilidades de conviver e participar das trocas sociais (Brasil, 2004);

- a efetiva configuração dos SRT como moradia requer, também, a localização na comunidade, fora dos limites dos espaços hospitalares/ institucionais, um espaço físico adequado, e a produção cotidiana de ambiente acolhedor de casa e de respeito à singularidade e aos direitos dos usuários como cidadãos;

- a reafirmação que os SRT são exclusivamente de natureza pública (Brasil, 2004);

- a garantia de cuidado e de reabilitação psicossocial dos moradores dos SRT nos serviços de saúde e de saúde mental, assim como de inserção em projetos de políticas públicas intersetoriais, nas formas associativas de organização de usuários e familiares e nas relações sociais e comunitárias do território.

7. A articulação do gestor estadual do SUS com o Ministério Público para a criação de Comissão Revisora de Internações Psiquiátricas Involuntárias de acordo com a Portaria GM n. 2391/2002.

8. A articulação com as instâncias do Poder Judiciário e com o Ministério Público para a elaboração de proposições objetivando a revisão de interdições judiciais, considerando que $31 \%$ dos moradores encontram-se interditados. Cabe destacar, também, a 
necessidade de avaliação detalhada da condição de aproximadamente $6 \%$ dos moradores com procuradores.

9. A articulação com as instâncias do Poder Judiciário e com o Ministério Público para analisar a situação de moradores de hospitais psiquiátricos do Estado de São Paulo com internação compulsória.

10. A articulação, nos âmbitos estadual e municipal, com as políticas públicas e as organizações da sociedade civil que atuam no campo do trabalho e emprego, especialmente na perspectiva da Economia Solidária, para criação e fortalecimento de empreendimentos solidários com a inclusão de pessoas com transtornos mentais. Indica-se a superação de utilização do trabalho como forma de ocupação no contexto asilar e, nas proposições a serem criadas, a adoção dos referenciais e diretrizes que vêm sendo elaborados na parceria das políticas nacionais de saúde mental e de Economia Solidária para o desenvolvimento de iniciativas de inserção no trabalho (Brasil, 2005, 2006).

11. A articulação, nos âmbitos estadual e municipal, com as políticas públicas e com os projetos da sociedade civil que atuam no campo da educação e da cultura para a construção de proposições que objetivem a inclusão de pessoas com transtornos mentais em projetos de alfabetização, assim como a criação e/ou fortalecimento de projetos culturais inclusivos.

12. A articulação com as políticas públicas, estadual e municipais, de atenção à infância à e juventude para a construção conjunta de estratégias de desinstitucionalização e, sobretudo, de proposições que visem à concretização das redes locais de atenção psicossocial e de projetos intersetoriais saúde, educação, cultura, desenvolvimento social - que superem as formas de institucionalização.

13. A articulação com as políticas públicas, estadual e municipais, de saúde da pessoa com deficiência, para aprofundamento da discussão sobre a situação de moradores com deficiência com vistas à elaboração de estratégias intersetoriais para efetivar a desinstitucionalização e a atenção à saúde no território.

14. A construção de estratégias com os gestores das políticas públicas de saúde bucal, em nível estadual e municipais, visando a garantir o acesso dos moradores aos serviços odontológicos.

15. A articulação com a Área Técnica de Saúde da População Indígena da Secretaria de Estado da Saúde do Estado de São Paulo e com outras políticas públicas e projetos que 
desenvolvem programas de defesa de direitos dessa população para construir alternativas culturalmente adequadas de desinstitucionalização.

16. A constituição de Grupo de Trabalho para realização de avaliação específica das condições dos moradores acamados, de forma a aprofundar o conhecimento e a compreensão das principais necessidades desse grupo visando à formulação de alternativas e respostas adequadas para a desinstitucionalização.

17. A articulação com o gestor da política nacional de saúde mental do Ministério de Saúde para o aprofundamento da discussão e formulação de medidas sobre a problemática, evidenciada no Censo, da presença de continuidade de internações de longa permanência com data de início após a promulgação das Leis 10.216 de 2001 e 10.708 de 2003.

Apesar de todas as recomendações propostas pelo Censo Psicossocial (2008), em um novo Censo Psicossocial realizado em 2014, pela SES/SP, observa-se que,

\begin{abstract}
Ao realizar o primeiro Censo Psicossocial dos Moradores de Hospitais Psiquiátricos do Estado de São Paulo, em 2008, a Secretaria de Estado da Saúde deu visibilidade a esses cidadãos, que por muitos anos foram considerados invisíveis. Ao refazer o censo em 2014, após todos os esforços feitos e a ampliação das políticas e estratégias de desinstitucionalização, esse desafio não diminuiu, pois o censo mostra 4.439 indivíduos a guardando que seus direitos funda mentais sejam garantidos [grifo nosso] (Cayres et al., 2015, p. 10).
\end{abstract}

É importante destacar que, de acordo com os dados descritos no Censo Psicossocial de 2014 (Cayres et al., 2015), no Censo de 2008, 6.349 pessoas estavam internadas por longo tempo, em 58 hospitais psiquiátricos em São Paulo, com condições para a ressocialização e, em 2014, ainda haviam 4.439 indivíduos em 53 hospitais psiquiátricos em funcionamento, sendo que entre um censo e outro ocorreram 1.170 óbitos (não foi possível identificar quantos realmente faziam parte da população descrita no Censo de 2008), 739 altas para SRT e o caso de um morador cujo destino não foi possível identificar, bem como, 702 novas internações entre 2008 e 2014.

Destaca-se que, as recomendações realizadas por Cayres et al. (2015) sejam atualizadas às recomendações realizadas no Censo Psicossocial (2008), visto que poucas mudanças ocorreram, elencando duas diretrizes principais: (1) o desenvolvimento de estratégias para a desinstitucionalização da população de moradores de hospitais psiquiátricos o mais rápido possível e, (2) inibir novas internações de longo prazo, por meio do fomento à implantação da RAPS. 
Ainda, de acordo com Cayres et al. (2015, p. 13), o perfil e o número de "moradores [nos hospitais psiquiátricos] já sinaliza as resistências e dificuldades em cumprir o que está assegurado por lei desde 2001 e preconizado pela política de saúde mental com a sua implantação."

Assim, com a realização dos Censos Psicossociais de 2008 e 2014, foi possível levantar os dados psicossociais das pessoas com transtornos mentais internadas há muito tempo nos hospitais psiquiátricos do Estado de São Paulo e a partir dessa realidade, esperavase da SES/SP e de todos os envolvidos na gestão da Política Estadual de Saúde Mental, a construção e a implementação urgente das ações, diretrizes, ou seja, das políticas públicas de desinstitucionalização para o encaminhamento das pessoas aos cuidados da RAPS disponível e a ser criada, principalmente com a implantação dos SRT nos municípios do Estado.

\subsection{REVISÃO DE LITERATURA E PROBLEMA DE PESQUISA}

A questão dos cuidados às pessoas com transtornos mentais, que são resultados de históricos de internação prolongada em hospitais psiquiátricos, tem sido tema de pesquisas e discussões a nível de políticas públicas de saúde, em todas as esferas, na busca de construir políticas que possibilitem a reabilitação psicossocial desses sujeitos, para que não somente ocorra sua desospitalização, mas sua reinserção na família, na comunidade, na sociedade, enquanto cidadão de direito, garantindo-lhes uma identidade enquanto ser social.

Falar em Direitos Humanos daqueles que têm seus direitos de cidadania e o direito à dignidade humana enquanto pessoa negados, nos leva às reflexões do sociólogo português Boaventura de Souza Santos, de acord o com o qual "a hegemonia dos direitos humanos como linguagem de dignidade humana é hoje incontestável. No entanto, esta hegemonia convive com uma realidade perturbadora. A grande maioria da população mundial não é sujeito de direitos humanos" (Santos, 2013, p. 15).

Mais ainda, Santos (2013, p. 15), é enfático em dizer que a grande maioria da população mundial "é objeto de discursos de direitos humanos", e, na maioria das vezes, o discurso não corresponde à prática, a não ser aquelas guiadas por interesses econômicos e políticos.

Na perspectiva sociológica de Boaventura de Souza Santos, os direitos humanos da pessoa com transtorno mental devem ser reflexos da defesa da sua dignidade enquanto ser humano livre, inserido dentro da comunidade. Nessa concepção, todos os povos são dignos da 
convivência humana em igualdade de condições, ou seja, "temos o direito a ser iguais, quando a diferença nos inferioriza; temos o direito a ser diferentes, quando a igualdade nos descaracteriza. Tratando-se igualmente os iguais e diferentemente os diferentes" (Santos, 2003, p. 56).

A Lei 10.216/2001, que dispõe sobre a proteção e os direitos da pessoa com transtorno mental, traz como fundamentos a dignidade humana e, como regra a liberdade, indica o atendimento preferencialmente desinstitucionalizado, que passa então a ter como objetivo fund amental à reinserção social dessa pessoa (Brasil, 2001).

Define-se assim, que o lugar da pessoa com transtorno mental deixa de ser o hospital psiquiátrico e passa a ser a comunidade; porém, para ter seus direitos à saúde, direitos humanos, direito à dignidade, direito à cidadania, essas pessoas precisam que o Estado desenvolva e implemente políticas públicas que possam realmente assegurar esses direitos (Amarante et al., 2016).

Em se tratando da questão da cidadania das pessoas com transtorno mental, torna-se importante destacar alguns trabalhos científicos publicados na literatura internacional que tratam das temáticas que fundamentam a presente investigação.

De acordo com Perron, Rudge e Holmes (2010), o conceito de cidadania cada vez mais se torna importante em campos específicos como a psiquiatria/saúde mental, constituindo-se em uma solução às questões de exclusão, discriminação e pobreza pelas que passam muitas pessoas com transtornos mentais, constituindo-se em uma poderosa estratégia para combater os estigmas sofridos por essas pessoas.

O trabalho de Davidson et al. (2010) traz a questão da Reforma Italiana da Saúde Mental, compartilhando a conviç̧ão fundamental no direito dos indivíduos com transtornos mentais em terem uma vida na comunidade, uma vez que os direitos básicos de inclusão social, autonomia e cidadania fornecem as bases necessárias à recuperação da pessoa.

Atterbury e Rowe (2017) abordam a questão da saúde mental comunitária, por meio de uma teoria aplicada da cidadania para apoiar a inclusão social, capacitação e inclusão de pessoas com diagnóstico de transtornos psiquiátricos, concluindo a pesquisa com uma discussão sobre os desafios de desenvolver o potencial individual e coletivo e o quadro de cidadania em relação aos sistemas atuais e futuros de cuidados de saúde mental da comunidade.

Sobre a questão de direitos humanos das pessoas com transtornos mentais, MfoafoM'Carthy e Huls (2014) fazem uma revisão na literatura existente sobre saúde mental e violações dos direitos humanos. Para tanto, utilizaram diversas palavras chaves em bases de 
dados para coletar dados, interpretações e publicações governamentais sobre saúde mental e direitos humanos, catalogando diversos artigos publicados e legislações que tratam dessa questão e afirmam que estas pessoas sofrem violações de direitos humanos em escala global dentro e fora das instituições psiquiátricas, que incluem negação de emprego, casamento, procriação e educação; desnutrição; abuso físico; negligência, entre outros.

De Leonardis, Mauri e Rotelli (1986) trazem em seu estudo a experiência italiana de desinstitucionalização na psiquiatria, que obteve o reconhecimento internacional como sendo o único exemplo de uma sociedade industrial que buscou eliminar a internação em hospital psiquiátrico como serviços de saúde mental prioritário.

Burti (2001) escreve um artigo no qual descreve a realidade dos cuidados de saúde mental na Itália e a implementação da legislação de reforma da saúde mental decorridos vinte anos do início das mudanças, que proibia admissões nos hospitais psiquiátricos estatais, estabeleceu a necessidade de serviços baseados na comunidade, permitindo a hospitalização somente em pequenas unidades de hospital geral, levando ao fim do sistema hospitalar mental estatal na Itália em 1998.

Morzycka-Markowska, Drozdowicz e Nasierowski (2015a), descrevem a implementação das mudanças legislativas derivadas da reforma psiquiátrica nos anos 60 e 70, afirmando que a antipsiquiatria italiana levou à experiência mais radical na desinstitucionalização da história, quando Franco Basaglia promoveu suas ideias por toda a Europa.

Burti (2016), em seu artigo que trata sobre os trinta e cinco anos de reabilitação psicossocial na Itália, é enfático ao afirmar que não há saúde mental sem respeito pela dignidade das pessoas com transtornos mentais em igualdade de condições com todos os outros cidadãos. Para tanto, a reabilitação não é uma exceção e a desinstitucionalização é o pré-requisito necessário, sendo que, passados trinta e cinco anos de psiquiatria comunitária, a Itália ainda deve aperfeiçoar seu modelo para que as pessoas com transtornos mentais sejam cada vez mais inseridas na sociedade.

Outro país fundamental como modelo para o processo de desinstitucionalização psiquiátrica foi a Inglaterra. Thornicroft (1993) realizou uma avaliação do fechamento de grandes hospitais psiquiátricos na Inglaterra, destacando que em 1954 havia 148 mil camas psiquiátricas e, em 1990, cerca de 50 mil ainda permaneceram. Evidenciou o resultado de que, de 350 pacientes desinstitucionalizados dos hospitais de Friern e Claybury entre 1985 e 1990, comparando antes e após a alta, no primeiro ano após a alta, 16\% foram readmitidos no hospital. As mudanças significativas $(\mathrm{p}<0,01)$ foram observadas para: a atitude dos pacientes 
(que preferiram seu novo modo de vida na comunidade); os custos dos cuidados (que foram inicialmente reduzidos em 5\% para os pacientes desinstitucionalizados): e a melhor qualidade de acomodação (o que permitiu maior escolha para os pacientes). Esses primeiros resultados sugeriram que o cuidado na comunidade não é pior, em muitos aspectos é melhor e não é mais caro do que os cuidados hospitalares.

McCrone e Becker (2000), em seu artigo abordam a temática da reforma psiquiátrica e o sistema de cuidados de saúde mental na Inglaterra, relatando o encerramento de mais de 90 hospitais psiquiátricos, após a reforma, sendo que os resultados dos arranjos de assistência após a desinstitucionalização demonstram que os cuidados de saúde mental da comunidade são viáveis e efetivados por meio dos serviços com tratamento domiciliar e foco comunitário.

Csipke et al. (2014), abordam a questão da atenção hospitalar cinquenta anos após o processo de desinstitucionalização, afirmando que ao longo desse tempo os serviços de saúde mental visaram a fornecer e a melhorar o atendimento hospitalar de alta qualidade, no entanto, os usuários de serviços e a equipe de enfermagem manifestaram frustração com a falta de atividades terapêuticas, seja, aqueles pacientes que permaneceram institucionalizados, não foram realizadas mudanças para que fossem inseridas atividades, sendo que os autores evidenciaram em suas conclusões acerca da necessidade de que atividades terapêuticas podem ser realizadas por pacientes agudamente e, de fato, são apreciadas.

Turner et al. (2015) faz uma retrospectiva da história dos serviços de saúde mental na Inglaterra moderna a partir das memórias médicas, descrevendo todo o percurso do processo de desinstitucionalização psiquiátrica, a estruturação de novas formas de cuidados das pessoas com transtornos mentais e a necessidade de contínuas mudanças diante do contexto social, cultural, político, médico e institucional de seus tratamentos, narrativa histórica estruturada em torno dos direitos (o direito à saúde e o direito à liberdade) e ainda ampliada pelo surgimento de novas categorias de organização, como "custos", "riscos", necessidades", "inclusão" e "igualdade", termos utilizados nos argumentos daqueles que são contra ou a favor da desinstitucionalização das pessoas com transtornos mentais.

Levando-se em consideração todas as lutas pela Reforma Psiquiátrica e a desinstitucionalização das pessoas com transtornos mentais de longa permanência em hospitais psiquiátricos, os movimentos em prol da luta pela preservação dos direitos das pessoas com transtornos mentais têm encontrado no Direito, principalmente na área dos Direitos Humanos, a base para que os direitos e a cidadania (direitos civis, políticos e sociais), sejam a linha mestra à construção de políticas públicas que possibilitem o resgate da 
dignidade humana desses cidadãos, visando a sua reabilitação psicossocial e a sua reinserção no meio familiar (quando possível) e/ou na comunidade (Amarante et al., 2016).

As políticas públicas deveriam ser voltadas, de acordo com Saraceno (2001), à reabilitação psicossocial. No Brasil, esta é um dos sete componentes da Rede de Atenção Psicossocial (RAPS), que destina-se a aumentar as habilidades da pessoa, diminuindo as deficiências e os danos da experiência do transtorno mental.

Saraceno (1996, p. 16) define a Reabilitação Psicossocial como "um processo de reconstrução, um exercício pleno da cidadania e, também, de plena contratualidade nos três grandes cenários: habitat, rede social e trabalho com valor social", sendo a noção de cidadania exatamente o núcleo da concepção do movimento da Reforma Psiquiátrica no Brasil.

A cidadania de uma pessoa com transtorno mental, para Saraceno (2001, p. 18), "não é a simples restituição de seus direitos formais, mas a construção de seus direitos substanciais, e é dentro de tal construção (afetiva, relacional, material, habitacional, produtiva) que se encontra a única Reabilitação possível".

No entanto, esse processo envolve, segundo Saraceno (1996, p. 13), "profissionais e todos os atores do processo de saúde-doença, ou seja, todos os usuários e a comunidade inteira", superando a visão tradicional que separa o sujeito do contexto social, configurandose como um conjunto de estratégias que podem possibilitar o resgate da singularidade, da objetividade, e o respeito à pessoa com transtorno mental, podendo resultar em melhoria na qualidade de vida.

Assim, a reabilitação psicossocial é uma estratégia para a inclusão social, exercício da cidadania, construção da identidade e da autonomia dos sujeitos, os quais ainda em sua maioria são mantidos por longo tempo em hospitais psiquiátricos, requerendo a definição de políticas públicas que contemplem os três cenários definidos por Saraceno (2001) como fund amental nesse processo: o habitar, a rede social, e o trabalho.

Ferrannini e Peloso (2016) analisam o processo de desinstitucionalização na Itália e abordam especialmente a questão da reabilitação psicossocial, construindo um sistema baseado em psiquiatria comunitária e em serviços ambulatoriais.

Morzycka-Markowska, Drozdowicz e Nasierowski (2015b) abordam a questão da reforma psiquiátrica na Itália a partir de 1978 com a Lei Basaglia, apontando que a reforma e suas consequências foram amplamente estudadas pelos pesquisadores, especialmente no Reino Unido e nos Estados Unidos da América, uma vez que a desinstitucionalização não teve como resultado o aumento das internações psiquiátricas compulsórias, tentativas de suicídio por parte das pessoas com transtornos mentais, tampouco aumentou o número de crimes 
cometidos por eles, assim como não causou transinstitucionalização, com a transferência de pacientes para o setor privado, conforme previam os grupos contrários a reforma.

Hazelton (2005) aborda a questão de a Saúde Mental ser vista como um grande desafio global, o que levou à reforma da saúde mental em muitos países, como Austrália, Reino Unido, Itália e Brasil, como resultado do aumento do interesse do governo nessa área, na adoção de desinstitucionalização e cuidados comunitários como opções oficialmente sancionadas, sendo que as novas orientações políticas caracterizaram-se pela preocupação com a participação da cidadania e a proteção dos direitos humanos dos usuários dos serviços de saúde mental.

Taylor, Killaspy e King (2017) afirmam que o processo de desinstitucionalização a partir dos cuidados em comunidade, mostra-se associado a uma melhor qualidade de vida para pessoas com transtorno mental com longa permanência em hospitais e de acordo com a perspectiva, 1579 usuários de serviços em nove países europeus, Bulgária, Alemanha, Grécia, Itália, Holanda, Polônia, Portugal, Espanha e Reino Unido que associaram a melhor qualidade no atendimento, assim como o aumento na autonomia dos usuários de serviços de cuidados na comunidade.

Fleury et al. (2016) realizaram um estudo de avaliação da implementação da Reforma de Saúde Mental de Quebec (MH) (2005-2015) que objetivou melhorar a acessibilidade, a qualidade e a continuidade dos cuidados por meio do desenvolvimento de cuidados primários e otimização de redes integradas de serviços, cujo resultado indica que, mesmo que a implementação não tenha sido totalmente alcançada na maioria das redes, a reforma de Quebec conseguiu melhorar os serviços de atenção primária com a criação de equipes de atenção primária para adultos e serviços únicos que aumentaram o acesso aos cuidados.

Entretanto, na contramão dos avanços no mundo e no Brasil no que tangem os processos de reforma psiquiátrica, com a desinstitucionalização de pessoas com transtornos mentais de hospitais psiquiátricos, a China, com a aprovação da Lei Nacional de Saúde Mental em 2012, tornou-se mais rigorosa em se tratando de ampliar o poder estatal, buscando padronizar as diversas práticas de admissão involuntária de pessoas com transtorno mental na China (Shao, Xie, 2015); (Emmanuel, Campbell, 2015).

Diante desse contexto, observamos que diversos países do mundo têm procurado instituir políticas de desinstitucionalização das pessoas com transtornos mentais internadas nos hospitais psiquiátricos e que no Brasil, mesmo com os avanços da Reforma Psiquiátrica e os componentes atuais da Política de Saúde Mental, como a variedade de leis e portarias disponíveis que garantem os direitos das pessoas com transtornos mentais, no Estado de São 
Paulo, em 2008, de acordo com o Censo Psicossocial, "a população moradora há mais de um ano em hospitais psiquiátricos [era] composta por 3.930 (três mil, novecentos e trinta) homens e 2.419 (duas mil, quatrocentas e dezenove) mulheres" (Barros, Bichaff, 2008, p. 114), ou seja, 6.349 (seis mil, trezentos e quarenta e nove) estavam hospitalizados e dependiam de políticas públicas que definissem instrumentos e estratégias que permitiriam a viabilização da reinserção social desses sujeitos à comunidade.

Assim, partindo-se da necessidade da análise das ações estratégicas à construção das políticas públicas de desinstitucionalização, ou seja, de direitos, cidadania e reabilitação psicossocial de pessoas com transtornos mentais com longa internação em hospitais psiquiátricos no Estado de São Paulo, a partir das recomendações propostas por Barros e Bichaff (2008), que orientam os gestores para a efetivação das políticas de desinstitucionalização dessas pessoas, têm-se a pergunta de pesquisa: Quais ações foram propostas e implementadas pela Secretaria de Estado da Saúde de São Paulo (SES/SP), para efetivar políticas públicas de desinstitucionalização, após o Censo Psicossocial (2008) de moradores em hospitais psiquiátricos do Estado?

Diante deste contexto, definimos como objeto desse estudo: as políticas públicas de desinstitucionalização efetivadas pela SES/SP, após o Censo Psicossocial (2008) de moradores em hospitais psiquiátricos do Estado de São Paulo, com a finalidade de analisar as ações de direitos e cidadania e reabilitação psicossocial efetivamente implementadas no Estado, derivadas do conjunto de recomendações propostas na obra resultante do referido Censo Psicossocial, para contribuir com a (re)formulação das políticas públicas de direitos, cidadania e reabilitação psicossocial.

Partimos do pressuposto que, se por um lado tem-se a Política Nacional de Saúde Mental, a qual visa a desinstitucionalizacão e tem como finalidade a inclusão social e a cidadania do sujeito com transtorno mental na sociedade, bem como as recomendações particulares propostas pelo $1^{\circ}$ Censo Psicossocial (2008) no que tange ao fortalecimento da RAPS, por outro lado, tem-se um típico fenômeno de reprodução do modelo psiquiátrico tradicional e os órgãos responsáveis pela formulação, execução e controle da política estadual, que não incorporam o discurso reformista baseado no conceito de reabilitação psicossocial e de direitos humanos do sujeito com transtorno mental. Portanto, não executam suas determinações e, sobretudo, intervêm de forma pouco efetiva em relação às estratégias de desinstitucionalização prevista na RAPS às pessoas com transtornos mentais de longa internação. 
Esse pressuposto nos leva a outras indagações centrais: apesar da realização dos Censos de 2008 e 2014, das recomendações propostas à desinstitucionalização das pessoas com transtornos mentais internadas nos hospitais psiquiátricos, por São Paulo ser a maior cidade do país, com as maiores e renomadas universidades, com uma economia fortemente industrializada, entre tantos outros fatores, o que impede que se cumpra uma agenda de políticas públicas de desinstitucionalização de pessoas com transtornos mentais internadas em hospitais psiquiátricos? O Estado de São Paulo define e executa uma efetiva política pública de saúde mental? Quais são os impedimentos para a desinstitucionalização?

Cabe aqui definirmos que política pública deve ser entendida como "uma estratégia de ação pensada, planejada e avaliada, guiada por uma racionalidade coletiva, na qual tanto o Estado como a sociedade, desempenham papéis ativos" (Pereira, 2011, p. 96). Assim, mesmo a política pública sendo um conjunto de ações que visem à garantia dos direitos sociais através da intervenção estatal e ao envolvimento de diversos atores na sociedade, como define Silva e Rosa (2014, p. 257), "é uma arena de disputas de modelos de sociedade e de gestão do Estado e, consequentemente, de modelos de política de saúde mental”.

Como pontua Oliveira (2017, p. 29), ao indagar "o que essa reforma entendeu e entende por desinstitucionalização?”, mesmo estando a RAPS instituída em vários territórios, o fechamento de hospitais psiquiátricos "ainda ocorrem no país após 16 anos da Lei 10.216 e mais de 30 anos do início da Reforma Psiquiátrica”, por outro lado, mostra um processo de "terceirização dos serviços de saúde", os vários hospitais psiquiátricos em funcionamento pleno, o 'grande novo negócio' das comunidades terapêuticas crescendo rapidamente e clínicas particulares mostrando que o espaço asilar ainda é presente e persistente, como que reafirmando a presença da "velha ordem", onde os interesses econômicos superam os direitos humanos.

Como já afirmavam Nicácio e Campos (2004, p. 72)

\footnotetext{
São múltiplos os desafios na cotidianidade dos serviços substitutivos e da produção de novas formas de cuidado e de interação com as pessoas com a experiência do sofrimento psíquico e é nesse processo que emerge a complexidade da atenção às situações de crise. Como em todos os percursos de transformação, corre-se o risco de reproduzir o modelo asilar, de atualizar o plano discursivo mantendo inaltera da a realidade.
}

Existem, ainda, aqueles que creem que "lugar de louco é no hospício", aqueles que veem a pessoa com transtorno mental como um risco à sociedade, levando-se em consideração a noção de periculosidade atribuída a esses indivíduos, segregados do convívio em sociedade, ou ainda aqueles que não possuem estrutura familiar para acolher a pessoa 
desinstitucionalizada, que, não poucas vezes, são "institucionalizados" em pequenos cômodos de suas casas, estigmatizados, cerceados dos seus direitos enquanto sujeitos históricos.

Diante desse cenário carregado de desafios não superados, almejando por estratégias efetivas que preencham as lacunas desse contexto, o que se vê são estratégias que caminham para o lado oposto, representando um retrocesso. Em 2017 foi publicada a Portaria $\mathrm{n}^{\mathrm{o}} 3.588$, anunciando investimento financeiro aos hospitais psiquiátricos e às comunidades terapêuticas (Brasil, 2017). De modo complementar, a Portaria $n^{\circ} 2.434$ de 2018 estipula aumento no repasse de verba por dia de internação hospitalar (Brasil, 2018).

A mais recentemente Lei publicada que trata sobre o tema, Lei $n^{\circ} 13.840$, vem mudando o cenário brasileiro ao aprovar, em 05 de junho de 2019, a internação compulsória e involuntária, que, portanto, volta a ser uma realidade no país (Brasil, 2019). Essas mudanças afetam drasticamente o cenário de saúde mental, pois reconsideram o isolamento social como uma intervenção terapêutica, ignorando o avanço construído pela RAPS e as políticas que visavam à desinstitucionalização (Brasil, 2019a).

Assim, para responder aos questionamentos formulados é fundamental definir os objetivos e um percurso metodológico, os quais apresentamos a seguir. 
2 OBJETIVOS 


\section{OBJETIVOS}

\subsection{OBJETIVO GERAL}

- Analisar as políticas públicas de Saúde Mental relacionadas aos direitos, à cidadania e à reabilitação psicossocial dos sujeitos com transtornos mentais, derivadas do conjunto de recomendações propostas na obra resultante do Censo Psicossocial dos moradores em hospitais psiquiátricos (2008), para contribuir com a (re)formulação das políticas públicas de direitos e cidadania e reabilitação psicossocial.

\subsection{OBJETIVOS ESPECÍFICOS}

- Identificar as ações propostas e implementadas pela Secretaria de Estado da Saúde da São Paulo (SES/SP) para efetivar políticas públicas de desinstitucionalização, após o Censo Psicossocial (2008), de moradores em hospitais psiquiátricos do Estado de São Paulo.

- Caracterizar e analisar as políticas públicas de desinstitucionalização das pessoas com transtornos mentais internadas em hospitais psiquiátricos no Estado de São Paulo. 


\section{MATERIAL E MÉTODO}

\subsection{BASE TEÓRICO-METODOLÓGICA DO ESTUDO}

Como sustentação teórico-metodológica que guiasse a construção da pesquisa de campo, optamos pela Teoria da Intervenção Práxica da Enfermagem em Saúde Coletiva (TIPESC), proposta por Egry (1996), que teve como fundamento os pressupostos do Materialismo Histórico e Dialético, valendo-se de categorias marxistas, visto que por meio da ação do trabalho, pode haver mudanças permanentes nos fenômenos, na realidade, o que não impede sua compreensão objetiva, à luz da dialética, que permite a capacitação total do movimento histórico em suas contradições, pois,

\footnotetext{
Na sua vertente metodológica, é a sistematização dinâmica de captar e interpretar um fenômeno articulado ao processo de produção e reprodução social referentes à saúde e doença de uma dada coletividade, no marco de sua conjuntura e estrutura, dentro de um contex to socialhistoricamente determinado; de intervir nessa realidade e, nessa intervenção, prosseguir reinterpretando a realidade para novamente nela interpor instrumentos de intervenção (Egry, 1996, p. 103).
}

Para Minayo (2008, p. 25), a dialética marxista "abarca não somente o sistema de relações que constrói o modo de conhecimento exterior ao sujeito, mas também as representações sociais que constituem a vivência das relações objetivas pelos atores sociais que lhe atribuem significados".

É sob esse ponto de vista que a presente pesquisa se situa na perspectiva dialética do Materialismo Histórico Dialético e na pesquisa qualitativa, visando a dar "significado e dar intencionalidade como inerentes aos atos, às relações, e às estruturas sociais, sendo estas últimas tomadas tanto no seu advento quanto na sua transformação, como construções humanas significativas" (Minayo, 2008, p. 22).

Dessa forma, o presente estudo procurou descrever esse movimento dinâmico da dialética, as contradições, os conflitos e as transformações que ocorreram no Estado de São Paulo, no decorrer do processo histórico da desinstitucionalização, buscando-se uma representação do real, dos fatos desencadeados, ações propostas ou implementadas para a construção de políticas públicas para a desinstitucionalização de pessoas com transtornos 
mentais internadas por longo tempo nos hospitais psiquiátricos, a partir das recomendações propostas pelo Censo Psicossocial no ano 2008.

Para tanto, tem-se que a Teoria de Intervenção Práxica da Enfermagem em Saúde Coletiva TIPESC - desenvolvida por Egry (1996), constitui-se em um instrumental teóricometodológico que deve ser sistematizado em cinco etapas: (1) captação da realidade objetiva que caracteriza-se pela identificação das ações propostas e implementadas pela Secretaria de Estado da Saúde de São Paulo (SES/SP) para efetivar políticas públicas de desinstitucionalização, após o Censo Psicossocial (2008) de moradores em hospitais psiquiátricos do Estado de São Paulo; (2) interpretação da realidade objetiva, a partir da análise das ações de desinstitucionalização conforme as recomendações propostas pelo Censo Psicossocial (2008) de moradores em hospitais psiquiátricos do Estado de São Paulo; para tornar-se possível a (3) construção do projeto de intervenção na realidade objetiva, com a proposição de ações a serem desenvolvidas, de modo que a (4) intervenção na realidade objetiva, resulte na efetivação das recomendações realizadas após o Censo 2008 e, com isso, tenha-se a (5), reinterpretação da realidade objetiva por meio do fortalecimento das RAPS, para a efetivação do processo de desinstitucionalização no Estado de São Paulo.

Entretanto, há que se apreender da totalidade da questão da Reforma Psiquiátrica no Estado de São Paulo, a realidade objetiva, definida de acordo com Egry (1996, p. 84), por três dimensões: a estrutural, a particular e a singular.

A análise dessas três dimensões recortadas da realidade objetiva, a estrutural, particular e singular, como define Egry (1996, p. 102), "fazem parte da mesma totalidade, estando fortemente articuladas entre si e que, sem a visualização de todas, mesmo com destaques distintos, não se pode proceder à totalização do fenômeno", ou seja, nos permitiu ter uma visão da categoria dimensional da totalidade do processo de desinstitucionalização no Estado de São Paulo, que levou a categoria dimensional de práxis social, visto que ainda conforme Egry (1996, p. 89), “a modificação prática do objeto não humano se traduz, por sua vez, numa transformação do homem como ser social", seja, somente políticas públicas efetivas de desinstitucionalização e reabilitação psicossocial é que possibilitam que as pessoas com transtornos mentais tornem-se verdadeiramente um ser social.

De acordo com Egry (1996, p. 84), “a dimensão estrutural compreende os processos de desenvolvimento da capacidade produtiva e do desenvolvimento das relações de produção, da formação econômica e social e das formas político-ideológicas derivadas", seja, caracteriza-se pelo contexto econômico político e social no qual se estrutura a sociedade.

Temos que: 
A dimensão particular compreende os processos de reprodução social manifestos nos perfis epidemiológicos de classe, integrados pelo perfil reprodutivo de classe e perfil de saúde-doença e, ainda, pelas formas especiais de prática e de ideologia em saúde (Egry, 1996,p. 84-5).

E, finalmente, temos que a dimensão singular "compreende os processos que, em última instância, levam a adoecer e a morrer ou, ao contrário, ao desenvolvimento do nexo bio-psíquico dado pelo funcionamento e consumo-trabalho individual do homem e pelas formas de participação individual na organização social e na expansão da sua consciência" (Egry, 1996, p. 85), seja, são as formas que se organizam para sustentar a vida e a saúde individual, ou ainda "os processos de trabalho específicos de uma unidade ou setor assistencial, dentro dos serviços”.

Quanto à abordagem foi realizada a pesquisa qualitativa, por considerar que investigações exploratórias proporcionam a formulação de questões ou de um problema a ser respondido, aumentar a familiaridade do pesquisador com um ambiente, fato ou fenômeno, para a realização de uma pesquisa futura mais precisa, ou modificar e clarificar conceitos (Marconi, Lakatos, 2010).

Conforme descreve Minayo (2010, p. 57), o método qualitativo pode ser definido como:

\footnotetext{
O que se aplica ao estudo da história, das relações, das representações, das crenças, das percepções e das opiniões, produtos das interpretações que os humanos fazem a respeito de como vivem, constroem seus artefatos e a si mesmos, sentem e pensam. Embora já tenham sido usadas para estudos de aglomerados de grandes dimensões (IBGE, 1976; Parga Nina et.al 1985), as abordagens qualitativas se conformam melhor a investigações de grupos e segmentos delimitados e focalizados, de histórias sociais sob a ótica dos atores, de relações e para análises de discursos e de documentos.
}

Ademais, a pesquisa qualitativa induz reflexões e, até mesmo, novos desdobramentos quanto à temática pesquisada (Minayo, 2010).

\subsection{CENÁRIO DO ESTUDO}

O cenário desta pesquisa foi o Estado de São Paulo representado pela SES/SP que é responsável pela elaboração de políticas estaduais de saúde e suas diretrizes, norteada pelos princípios do SUS, que tem como propósito promover a saúde priorizando as ações preventivas, democratizando as informações relevantes para que a população conheça seus direitos e os riscos à sua saúde. A SES/SP é organizada conforme mostra Figura 1: 
Figura 1 - Organograma da SES/SP

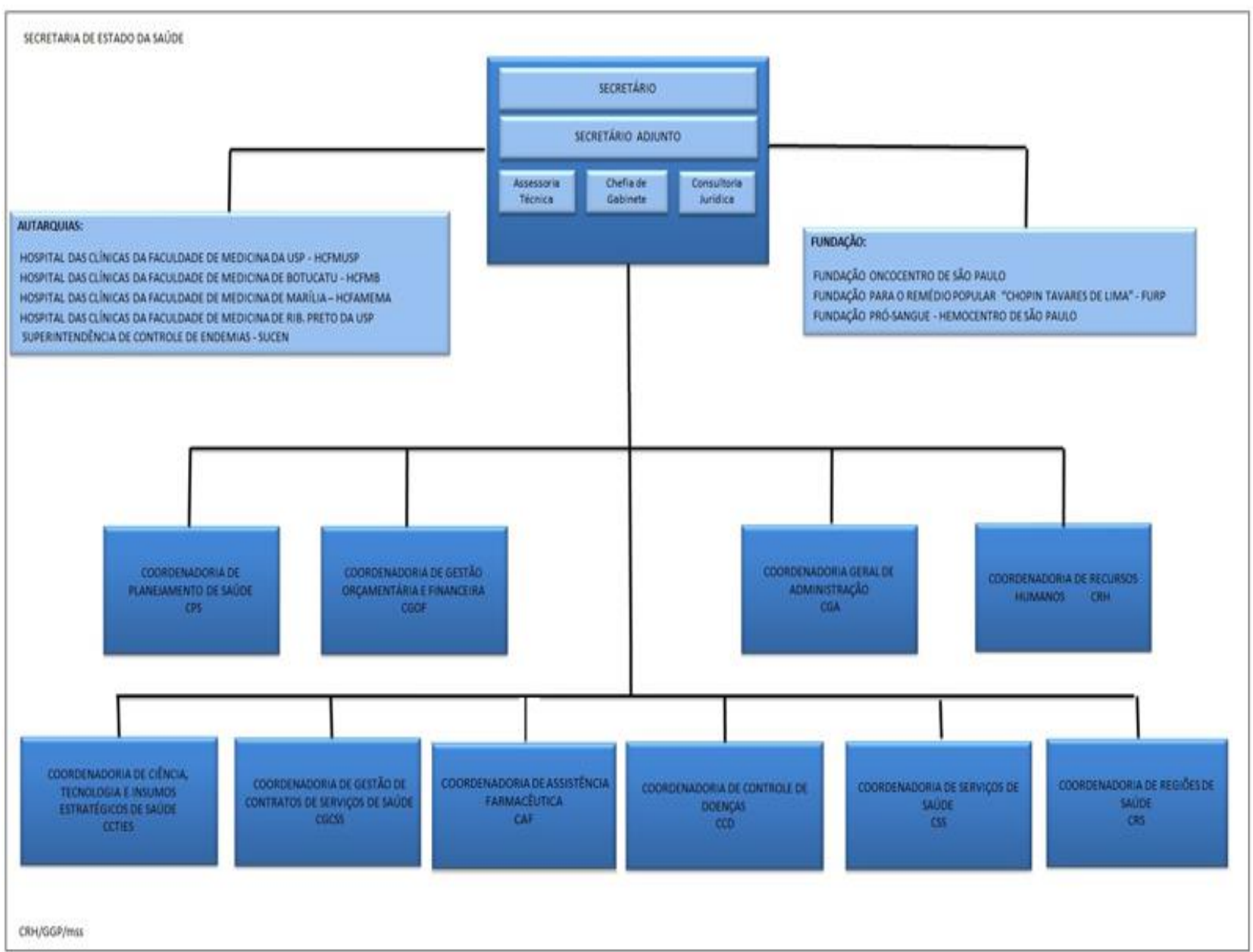

Fonte: São Paulo, s/d.

A SES/SP é responsável pela articulação e pelo planejamento de ações desenvolvidas pelos 17 Departamentos Regionais de Saúde (DRS), I Grande São Paulo; II Araçatuba; III Araraquara; IV Baixada Santista; V Barretos; VI Bauru; VII Campinas; VIII Franca; IX Marília; X Piracicaba; XI Presidente Prudente; XII Registro; XIII Ribeirão Preto; XIV São João da Boa Vista; XV São José do Rio Preto; XVI Sorocaba; XVII Taubaté; distribuídos pelo Estado (São Paulo, 2017d). 
Figura 2 - Estado de São Paulo segundo Departamentos de Saúde, 2012.

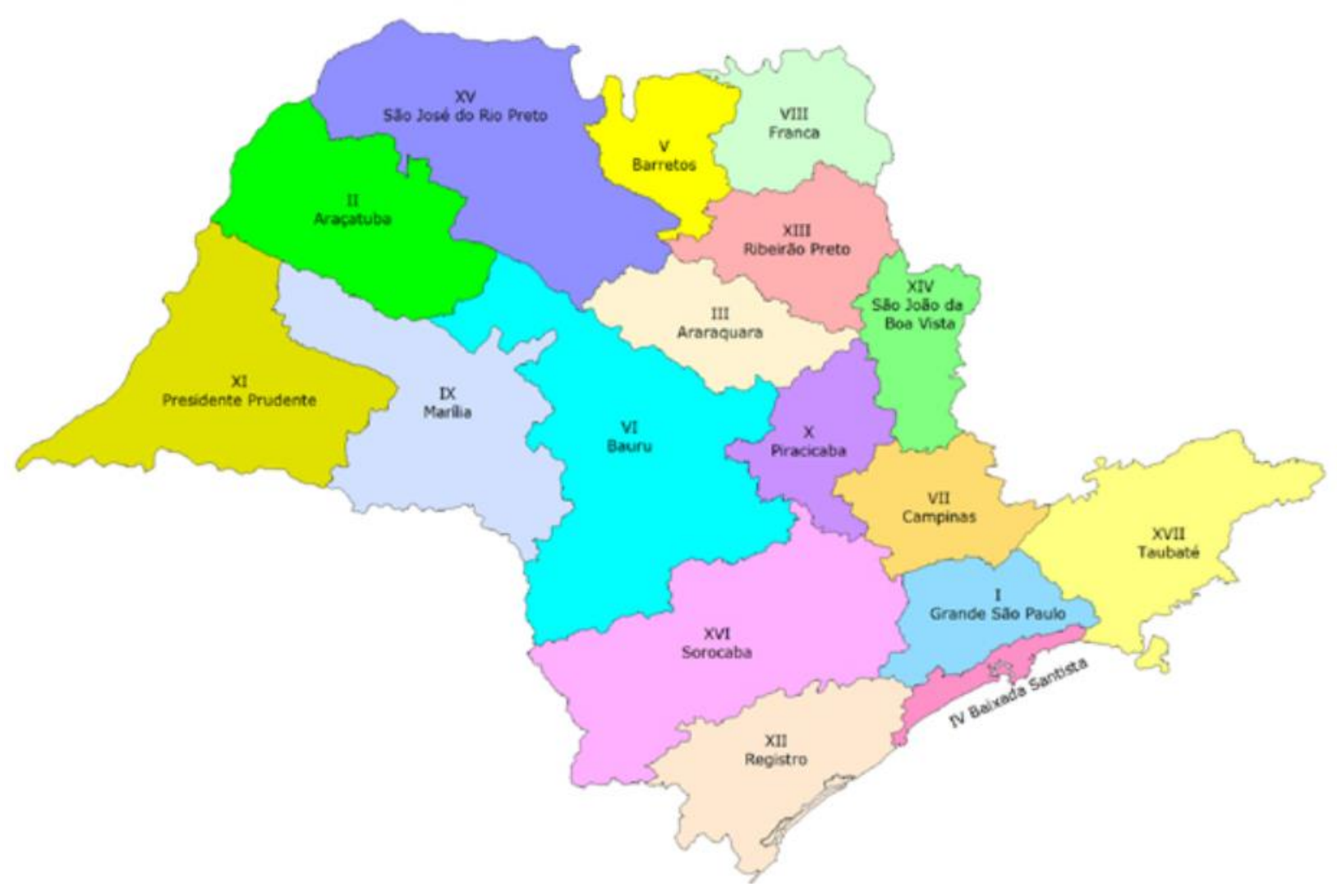

Fonte: São Paulo, 2017d.

Desde o ano de 2008, quando se realizou o Censo Psicossocial (2008) até os dias atuais, a SES/SP foi gerenciada por cinco gestões de secretários estaduais de saúde. A SES/SP é vinculada e subordinada ao Governo Estadual, na referida Secretaria tem-se o Conselho Estadual de Saúde (CES/SP) e a Comissão Intergestores Bipartite (CIB).

O CES, instituído pela Lei 8.356 de 1993, é uma instância do SUS com o objetivo de realizar deliberações a respeito de políticas de saúde. A CIB, por sua vez, é uma instância do SUS, responsável pela deliberação e avaliação dos pleitos de habilitação dos municípios nas condições de Gestão Plena, da Atenção Básica, do Sistema Municipal e da Atenção Básica Ampliada, baseado na Norma Operacional Básica (NOB/96) e a Norma Operacional de Assistência em Saúde (NOAS/02) (São Paulo, s/d). Além disso, a SES/SP possui dezesseis instituições de saúde, listadas no quadro abaixo: 
Quadro 1 - Instituições da SES/SP

Centro de Referência e Treinamento DST AIDS - CRT/AIDS

Centro de Vigilância Epidemiológica - CVE

Centro de Vigilância Sanitária - CVS

Fundação Oncocentro de São Paulo - FOSP

Fundação para o Remédio Popular - FURP

Fundação Pro Sangue Hemocentro de São Paulo

Instituto Adolfo Lutz - IAL

Instituto Butantan

Instituto Pasteur

Instituto de Saúde

Instituto Lauro de Souza Lima

Superintendência de Controle de Endemias - SUCEN

Coordenadoria de Recursos Humanos

Centro de Referência de Álcool, Tabaco e Outras Drogas - CRATOD

Coordenadoria de Controle de Doenças

Centro de Referência e Treinamento DST AIDS - CRT/AIDS

Fonte: São Paulo, s/d.

$\mathrm{Na}$ estrutura da SES/SP existem as seguintes coordenadorias: Coordenadoria de Assistência Farmacêutica (CAF); Coordenadoria de Ciência, Tecnologia e Insumos Estratégicos de Saúde (CCTIES); Coordenadoria de Controle de Doenças (CCD); Coordenadoria de Gestão de Contratos de Serviços de Saúde (CGCSS); Coordenadoria de Gestão Orçamentária e Financeira (CGOF); Coordenad oria de Planejamento de Saúde (CPS); Coordenadoria de Recursos Humanos (CRH); Coordenadoria de Regiões de Saúde (CRS); Coordenadoria de Serviços de Saúde (CSS) e Coordenadoria Geral de Administração (CGA). (São Paulo, 2017d).

Ainda na estrutura da SES/SP tem-se a Área Técnica Saúde Mental, Álcool e Drogas que está ligada diretamente a Chefia de Gabinete. A referida Área Técnica é responsável pela realização de todas as ações voltadas à Saúde Mental, Álcool e outras Drogas, bem como pelo apoio e qualificação dos profissionais envolvidos nas Redes de Atenção Psicossocial (RAPS) (São Paulo, s/d). A Rede atua de acordo com o modelo organizado das Redes de Atenção à Saúde, instituídos a partir da Portaria n 7508 de 2011 e conta com 63 RAPS nos municípios do Estado (São Paulo, 2015). 
Em relação à quantidade de instituições e/ou serviços na área de Saúde Mental da SES/SP, bem como os quantitativos de leitos psiquiátricos, gestão estadual ou municipal, etc, estes foram apresentados separadamente no capítulo dos resultados da pesquisa documental deste estudo.

A SES/SP também é responsável pela articulação junto aos municípios como indutor das políticas públicas de Saúde Mental. Um órgão muito importante é o Conselho de Secretários Municipais de Saúde do Estado de São Paulo (COSEMS/SP), responsável por defender os interesses dos municípios do Estado em diferentes fóruns de saúde pública, tanto na Comissão Intergestores Bipartite (CIB), como no Conselho Estadual de Saúde (CES/SP). Recebe financiamento municipal e federal, realizando reuniões ordinárias mensalmente (COSEMS/SP, s/d). A gestão tem duração de 2 anos, e desde 2008 tem sido presidida pelos seguintes membros: Jorge Harada (2007-2009), Maria do Carmo Cabral Carpintero (20092011), Ademar Arthur Chioro dos Reis (2011-2013 e 2013-2014), José Fernando Casquel Monti (2014-2015); Stenio José Correia Miranda (2015-2017) e atualmente por Carmino Antonio de Souza (2017-2019). Em relação ao COSEMS/SP, também apresentamos nos resultados da pesquisa documental, em subcapítulo específico, as documentações pertinentes ao objeto deste estudo.

\subsection{FONTE DE DADOS}

Para identificação da realidade objetiva e da identificação de ações propostas e implementadas pela Secretaria de Estado da Saúde de São Paulo (SES/SP) na efetivação de políticas públicas de desinstitucionalização, de moradores em hospitais psiquiátricos do Estado de São Paulo, após o Censo Psicossocial (2008), utilizamos duas fontes de dados, sendo a primeira a pesquisa documental e a segunda as entrevistas semi-estruturadas com os sujeitos participantes. Estes dados após serem analisados separadamente, foram tratados nos capítulos dos resultados deste estudo. A seguir apresentamos como se deu a seleção dos documentos na pesquisa documental e após, explicitamos sobre os sujeitos participantes desta pesquisa.

\subsubsection{Pesquisa documental}

A pesquisa documental, de acordo com Pádua (1997, p. 62), “é aquela realizada a partir de documentos, contemporâneos ou retrospectivos, considerados cientificamente 
autênticos (não fraudados)", pesquisa que tem sido utilizada largamente "nas ciências sociais, na investigação histórica, a fim de descrever/comparar fatos sociais, estabelecendo suas características ou tendências $[\ldots]$ ”..

A pesquisa documental é de acordo com Gil (2002, p. 62-3), "fonte rica e estável de dados", não implicando em altos custos, não exigindo um contato próximo com os sujeitos da pesquisa, ao mesmo tempo em que traz a possiblidade de uma leitura aprofundada das fontes.

Os documentos, segundo Marconi e Lakatos (2010), são separados em apenas dois grupos: documentos escritos, em que estão contidos os documentos oficiais, publicações parlamentares, documentos jurídicos, fontes estatísticas, publicações administrativas e documentos particulares; e nos demais estão contidos documentos iconográficos, sendo imagens, desenhos, pinturas, fotografias, objetos, canções folclóricas, vestuário e folclore.

A pesquisa documental e a pesquisa bibliográfica muito se assemelham, e por vezes são confundidas, todavia, existe pequena diferença entre elas, sendo apenas a natureza das fontes. A pesquisa bibliográfica é fundamentada nas contribuições de diferentes autores sobre um mesmo tema, enquanto a pesquisa documental sustenta-se em materiais diversos que não receberam tratamento analítico. No entanto, ambas pesquisas seguem os mesmos caminhos metodológicos, descritos na pesquisa bibliográfica. O início da pesquisa documental se dá a partir da exploração das fontes documentais, geralmente estando em quantitativo considerável (Gil, 2002).

\subsubsection{Sujeitos participantes do estudo}

A proposta inicial dessa investigação em relação aos participantes do estudo está descrita abaixo:

- Secretário Estadual de Saúde do Estado de São Paulo (SES/SP) da época do Censo Psicossocial (2008) e gestões posteriores: responsável pela formulação da Política Estadual de Saúde e de suas diretrizes, norteada pelos princípios do SUS, que tem como propósitos promover a saúde priorizando as ações preventivas, democratizando as informações relevantes para que a população conheça seus direitos e os riscos à sua saúde;

- Coordenador da Área Técnica de Saúde Mental, Álcool e Drogas (SES/SP) da época de realização dos dois Censos Psicossociais e gestões posteriores: contribui tecnicamente para a construção de Políticas Estadual pautadas na garantia de direitos e cidadania; 
- Representante do Conselho de Secretários Municipais de Saúde do Estado de São Paulo "Dr. Sebastião de Moraes" (COSEMS/SP), entidade que representa os interesses das Secretarias Municipais de Saúde, congrega todos os Secretários Municipais de Saúde como membros-efetivos e defende os interesses dos Municípios nas pactuações interfederativas do Sistema Único de Saúde (SUS);

- Representante da Comissão de Saúde Mental, Álcool e outras Drogas do Conselho Estadual de Saúde do Estado de São Paulo (CES/SP), instância colegiada deliberativa e de natureza permanente do SUS, vinculado à SES/SP cujas comissões são compostas por Conselheiros Titulares e Suplentes e convidados indicados pelos segmentos que atuam na formulação de estratégias e no controle da execução da política de saúde, inclusive nos aspectos econômicos e financeiros;

- Coordenador do Centro de Apoio Operacional Cível e de Tutela Coletiva (CAOMPSP) Direitos Humanos e Direitos Sociais: órgão auxiliar da atividade funcional do Ministério Público do Estado de São Paulo: responsável pelo exercício de atividades indutoras da política institucional. Direitos Humanos que, por afirmação histórica, caracteriza-se e pela complementaridade e interdependência abrange, na área cível, a defesa do idoso, da pessoa com deficiência, saúde pública e dentro desta o transtorno mental, inclusão social e o zelo pelo efetivo respeito dos poderes Públicos e dos serviços de relevância aos direitos assegurados na Constituição da República;

- Coordenador do Núcleo Especializado de Cidadania e Direitos Humanos da Defensoria Pública do Estado de São Paulo: é uma instituição permanente cuja atribuição é oferecer aos cidadãos necessitados, de forma integral e gratuita, orientação jurídica, promoção dos direitos humanos e a defesa dos direitos individuais e coletivos, em todos os graus, judicial e extrajudicialmente;

- Outros sujeitos citados pelos entrevistados, que puderam revelar contradições nesse processo de construção de políticas públicas de desinstitucionalização de pessoas com transtornos mentais, com base nas recomendações do Censo Psicossocial dos moradores em hospitais psiquiátricos (2008).

Para iniciarmos a coleta de dados, a partir da proposta inicial convidamos os participantes nominados, iniciando pelos Secretários de Saúde da SES/SP, exceto o Secretário da época do Censo Psicossocial (2008), Dr. Luiz Roberto Barradas Barata, já falecido. Os 
demais secretários de saúde que assumiram a SES/SP nas gestões posteriores não aceitaram participar da pesquisa justificando indisponibilidade de agenda.

O Chefe de Gabinete da SES/SP, Dr. Nilson Ferraz Paschoa, na ocasião da nossa coleta de dados, foi convidado a participar da nossa pesquisa, pois estava comandando a pasta devido o secretário da SES/SP na época estar em licença para candidatura em eleições, porém ele também não aceitou nosso convite, atribuindo à coordenadora da Área Técnica de Saúde Mental, Álcool e Drogas (SES/SP), Dra Rosângela Elias a responder pela pasta (Anexo A). Assim, a referida coordenadora, participou em duas entrevistas, sendo uma delas, respondendo pela SES/SP e outra pela Coordenadoria da Área Técnica de Saúde Mental, Álcool e Drogas (SES/SP).

Todos os demais convidados da lista descrita anteriormente aceitaram participar do estudo. Também, alguns nomes foram citados pelos entrevistados, sendo uma representante do Ministério Público Federal (MPF) que atua conjuntamente com o Ministério Público Estadual de São Paulo (MPSP) no campo da Saúde Mental, uma das organizadoras do Censo Psicossocial de 2014 e uma trabalhadora militante da Saúde Mental, que participa ativamente dos grupos de trabalho e discussão para a desinstitucionalização das pessoas com transtornos mentais em hospitais psiquiátricos no Estado de São Paulo e que trabalhou muitos anos em hospitais psiquiátricos na região de Sorocaba na época do Censo Psicossocial (2008). Todos os citados pelos entrevistados foram convidados a participar do estudo e aceitaram.

\subsection{COLETA DOS DADOS}

Para a seleção dos documentos, segundo (Flick, 2009), devemos seguir quatro critérios, iniciando pela autenticidade (é genuíno e de origem inquestionável?), seguido da credibilidade ou exatidão (não contém erros e distorções?), depois representatividade (é típico do seu tipo? Se não for, qual a extensão dessa não tipicidade?), e por fim, significado (é claro e compreensível?). Diante disso, os questionamentos formulados para a seleção, tornam-se tão importantes quando o próprio documento, pois lhe é conferido sentido.

A coleta de dados também se deu com a pesquisa documental e com a realização das entrevistas com os sujeitos participantes, conforme apresentamos a seguir.

Em relação à pesquisa documental com o objetivo de identificar as ações de desinstitucionalização efetivadas pela SES/SP, após a realização dos Censos Psicossociais de 2008 e 2014, realizamos uma pesquisa inicial na Base de Dados LEGSES-SP que contempla 
atualmente, a legislação relacionada à saúde no âmbito do Estado de São Paulo com relevância e prioridade às Resoluções do Secretário, a partir de 1990, utilizando a metodologia e a tecnologia de Textos Completos em Legislação da Biblioteca Virtual em Saúde (BVS), desenvolvidas em parceria entre a ANVISA e a BIREME por meio do projeto VISALEGIS.

Também, realizamos a seleção de documentos nos sites oficiais do COSEMS/SP, CES/SP, MPSP, Defensoria Pública/SP e legislação nacional, para complementar com a análise temática das entrevistas com os sujeitos participantes e que estão explicitados no capítulo dos resultados de Pesquisa Documental, por meio de um quadro demonstrativo.

A partir do acesso aos sites das instituições supracitadas, buscou-se documentos cujo tema abordasse Saúde Mental, dentre eles portarias, leis, decretos, notas técnicas, resoluções, apresentações em PowerPoint e notícias em sites oficiais.

Após o acesso a esses documentos, realizou-se a leitura inicial com o objetivo de filtrar os documentos que atendessem aos questionamentos metodológicos. A partir disso, houve a separação deles quanto ao órgão emissor, sendo Ministério da Saúde (MS), SES/SP, COSEMS/SP, MPSP, CES/SP e Defensoria Pública/SP, para que então fosse realizada a leitura dos documentos na íntegra e, por fim, a análise dos documentos, procedendo com a análise temática.

Após a pesquisa documental, realizamos as entrevistas semi-estruturadas com os sujeitos participantes deste estudo. Ao falar em entrevista como técnica privilegiada de comunicação e coleta de dados, Minayo (2010, p. 261) destaca que se trata da estratégia mais utilizada no trabalho de campo, ressaltando o seguinte conceito:

[...] é acima de tudo uma conversa a dois, ou entre vários interlocutores, realizada por iniciativa do entrevistador, destinada a construir informações pertinentes para um objeto de pesquisa, e abordagem pelo entrevistador, de temas igualmente pertinentes tendo em vista este objetivo.

As entrevistas podem até mesmo ser consideradas conversas com finalidades, se caracterizando por sua forma de organização. As entrevistas, para Minayo (2012), podem ser classificadas em: a) sondagem de opinião; b) entrevista semi-estruturada; c) entrevista aberta ou em profundidade; d) entrevista focalizada; e) entrevista projetiva.

Para esse estudo, o instrumento de pesquisa foi a entrevista semi-estruturada (Apêndice A), cujo roteiro de perguntas foi estruturado com questões fundamentais e amplas a partir da leitura das recomendações propostas no Censo Psicossocial (2008), que possibilitou aos participantes da pesquisa uma reflexão profunda sobre o objeto de estudo. 
Novas indagações puderam ser realizadas no decorrer das entrevistas, além daquelas definidas no roteiro de perguntas, de acordo com o cargo/ocupação do participante na gestão estadual ou municipal.

Para acessar os participantes, foi realizado contato via telefônico, por endereço eletrônico, ou pessoalmente pela pesquisadora, para explicar os objetivos do estudo, esclarecimento de dúvidas e assinatura do Termo de Consentimento Livre e Esclarecido (TCLE), conforme modelo (Apêndice B), para dar início à coleta de dados.

A pesquisadora se deslocou até o local de atuação do profissional, com agendamento prévio para a realização da entrevista de acordo com a disponibilidade do participante e em dois casos, os sujeitos participantes se deslocaram até a Escola de Enfermagem da Universidade de São Paulo (EEUSP), onde foi disponibilizada uma sala individual para eles. Após a assinatura do TCLE e esclarecimentos de dúvidas, deu-se início as entrevistas com a aplicação do roteiro já nominado anteriormente. A duração das entrevistas foi de aproximadamente duas horas, sendo as mesmas individuais e sem interrupções por terceiros. Ao todo foram realizad as onze entrevistas, no período de março a julho de 2018.

Quanto ao financiamento para essa pesquisa, todos os custos foram arcados pela pesquisadora principal. Os entrevistados não tiveram despesas ou prejuízos com a participação nessa pesquisa, apenas um possível leve desconforto em virtude do tempo de entrevista realizada.

\subsection{ASPECTOS ÉTICOS}

Foram respeitados os preceitos éticos de participação voluntária e consentida e que atendem a todas as especificações da Resolução nº 466 de 12 de dezembro de 2012, que aprova as diretrizes e normas regulamentadoras de pesquisas envolvendo seres humanos (Brasil, 2013). O projeto de pesquisa foi encaminhado ao Comitê de Ética da EEUSP-SP para análise e parecer, tendo sido aprovado para a sua execução sob o Parecer $n^{\circ} 2.384 .307$ (Anexo E).

Para este estudo, foi pedido autorização institucional para realização de pesquisa científica conforme modelo (Apêndice C), obtendo-se a referida autorização da SES/SP (Anexo A), do CES/SP (Anexo B), do COSEMS/SP (Anexo C) e do MPSP (Anexo D). 


\title{
3.6 ANÁLISE DOS DADOS
}

A análise temática de acordo com Boyatzis (1998) é uma metodologia utilizada para identificar e analisar temas a partir de dados coletados. Outros autores acrescentam ainda que: “[...] Análise Temática não é apegada a qualquer arcabouço teórico pré-existente e, por conseguinte, ela pode ser utilizada em diferentes quadros teóricos (embora não todos), e pode ser usada para fazer coisas diferentes dentro deles" (Braun, Clarke, 2006, p. 81).

Além disso, os autores identificam algumas possibilidades por meio da análise:

\begin{abstract}
O tipo de perguntas que você precisa para estar se perguntando na fase final da sua análise, incluem: "O que é que este tema significa?" "Qua is são as premissas que o sustentam" "Quais são as implicações deste tema?" "Que condições são 12 susceptíveis de ter dado origem a ele" "Por que as pessoas falam sobre isso dessa maneira particular (a o contrário de outras formas)?" e "Qual é a história geral que os diferentes temas revelam sobre o assunto?”. Esses tipos de perguntas devem orienta $r$ a análise, uma vez que você tem uma noção clara do seu mapa temático (Braun, Clarke, 2006, p. 94).
\end{abstract}

Em relação ao procedimento metodológico da análise, a mesma ocorre em seis passos, iniciando com a familiarização do pesquisador com os dados a serem pesquisados, seguido da codificação dos dados, busca por temas, revisão dos temas a serem abordados, após isso, definição e nomeação dos temas e por fim, a discussão dos resultados (Braun, Clarke, 2006).

$\mathrm{Na}$ presente pesquisa, os documentos e entrevistas com os sujeitos participantes foram submetidos à análise temática e os resultados foram apresentados em forma de um quadro demonstrativo que encontra-se no Capítulo de Discussão.

Após a pesquisa documental, todos os dados foram separados e catalogados, assim como as entrevistas foram gravadas e transcritas para que nenhuma informação relevante fosse perdida no decorrer do processo de construção da análise de acordo com as três categorias dimensionais de análise propostas por Egry (1996, p. 80): "a da totalidade, a da práxis e a da interdependência do estrutural, do particular e do singular”.

As categorias empíricas foram elaboradas após a identificação das frases temáticas. Estas foram agrupadas a partir de afinidades entre os temas e nos permitiram a definição das três categorias sendo:

- Categoria 1 - A Instituição Manicomial;

- Categoria 2 - A Desinstitucionalização no Estado de São Paulo; 
- Categoria 3 - Redes de Atenção Psicossocial (RAPS) do Estado de São Paulo: A Desinstitucionalização.

As entrevistas realizadas resultaram em um volume de aproximadamente trezentas páginas transcritas das gravações, sendo que para que as categorias de análise emergissem, as narrativas dos entrevistados foram agrupadas por temas significativos da pesquisa, sendo então abstraídas as frases temáticas, com o objetivo de explicar a realidade de acordo com as três categorias dimensionais de análise propostas por Egry (1996).

Destacamos que, devido ao fato dos entrevistados terem expressado em seus discursos, seus valores, crenças e concepções sobre a questão das políticas públicas do Estado de São Paulo, optamos por não os identificar nominalmente, utilizando como critério a codificação da letra: "E" que se refere ao termo Entrevistado; seguido pelas letras de A até L que sinalizam os entrevistados conforme a sequência de entrevistas agendadas no período da coleta de dados, e uma sequência numérica que se refere ao número da frase temática extraída das entrevistas de cada entrevistado, ou seja, EA01, EA02, EB01, EB02, e assim por diante.

Os capítulos que seguem, de Resultados e de Discussão, respectivamente, tentam fazer a interpretação da realidade objetiva, a partir da identificação e da análise das ações relatadas por documentos e entrevistados frente às recomendações propostas pelo Censo Psicossocial (2008) de moradores em hospitais psiquiátricos do Estado de São Paulo. 
4 RESULTADOS

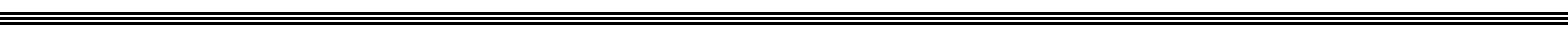




\section{RESULTADOS}

\subsection{A PESQUISA DOCUMENTAL}

Para apresentação dos resultados da pesquisa documental, iniciamos pela identificação e caracterização de hospitais psiquiátricos atualmente presentes no Estado de São Paulo.

Iniciamos a pesquisa acessando a página oficial da SES/SP e constatamos que estas informações não estão disponíveis ao público que acessa a referida página, pois quando digitamos as palavras chave "leitos psiquiátricos" ou "saúde mental", somos direcionados a outra página, que apresenta entre outras notícias, o título "Panorama de Saúde Mental leitos psiquiátricos e assistência extra-hospitalar". Quando clicamos no referido título, a página mostra a seguinte mensagem "página não encontrada" (São Paulo, 2019a).

Assim, esta pesquisadora solicitou diretamente à Dra. Rosangela Elias, Coordenadora atual da Área Técnica de Saúde Mental, Álcool e Drogas (SES/SP), as informações necessárias devido à importância para esse estudo. Em planilha de Excel recebida por $e$-mail da referida Coordenadora, no dia 04 de novembro de 2019, pode-se obter as seguintes informações: 32 hospitais psiquiátricos (Tabela 1), 519 CAPS e 307 residências terapêuticas (Tabela 2), nas 17 Regionais de Saúde conforme segue abaixo:

Tabela 1 - Hospitais Psiquiátricos do Estado de São Paulo/SP

(continua)

\begin{tabular}{|c|c|c|c|c|c|}
\hline Instituição & DRS & MUNICÍPIO & GESTÃO & SUS & EXISTENTES \\
\hline Hospital Espírita & Araçatuba & Penápolis & Municipal & 60 & 60 \\
\hline Casa Cairbar Schutel & Araraquara & Araraquara & Municipal & 30 & 30 \\
\hline $\begin{array}{l}\text { CAIS Candido de Moura } \\
\text { Campos Botucatu }\end{array}$ & Bauru & Botucatu & Estadual & 80 & 80 \\
\hline $\begin{array}{l}\text { CAIS Clemente Ferreira } \\
\text { de Lins }\end{array}$ & Bauru & Lins & Estadual & 116 & 116 \\
\hline $\begin{array}{l}\text { Seara Hospital } \\
\text { Psiquiátrico }\end{array}$ & Campinas & Americana & Municipal & 94 & 139 \\
\hline Clínica Fazenda Palmeiras & Campinas & Amparo & Municipal & 160 & 273 \\
\hline IRPSI & Campinas & Indaiatuba & Municipal & 69 & 115 \\
\hline
\end{tabular}


Tabela 1 - Hospitais Psiquiátricos do Estado de São Paulo/SP

(continuação)

\begin{tabular}{|c|c|c|c|c|c|}
\hline Instituição & DRS & MUNICÍPIO & GESTÃO & SUS & EXISTENTES \\
\hline $\begin{array}{l}\text { Hospital Psiquiátrico } \\
\text { Allan Kardec Franca SP }\end{array}$ & Franca & Franca & Municipal & 200 & 270 \\
\hline $\begin{array}{l}\text { Complexo Hospitalar } \\
\text { Juquery Franco da Rocha }\end{array}$ & GSP & $\begin{array}{l}\text { Franco da } \\
\text { Rocha }\end{array}$ & Estadual & 230 & 230 \\
\hline $\begin{array}{l}\text { Hospital de Desinternação } \\
\text { Progressiva }\end{array}$ & GSP & $\begin{array}{l}\text { Franco da } \\
\text { Rocha }\end{array}$ & НСТР & 210 & 210 \\
\hline $\begin{array}{l}\text { Lar Bussocaba } \\
\text { Assistência Vicentina }\end{array}$ & GSP & Osasco & Municipal & 11 & 66 \\
\hline Hospital Lacan & GSP & $\begin{array}{l}\text { São Bernardo } \\
\text { do Campo }\end{array}$ & Estadual & 192 & 192 \\
\hline $\begin{array}{l}\text { CAISM Dr. David } \\
\text { Capistrano da Costa Filho } \\
\text { da Água Funda SP }\end{array}$ & GSP & São Paulo & Estadual & 130 & 130 \\
\hline $\begin{array}{l}\text { CAISM Philippe Pinel } \\
\text { São Paulo }\end{array}$ & GSP & São Paulo & Estadual & 134 & 134 \\
\hline $\begin{array}{l}\text { Ca sa de Saúde de São } \\
\text { Joao de Deus }\end{array}$ & GSP & São Paulo & Municipal & 90 & 144 \\
\hline $\begin{array}{l}\text { Centro Hospitalar do } \\
\text { Sistema Penitenciário São } \\
\text { Paulo }\end{array}$ & GSP & São Paulo & Estadual & 8 & 8 \\
\hline $\begin{array}{l}\text { Hospital Psiquiátrico de } \\
\text { Vila Mariana }\end{array}$ & GSP & São Paulo & Estadual & 27 & 27 \\
\hline $\begin{array}{l}\text { HCFAMEMA Hosp. } \\
\text { Clínico Cirúrgico }\end{array}$ & Marília & Marilia & Estadual & 15 & 15 \\
\hline $\begin{array}{l}\text { Hospital Espírita de } \\
\text { Marilia }\end{array}$ & Marília & Marilia & Municipal & 142 & 142 \\
\hline Clínica Sayao Araras & Piracicaba & Araras & Estadual & 42 & 160 \\
\hline $\begin{array}{l}\text { Bezerra de Menezes Rio } \\
\text { Claro }\end{array}$ & Piracicaba & Rio Claro & Estadual & 100 & 114 \\
\hline $\begin{array}{l}\text { Hospital Psiquiátrico } \\
\text { Espírita Bezerra de } \\
\text { Menezes P Prudente }\end{array}$ & $\begin{array}{l}\text { Presidente } \\
\text { Prudente }\end{array}$ & $\begin{array}{l}\text { Presidente } \\
\text { Prudente }\end{array}$ & Estadual & 160 & 172 \\
\hline $\begin{array}{l}\text { Hospital Santa Tereza de } \\
\text { Ribeirão Preto }\end{array}$ & Ribeirão Preto & Ribeirão Preto & Estadual & 280 & 280 \\
\hline $\begin{array}{l}\text { Cais Centro Atenção } \\
\text { Integral Saúde Santa Rita } \\
\text { Passa Quatro }\end{array}$ & Ribeirão Preto & $\begin{array}{l}\text { Santa Rita do } \\
\text { Passa Quatro }\end{array}$ & Estadual & 240 & 240 \\
\hline
\end{tabular}


Tabela 1 - Hospitais Psiquiátricos do Estado de São Paulo/SP

\begin{tabular}{|c|c|c|c|c|c|}
\hline Instituição & DRS & MUNICÍPIO & GESTÃO & SUS & $\begin{array}{r}\text { (continuação } \\
\text { EXISTENTES }\end{array}$ \\
\hline $\begin{array}{l}\text { Centro de Reabilitação de } \\
\text { Casa Branca }\end{array}$ & $\begin{array}{c}\text { São João da Boa } \\
\text { Vista }\end{array}$ & Casa Branca & Estadual & 320 & 320 \\
\hline $\begin{array}{l}\text { Clínica de Repouso Santa } \\
\text { Rosa Espírito Santo do } \\
\text { Pinhal }\end{array}$ & $\begin{array}{c}\text { São João da Boa } \\
\text { Vista }\end{array}$ & $\begin{array}{l}\text { Espírito Santo } \\
\text { do Pinhal }\end{array}$ & Estadual & 50 & 99 \\
\hline $\begin{array}{l}\text { Instituto Bezerra de } \\
\text { Menezes Espírito Santo } \\
\text { do Pinhal }\end{array}$ & $\begin{array}{c}\text { São João da Boa } \\
\text { Vista }\end{array}$ & $\begin{array}{l}\text { Espírito Santo } \\
\text { do Pinhal }\end{array}$ & Estadual & 266 & 279 \\
\hline $\begin{array}{l}\text { Instituto Américo Bairral } \\
\text { de Psiquiatria }\end{array}$ & $\begin{array}{c}\text { São João da Boa } \\
\text { Vista }\end{array}$ & Itapira & Estadual & 500 & 817 \\
\hline CVV Francisca Julia & Taubaté & $\begin{array}{l}\text { São José dos } \\
\text { Campos }\end{array}$ & Municipal & 147 & 147 \\
\hline $\begin{array}{l}\text { Hospital Psiquiátrico } \\
\text { Mahatma Gandhi }\end{array}$ & $\begin{array}{l}\text { São José do Rio } \\
\text { Preto }\end{array}$ & Catanduva & Municipal & 138 & 155 \\
\hline $\begin{array}{l}\text { Hospital Tereza Perlatti } \\
\text { Jau }\end{array}$ & $\begin{array}{c}\text { São José do Rio } \\
\text { Preto }\end{array}$ & $\mathrm{Jau}$ & Estadual & 210 & 220 \\
\hline $\begin{array}{l}\text { Hospital Bezerra de } \\
\text { Menezes }\end{array}$ & $\begin{array}{c}\text { São José do Rio } \\
\text { Preto }\end{array}$ & $\begin{array}{l}\text { São José do } \\
\text { Rio Preto }\end{array}$ & Estadual & 160 & 209 \\
\hline
\end{tabular}

Fonte: Material adaptado, cedido à pesquisadora por Dr. ${ }^{a}$ Rosangela Elias, Coordenação da Área Técnica de Saúde Mental, Álcool e Drogas (SES/SP), 2019.

Em relação à lista de clínicas e hospitais psiquiátricos localizados no Estado de São Paulo, as 32 instituições hospitalares possuem 5593 leitos psiquiátricos atualmente, conforme a planilha fornecida à pesquisadora pela atual Coordenadora da Área Técnica de Saúde Mental, Álcool e Drogas (SES/SP). Destas instituições, 11 são administradas pelo município e 21 são administradas pelo Estado. Destes leitos, 4611 são mantidos com recursos do SUS e 982 não.

A média do número de leitos disponíveis nas referidas instituições variou de 08 a 500 leitos, porém das 32 instituições hospitalares, 26 possuem mais de 50 leitos de internação psiquiátrica disponíveis, restando apenas 06 com menos de 50 leitos.

Em relação ao número de pacientes internados em leitos SUS, os Censos Psicossociais realizados em 2008 e em 2014 mostram que em 2008 havia 6.349 moradores em 12.076 leitos SUS distribuídos em 58 hospitais psiquiátricos e em 2014 havia 4.439 moradores em 53 hospitais psiquiátricos, porém no Censo de 2014, os pesquisadores responsáveis não citaram no estudo, o número total de leitos psiquiátricos disponíveis mantidos com recursos do SUS (Barros, Bichaff, 2008; Cayres et al., 2015). Assim, não é possível compararmos os resultados 
atuais de 4611 leitos mantidos com recursos do SUS em relação aos leitos SUS disponíveis na época do Censo Psicossocial realizado em 2014.

Os números apresentados em Reunião do COSEMS/SP no ano de 2019 sinalizam que 1.619 pessoas com transtornos mentais estão há mais de um ano internadas em hospitais psiquiátricos atualmente no Estado de São Paulo e que precisam ser encaminhados para residências terapêuticas e destes, 102 estão em três hospitais de custódia do Estado (COSEMS/SP, 2019).

Em relação ao número de clínicas, prontos socorros, prontos atendimentos e hospitais gerais com leitos psiquiátricos no Estado de São Paulo, a referida Coordenadora da Área Técnica de Saúde Mental, Álcool e Drogas (SES/SP) informou que atualmente, existem 81 instituições hospitalares distribuídas nos municípios do Estado, perfazendo um total de 1.188 leitos psiquiátricos dos quais 1104 são leitos psiquiátricos mantidos com recursos do SUS.

No que tange à taxa de cobertura dos CAPS, têm-se abaixo dados de 2012 (Figura 3), conforme publicado pelo boletim eletrônico do grupo técnico de avaliação e informações de saúde (Mendes, Takashi, 2013), assim como a taxa de cobertura nos anos de 2015 e 2016 (Figuras 4 e 5, respectivamente).

Figura 3 - Taxa de Cobertura de CAPS pelas Regiões de Saúde, Estado de São Paulo, 2012

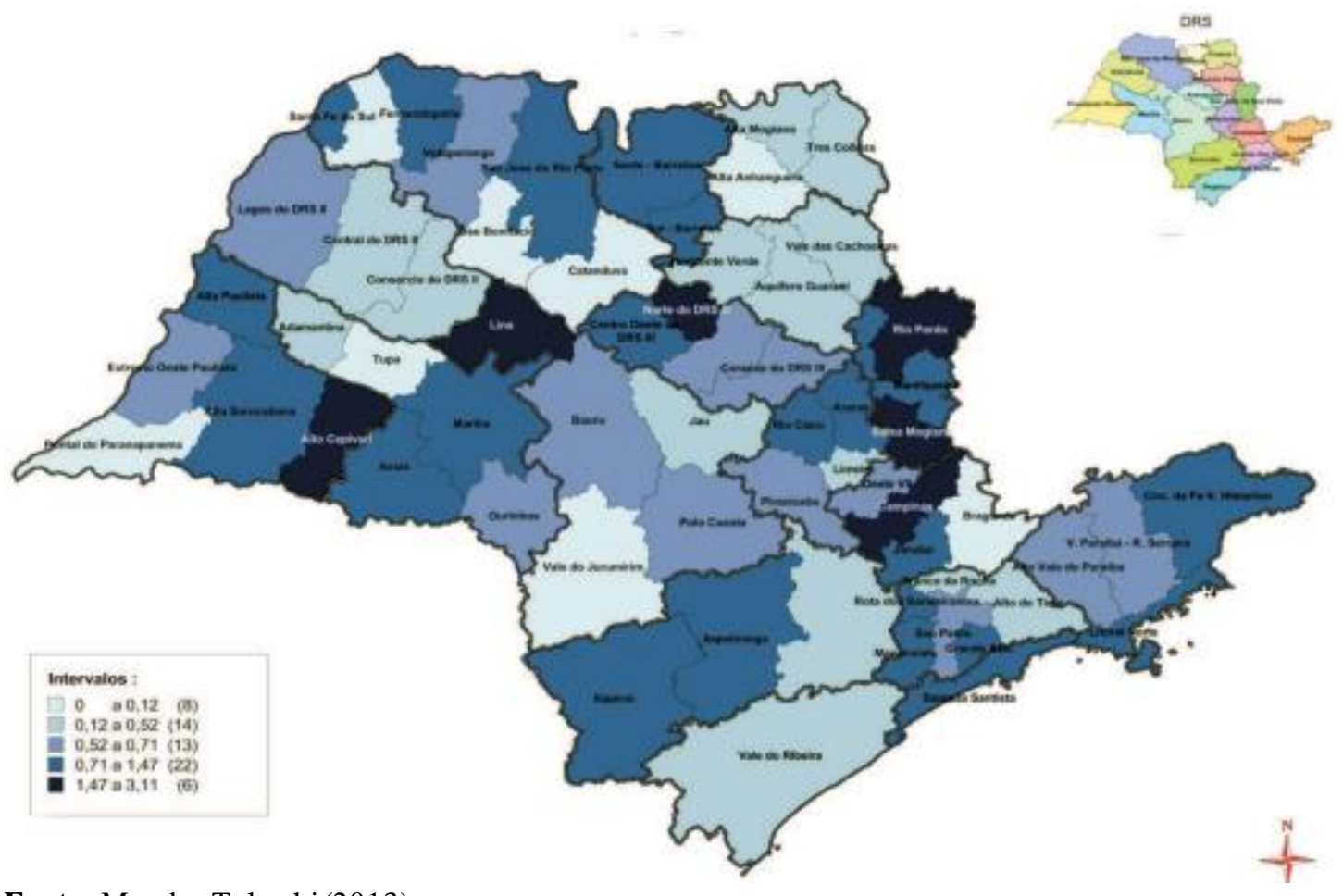

Fonte: Mendes,Takashi(2013). 
Figura 4 - Taxa de Cobertura de CAPS pelas Regiões de Saúde, Estado de São Paulo, 2015

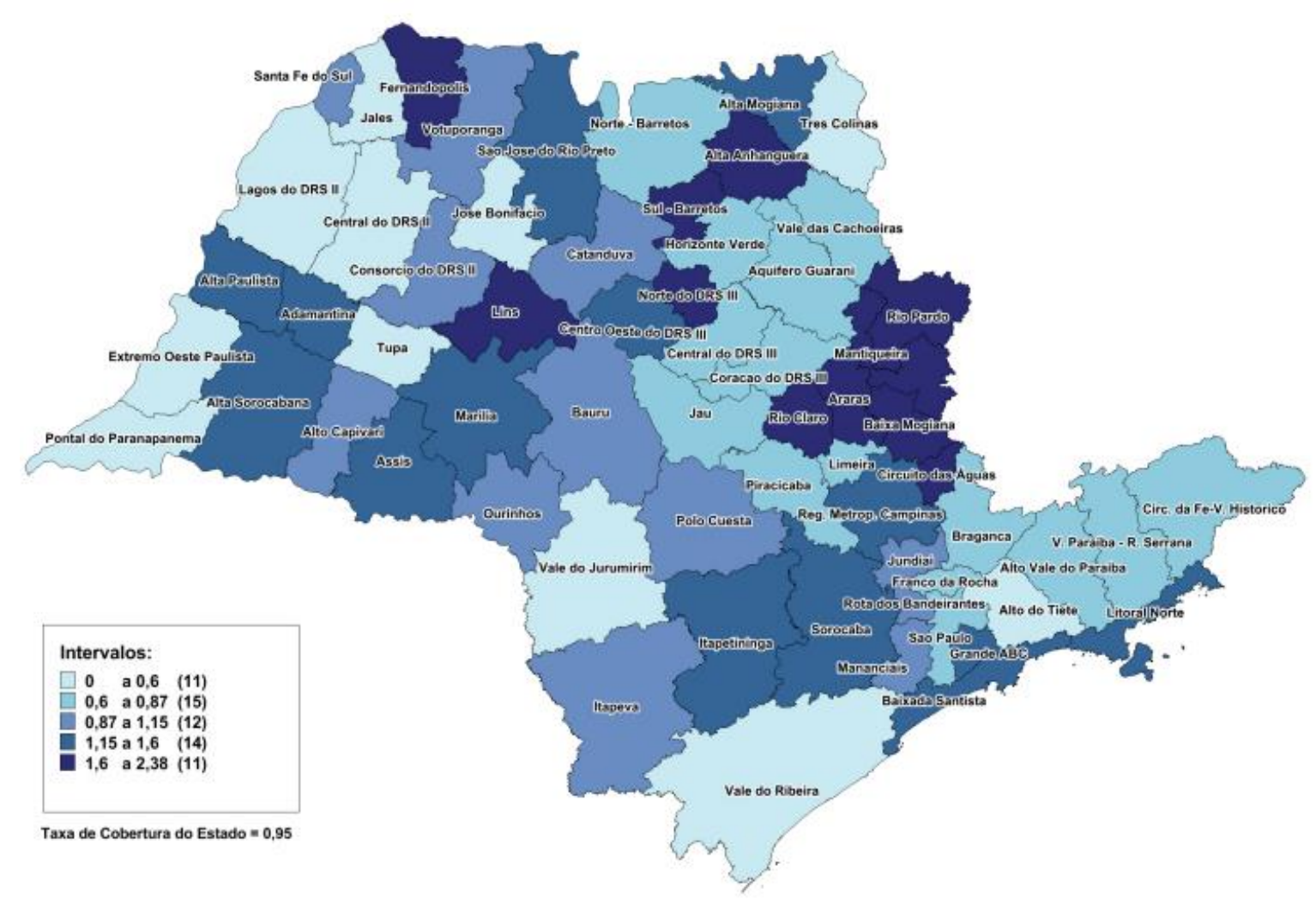

Fonte: Mendes, Osiano (2016).

Figura 5 - Taxa de Cobertura de CAPS pelas Regiões de Saúde, Estado de São Paulo, 2016

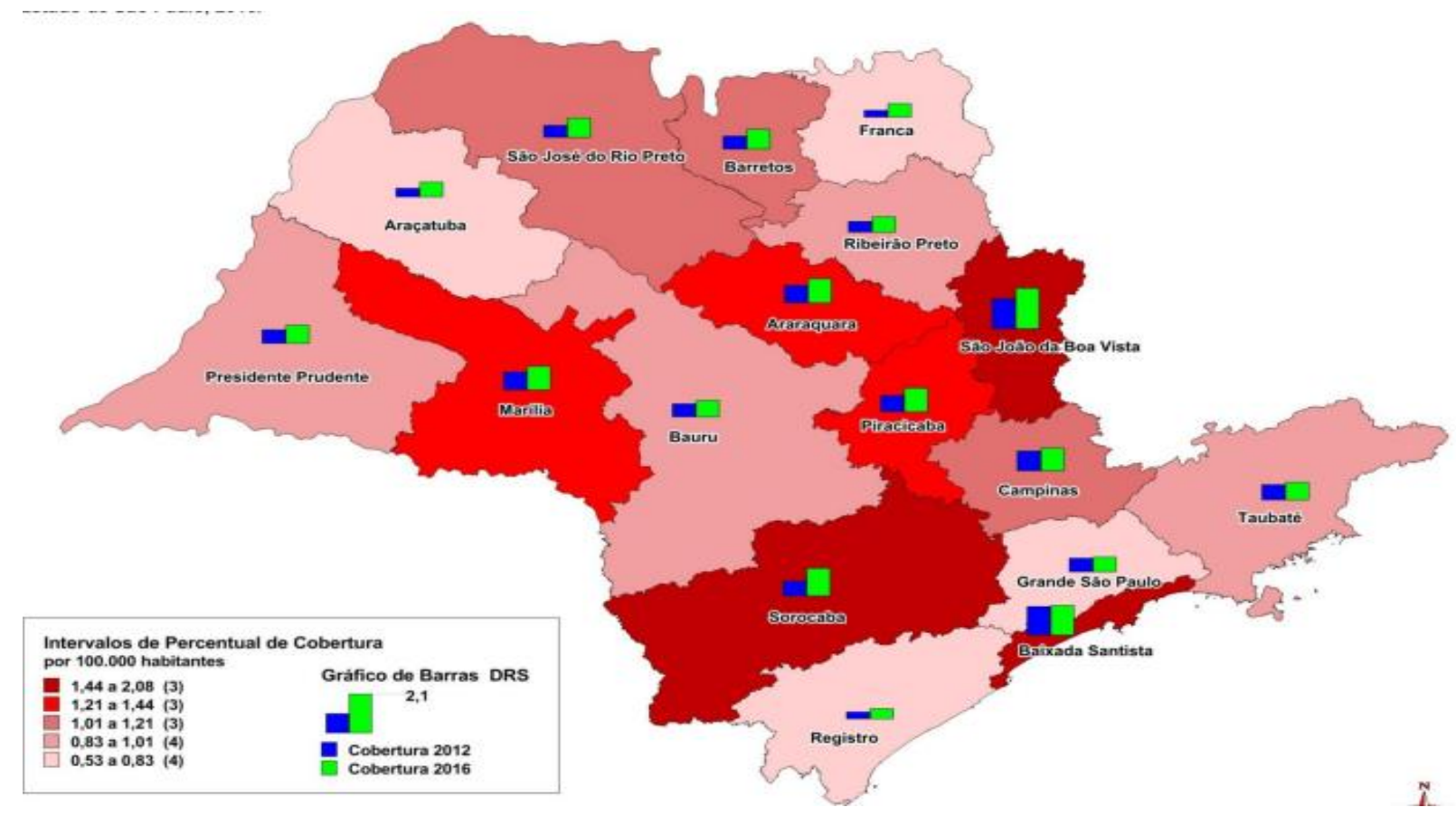

Fonte: Material cedido à pesquisadora por Dr. ${ }^{a}$ Rosangela Elias, Coordenação da Área Técnica de Saúde Mental, Álcool e Drogas (SES/SP), 2019. 
Na última tabela apresentam-se o quantitativo de CAPS e SRT cadastrados no CNES, 519 CAPS e 307 SRT distribuídos nas 17 DRS do Estado de São Paulo.

Tabela 2 - Quantidade de CAPS e RT

\begin{tabular}{|c|c|c|}
\hline DRS & CAPS & RT CNES \\
\hline 01 - Grande São Paulo & 168 & 78 \\
\hline 02 - Araçatuba & 11 & 6 \\
\hline 03 - Araraquara & 15 & 1 \\
\hline 04 - Baixada Santista & 29 & 3 \\
\hline 05 - Barretos & 5 & 0 \\
\hline 06 - Bauru & 29 & 19 \\
\hline 07 - Campinas & 60 & 28 \\
\hline 08 - Franca & 9 & 0 \\
\hline 09 - Marilia & 24 & 12 \\
\hline 10 - Piracicaba & 25 & 5 \\
\hline 11 - Presidente Prudente & 14 & 9 \\
\hline 12 - Registro & 6 & 3 \\
\hline 13 - Ribeirão Preto & 14 & 30 \\
\hline 14 - São João da Boa Vista & 20 & 24 \\
\hline 15 - São Jose do Rio Preto & 22 & 3 \\
\hline 16 - Sorocaba & 40 & 71 \\
\hline 17 - Taubaté & 28 & 15 \\
\hline Total Geral & 519 & 307 \\
\hline
\end{tabular}

Fonte: Material adaptado, cedido à pesquisadora por $\mathrm{Dr}^{\mathrm{a}}$ Rosangela Elias, Coordenação da Área Técnica de Saúde Mental, Álcool e Drogas (SES/SP), 2019.

Com a caracterização dos serviços especializados na atenção em Saúde Mental no Estado de São Paulo, identificamos, também, na pesquisa documental, a legislação e notícias pertinentes ao objeto de nosso estudo, demonstrados no quadro abaixo, ou seja, uma síntese da classificação realizada sobre todo o material obtido, seguindo a cronologia das publicações. 
Quadro 2 - Legislação nacional, estadual, municipal e informações relacionadas a nosso objeto de estudo.

\begin{tabular}{|c|c|}
\hline \multicolumn{2}{|r|}{ LEGISLAÇÃO NACIONAL EM SAÚDE MENTAL } \\
\hline Declaração de Caracas & $\begin{array}{c}\text { Documento da Organização Pan-Americana de Saúde (OPAS) de } 14 \text { novembro de 1990, que conclama a todos a } \\
\text { “apoiar a reestruturação da Atenção Psiquiátrica” com bases em princípios comunitários e defesa dos direitos humanos } \\
\text { e civis dos pacientes com transtornos mentais. }\end{array}$ \\
\hline $\begin{array}{l}\text { Lei }^{\circ} 8.080, \text { de } 19 \text { de setembro de } \\
1990\end{array}$ & $\begin{array}{c}\text { Dispõe sobre as condições para a promoção, proteção e recuperação da saúde, a organização e o funcionamento dos } \\
\text { serviços correspondentes e dá outras providências. }\end{array}$ \\
\hline $\begin{array}{l}\text { Lei }{ }^{\circ} 8.142 \text {, de } 28 \text { de dezembro de } \\
1990\end{array}$ & $\begin{array}{l}\text { Dispõe sobre a participação da comunidade na gestão do Sistema Único de Saúde (SUS) e sobre as transferências } \\
\text { intergovernamentais de recursos financeiros na área da saúde e dá outras providências. }\end{array}$ \\
\hline $\begin{array}{l}\text { Portaria }^{\circ} 106, \text { de } 11 \text { de fevereiro de } \\
2000\end{array}$ & Institui os Serviços Residenciais Terapêuticos. \\
\hline $\begin{array}{l}\text { Portaria } n^{\circ} 1220 / \mathrm{GM} \text { de } 7 \text { de } \\
\text { novembro de } 2000\end{array}$ & $\begin{array}{c}\text { Implementa os programas terapêuticos na modalidade de residências terapêuticas, destinadas a pacientes psiquiátricos } \\
\text { com longa permanência hospitalar. }\end{array}$ \\
\hline Lei $\mathrm{n}^{\circ} 10.216$, de 6 de abril de 2001 & $\begin{array}{c}\text { Dispõe sobre a proteção e os direitos das pessoas portadoras de transtornos mentais e redireciona o modelo assistencial } \\
\text { em saúde mental. }\end{array}$ \\
\hline $\begin{array}{l}\text { Portaria } n^{\circ} 251 \text {, de } 31 \text { de janeiro de } \\
2002\end{array}$ & $\begin{array}{c}\text { Estabelece diretrizes e normas para a assistência hospitalar em psiquiatria, reclassifica os hospitais psiquiátricos, define } \\
\text { a estrutura, a porta de entrada para as internações psiquiátricas na rede do SUS e institui o Programa Nacional de } \\
\text { Avaliação dos Serviços Hospitalares (PNASH/Psiquiatria). }\end{array}$ \\
\hline $\begin{array}{l}\text { Portaria 2391, de } 26 \text { de dezembro de } \\
2002\end{array}$ & $\begin{array}{c}\text { Regulamenta o controle das internações psiquiátricas involuntárias (IPI) e voluntárias (IPV) de acordo com o disposto } \\
\text { na Lei 10.216, de } 6 \text { de abril de 2002, e os procedimentos de notificação da Comunicação das IPI e IPV ao Ministério } \\
\text { Público pelos estabelecimentos de saúde, integrantes ou não do SUS. }\end{array}$ \\
\hline $\begin{array}{l}\text { Portaria }^{\circ} 336 \text {, de } 19 \text { de fevereiro de } \\
2002\end{array}$ & Estabelece as modalidades de CAPS e equipe mínima. \\
\hline $\begin{array}{l}\text { Resolução - RDC n }{ }^{\circ} .50, \text { de } 21 \text { de } \\
\text { fevereiro de } 2002\end{array}$ & $\begin{array}{c}\text { Aprova o Regulamento Técnico destinado ao planejamento, programação, elaboração, avaliação e aprovação de } \\
\text { projetos físicos de estabelecimentos assistenciais de saúde. }\end{array}$ \\
\hline Lei n ${ }^{\circ} 10.708$, de 31 de julho de 2003 & $\begin{array}{l}\text { Institui o auxílio-reabilitação psicossocial para pacientes acometidos de transtornos mentais egressos de internações } \\
\text { "De Volta para Casa". }\end{array}$ \\
\hline $\begin{array}{l}\text { Portaria }{ }^{\circ} 1935 \text {, de } 16 \text { de setembro de } \\
2004\end{array}$ & $\begin{array}{c}\text { Destina incentivo financeiro antecipado para Centros de Atenção Psicossocial em fase de implantação, e dá outras } \\
\text { providências. }\end{array}$ \\
\hline $\begin{array}{l}\text { Portaria }^{\circ} 245, \text { de } 17 \text { de fevereiro de } \\
2005\end{array}$ & Destina incentivo financeiro para implantação de CAPS. \\
\hline $\begin{array}{c}\text { Portaria } n^{\circ} 1.190,04 \text { de junho de } \\
2009 \\
\end{array}$ & $\begin{array}{l}\text { gencial de Ampliação do Acesso ao Tratamento e Prevenção em Álcool e outras Drogas no } \\
\text { o de Saúde - SUS (PEAD 2009-2010) e define suas diretrizes gerais, ações e metas. }\end{array}$ \\
\hline
\end{tabular}




\begin{tabular}{|c|c|}
\hline $\begin{array}{c}\text { Portaria }^{\circ} 2644 \text {, de } 28 \text { de outubro de } \\
2009\end{array}$ & Estabelece nova classificação dos hospitais psiquiátricos de acordo com o porte e reajusta incrementos. \\
\hline $\begin{array}{l}\text { Decreto } \mathrm{n}^{\circ} 7.179, \text { de } 20 \text { de maio de } \\
2010\end{array}$ & $\begin{array}{l}\text { Institui o Plano Integrado de Enfrentamento ao Crack e outras Drogas, cria o seu Comitê Gestor, e dá outras } \\
\text { providências. }\end{array}$ \\
\hline $\begin{array}{c}\text { Portaria }^{\circ} 4.279 \text { de } 30 \text { de dezembro } \\
\text { de } 2010\end{array}$ & Estabelece diretrizes para a organização da Rede de Atenção à Saúde no âmbito do Sistema Único de Saúde (SUS). \\
\hline $\begin{array}{l}\text { Portaria } \mathrm{n}^{\circ} 3.088 \text {, de } 23 \text { de dezembro } \\
\text { de } 2011\end{array}$ & $\begin{array}{l}\text { republicada em } 21 \text { de maio de 2013- Institui a Rede de Atenção Psicossocial para pessoas com sofrimento ou transtorno } \\
\text { mental e com necessidades decorrentes do uso de crack, álcool e outras drogas, no âmbito do Sistema Único de Saúde } \\
\text { (SUS). }\end{array}$ \\
\hline $\begin{array}{l}\text { Decreto }^{\circ} 7.508, \text { de } 28 \text { de junho de } \\
2011\end{array}$ & $\begin{array}{l}\text { Regulamenta a Lei no 8.080, de } 19 \text { de setembro de 1990, para dispor sobre a organização do Sistema Único de Saúde- } \\
\text { SUS, o planejamento da saúde, a assistência à saúde e a articulação interfederativa, e dá outras providências. }\end{array}$ \\
\hline $\begin{array}{l}\text { Portaria } \mathrm{n}^{\circ} 3.090 \text {, de } 23 \text { de dezembro } \\
\text { de } 2011\end{array}$ & $\begin{array}{l}\text { Republicada em } 26 \text { de dezembro de } 2011 \text { Altera a Portaria no } 106 \text { de } 11 \text { de fevereiro de } 2000 \text {, e dispõe, no âmbito da } \\
\text { Rede de Atenção Psicossocial, sobre o repasse de recursos de incentivo de custeio e custeio mensal para implantação } \\
\text { e/ou implementação e funcionamento dos Serviços Residenciais Terapêuticos (SRT). }\end{array}$ \\
\hline $\begin{array}{l}\text { Portaria } \mathrm{n}^{\mathbf{0}} 3.089 \text {, de } 23 \text { de dezembro } \\
\text { de } 2011 \text { (republicada) }\end{array}$ & Republicada em 26 de dezembro de 2011. Dispõe sobre o financiamento dos CAPS - custeio. \\
\hline $\begin{array}{l}\text { Resolução - RDC n }{ }^{\circ} 29, \text { de } 30 \text { de } \\
\text { junho de } 2011\end{array}$ & $\begin{array}{l}\text { Dispõe sobre os requisitos de segurança sanitária para o funcionamento de instituições que prestem serviços de atenção } \\
\text { a pessoas com transtomos decorrentes do uso, abuso ou dependência de substâncias psicoativas. }\end{array}$ \\
\hline $\begin{array}{l}\text { Portaria } \mathrm{n}^{\circ} 121, \text { de } 25 \text { de janeiro de } \\
2012 \text { (republicada) }\end{array}$ & $\begin{array}{l}\text { Republicada em } 21 \text { de maio de } 2013 \text { Institui a Unidade de Acolhimento (UA) no componente de atenção residencial de } \\
\text { caráter transitório da RAPS. }\end{array}$ \\
\hline $\begin{array}{l}\text { Nota Técnica sobre a republicação da } \\
\text { Portaria } \text { n }^{\circ} 121 \text {, de } 25 \text { de janeiro de } \\
2012\end{array}$ & Esclarecimentos quanto ao funcionamento da Unidade de Acolhimento e modificações da republicação. \\
\hline $\begin{array}{l}\text { Portaria } \mathrm{n}^{\mathbf{0}} 130, \text { de } 26 \text { de janeiro de } \\
2012 \text { (republicada) } \\
\end{array}$ & Republicada em 21 de maio de 2013. Redefine o CAPS AD III e os incentivos financeiros. \\
\hline $\begin{array}{l}\text { Portaria } \mathrm{n}^{\circ} 132 \text {, de } 26 \text { de janeiro de } \\
2012\end{array}$ & $\begin{array}{l}\text { Institui incentivo financeiro de custeio para desenvolvimento do componente Reabilitação Psicossocial da Rede de } \\
\text { Atenção Psicossocial do Sistema Único de Saúde (SUS). }\end{array}$ \\
\hline $\begin{array}{l}\text { Portaria n }{ }^{\circ} 148 \text {, de } 31 \text { de janeiro de } \\
\qquad 2012\end{array}$ & $\begin{array}{c}\text { Define as normas de funcionamento e habilitação do Serviço Hospitalar de Referência para atenção a pessoas com } \\
\text { sofrimento ou transtomos mental e com necessidades de saúde decorrentes do uso de álcool, crack e outras drogas do } \\
\text { Componente Hospitalar da RAPS e institui incentivos financeiros de investimento e custeio. }\end{array}$ \\
\hline $\begin{array}{c}\text { Portaria }^{\circ} 349, \text { de } 29 \text { de fevereiro de } \\
2012 \\
\end{array}$ & Altera e acresce dispositivo à Portaria no 148 de 31/01/2012. \\
\hline $\begin{array}{c}\text { Portaria }^{\circ} 1615, \text { de } 26 \text { de julho de } \\
2012\end{array}$ & Altera a portaria n $^{\circ} 148$ de 31/01/2012 em relação ao número de leitos e incentivo financeiro. \\
\hline Portaria $\mathrm{n}^{\circ} 854$, de 22 de ago. de 2012 & Alteração tabela de procedimentos dos CAPS. \\
\hline
\end{tabular}




\begin{tabular}{|c|c|}
\hline $\begin{array}{l}\text { Portaria }^{\circ} 953 \text {, de } 12 \text { de setembro de } \\
2012\end{array}$ & $\begin{array}{c}\text { Inclui os Serviços Hospitalares de Referência para a atenção a pessoas com sofrimento ou transtorno mental incluindo } \\
\text { aquelas com necessidades de saúde decorrentes do uso de álcool e outras drogas. }\end{array}$ \\
\hline $\begin{array}{c}\text { Portaria } \mathrm{n}^{\circ} 857 \text {, de } 22 \text { de agosto de } \\
2012\end{array}$ & Habilitada tabela de incentivos e procedimentos dos Serviços Residenciais Terapêuticos (SRT). \\
\hline $\begin{array}{l}\text { Nota Técnica sobre a Portaria }{ }^{\circ} 148 \\
\text { de } 31 \text { de janeiro de } 2012\end{array}$ & Apresenta informações sobre a implantação de leitos de saúde mental em Hospital Geral. \\
\hline $\begin{array}{l}\text { Nota Técnica sobre a republicação da } \\
\text { Portaria }{ }^{\circ} 121 \text {, de } 25 \text { de janeiro de } \\
\qquad 2012\end{array}$ & Esclarecimentos quanto ao funcionamento da Unidade de Acolhimento e modificações da republicação. \\
\hline $\begin{array}{l}\text { Decreto }^{\circ} 8.163 \text {, de } 20 \text { de dezembro } \\
\text { de } 2013\end{array}$ & Institui o Programa Nacional de Apoio ao Associativismo e Cooperativismo Social - Pronacoop Social. \\
\hline Nota Técnica 41/2013 & Unidade de Acolhimento. \\
\hline $\begin{array}{l}\text { Portaria }{ }^{\circ} 412 \text {, de } 15 \text { de março de } \\
\qquad 2013\end{array}$ & $\begin{array}{l}\text { Redefine as orientações para operacionalização das transferências de recursos federais aos Estados, ao Distrito Federal } \\
\text { e aos Municípios, a serem repassados de forma automática, sob a modalidade fundo a fundo, em conta única e } \\
\text { específica para cada bloco de financiamento de que trata a Portaria nº } 204 / \mathrm{GM} / \mathrm{MS} \text {, de } 29 \text { de janeiro de } 2007 \text {. }\end{array}$ \\
\hline Portaria $\mathrm{n}^{\circ} 615$ de 15 de abril de 2013 & $\begin{array}{c}\text { Dispõe sobre o incentivo financeiro de investimento para construção de Centro de Atenção Psicossocial (CAPS) e } \\
\text { Unidades de Acolhimento, em conformidade com a Rede de Atenção Psicossocial para pessoas com sofrimento ou } \\
\text { transtorno mental incluindo aquelas com necessidades decorrentes do uso de crack, álcool e outras drogas no âmbito do } \\
\text { Sistema Único de Saúde (SUS). }\end{array}$ \\
\hline $\begin{array}{l}\text { Portaria }^{\circ} 1.966 \text {, de } 10 \text { de setembro } \\
\text { de } 2013\end{array}$ & $\begin{array}{c}\text { Altera custeio dos CAPS 24h (CAPS III } \\
\text { e CAPS ad III). }\end{array}$ \\
\hline Saúde mental & Cadernos de atenção básica, $\mathrm{n}^{\circ} 34$ publicado pelo Ministério da Saúde em 2014 , a respeito da saúde mental. \\
\hline $\begin{array}{l}\text { Portaria 2840, de } 29 \text { de dezembro de } \\
2014\end{array}$ & Cria o Programa de Desinstitucionalização, integrante do componente: Estratégias de desinstitucionalização da RAPS. \\
\hline $\begin{array}{l}\text { Atenção Psicossocial a Crianças e } \\
\text { Adolescentes no SUS. Tecendo Redes } \\
\text { para Garantir Direitos, } 2014\end{array}$ & Manual do Ministério da Saúde sobre Atenção psicossocial a crianças e adolescentes no SUS. \\
\hline Lei ${ }^{\circ} 13.146$, de 6 de julho de 2015 & Institui a Lei Brasileira de Inclusão da Pessoa com Deficiência (Estatuto da Pessoa com Deficiência). \\
\hline $\begin{array}{l}{\text { Portaria }{ }^{\circ}}^{\circ} 1.727, \text { de } 24 \text { de novembro } \\
\text { de } 2016\end{array}$ & $\begin{array}{l}\text { Dispõe sobre a homologação do resultado final do Programa Nacional de Avaliação dos Serviços Hospitalares - } \\
\text { PNASH/Psiquiatria 2012/2014. }\end{array}$ \\
\hline $\begin{array}{c}\text { Portaria }^{\circ} 3.588 \text {, de } 21 \text { de dezembro } \\
\text { de } 2017\end{array}$ & $\begin{array}{c}\text { Altera as Portarias de Consolidação } \mathrm{n}^{\circ} 3 \text { e } \mathrm{n}^{\circ} 6 \text {, de } 28 \text { de setembro de } 2017 \text {, para dispor sobre a Rede de Atenção } \\
\text { Psicossocial, e dá outras providências. }\end{array}$ \\
\hline \multicolumn{2}{|r|}{ LEGISLAÇÃO DO ESTADO DE SÃO PAULO - SES/SP } \\
\hline $\begin{array}{l}\text { Resolução SS-294 de } 29 \text { de agosto de } \\
2007\end{array}$ & $\begin{array}{l}\text { Institui Grupo de Trabalho para construção de proposta de desinstitucionalização de pacientes } \\
\text { de longa permanência dos hospitais psiquiátricos do Estado de São Paulo. }\end{array}$ \\
\hline
\end{tabular}




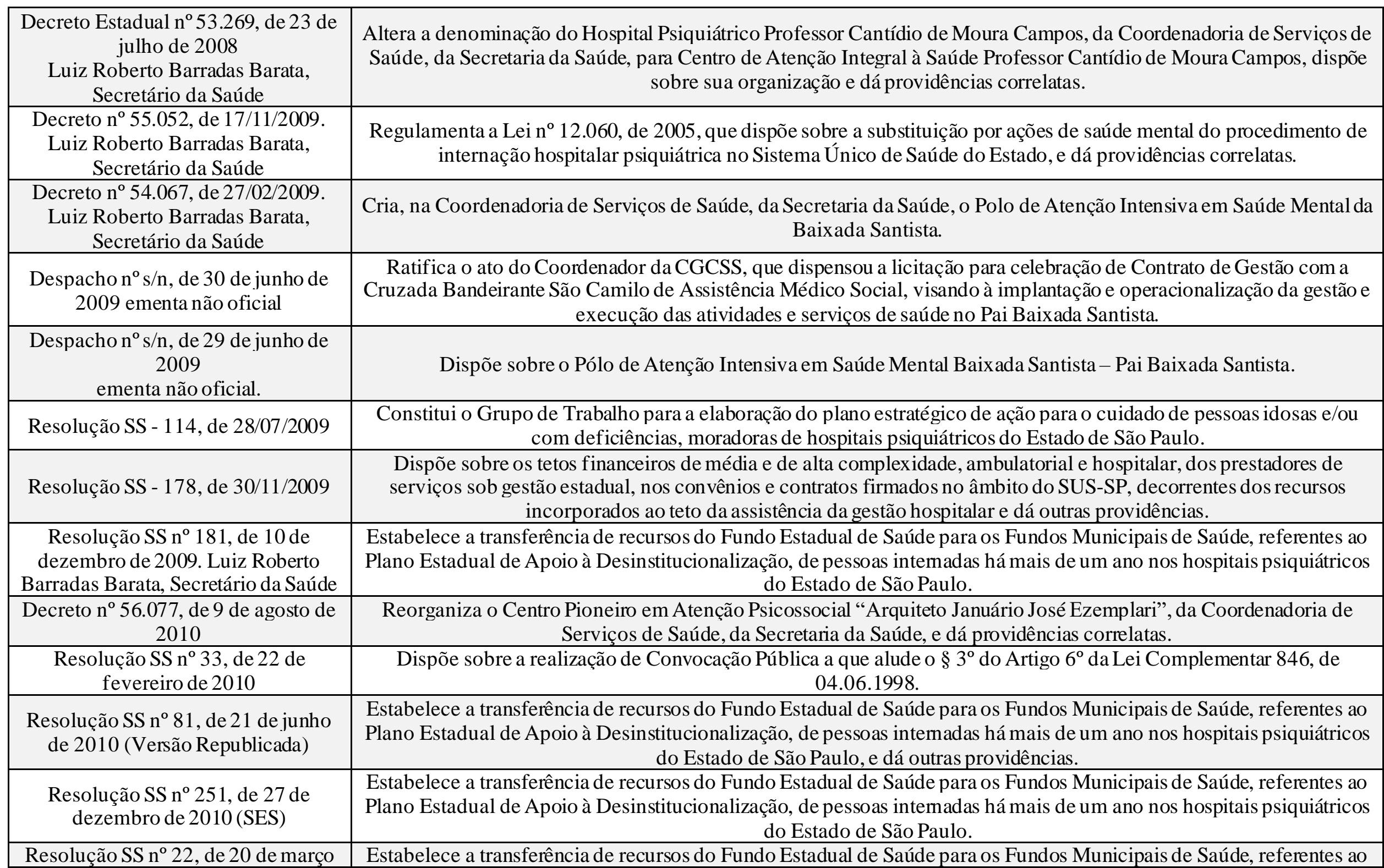




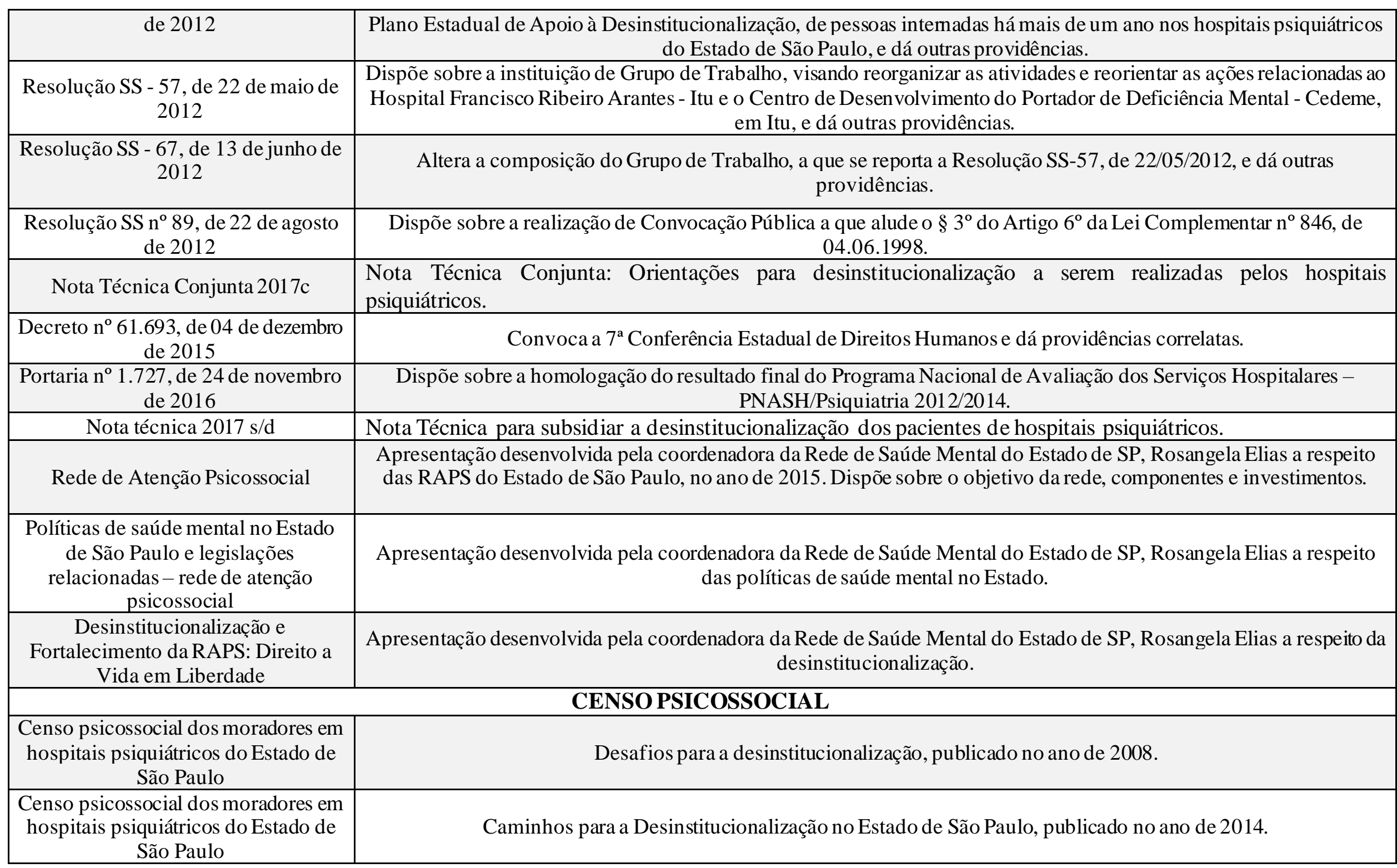




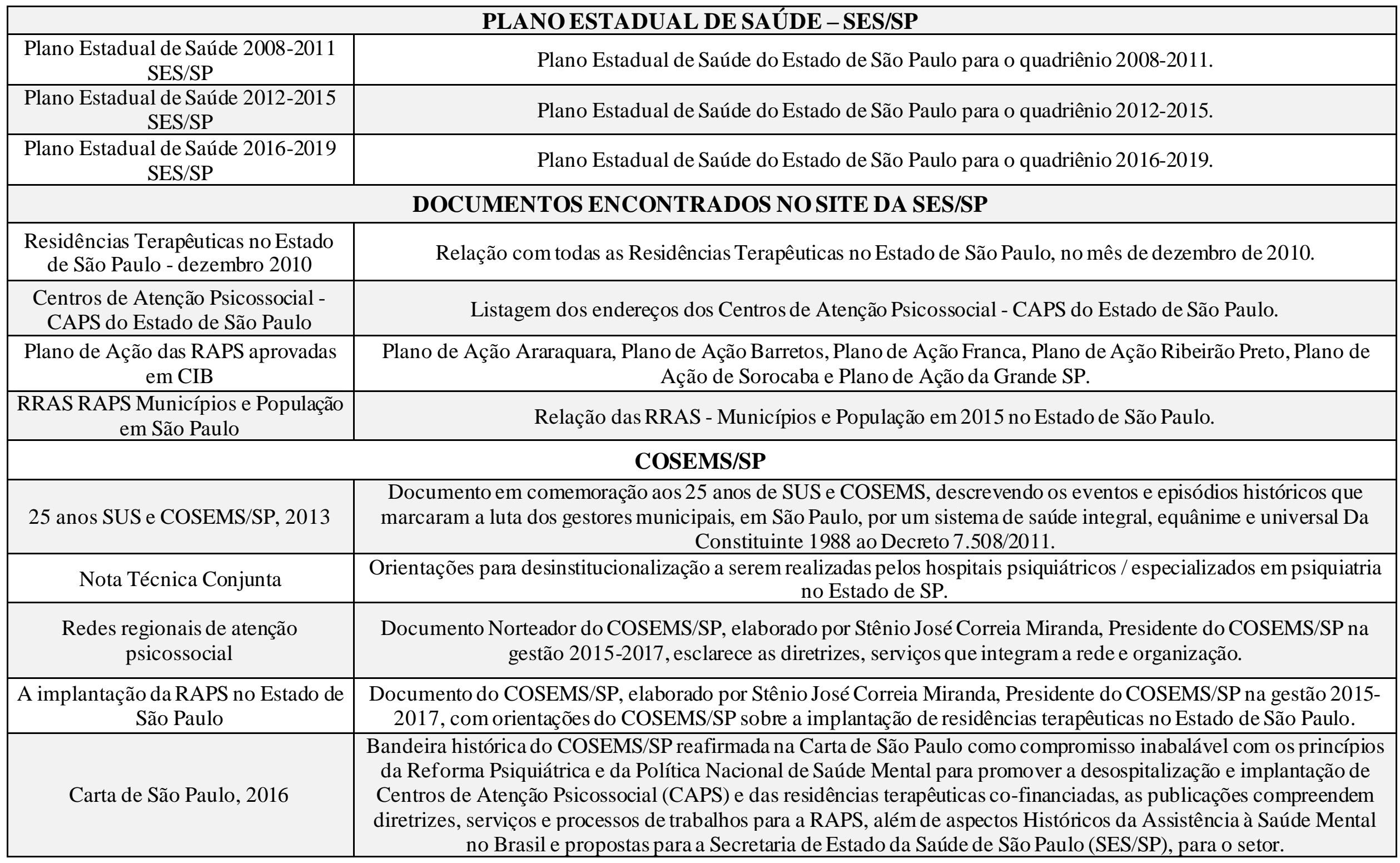




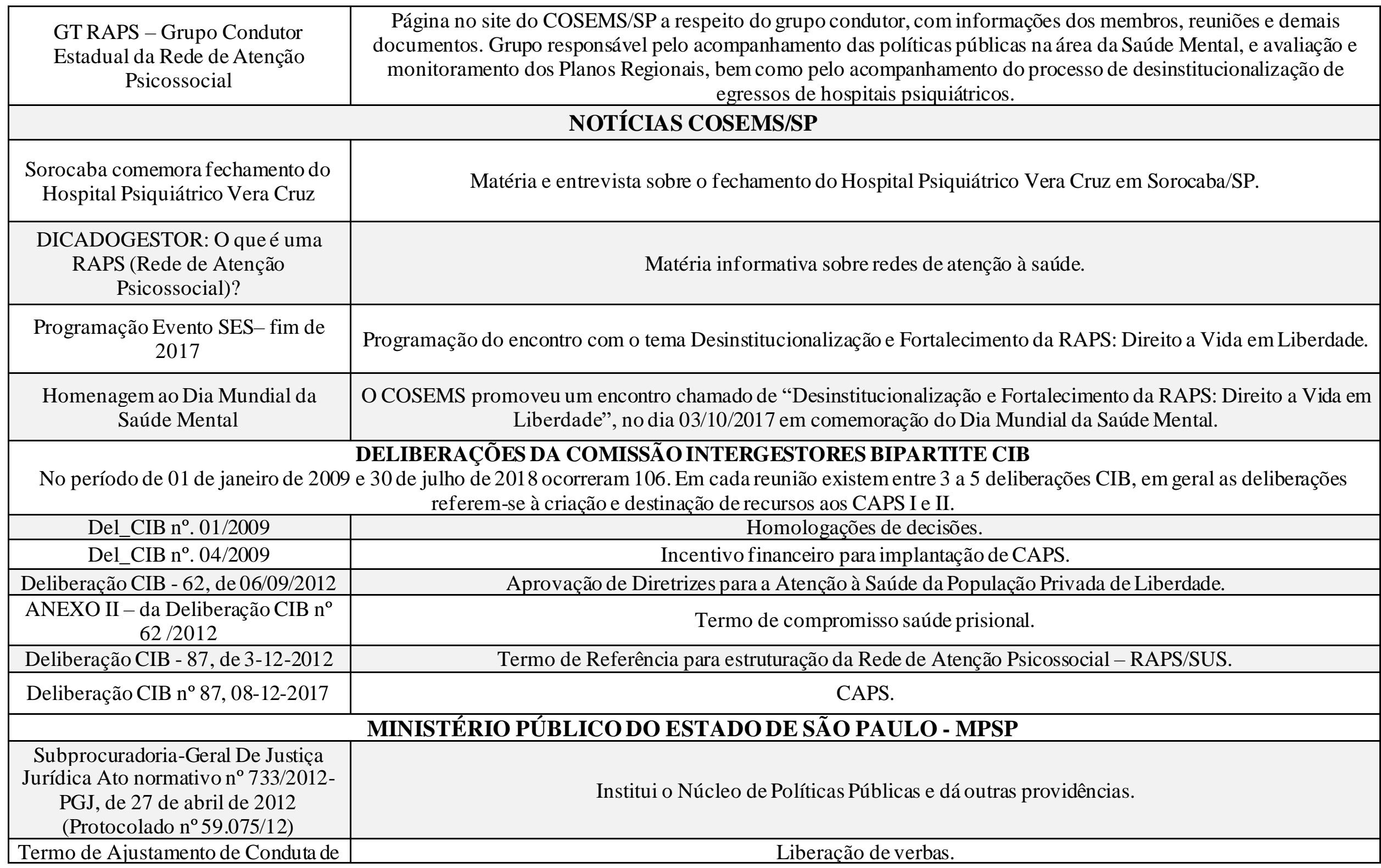




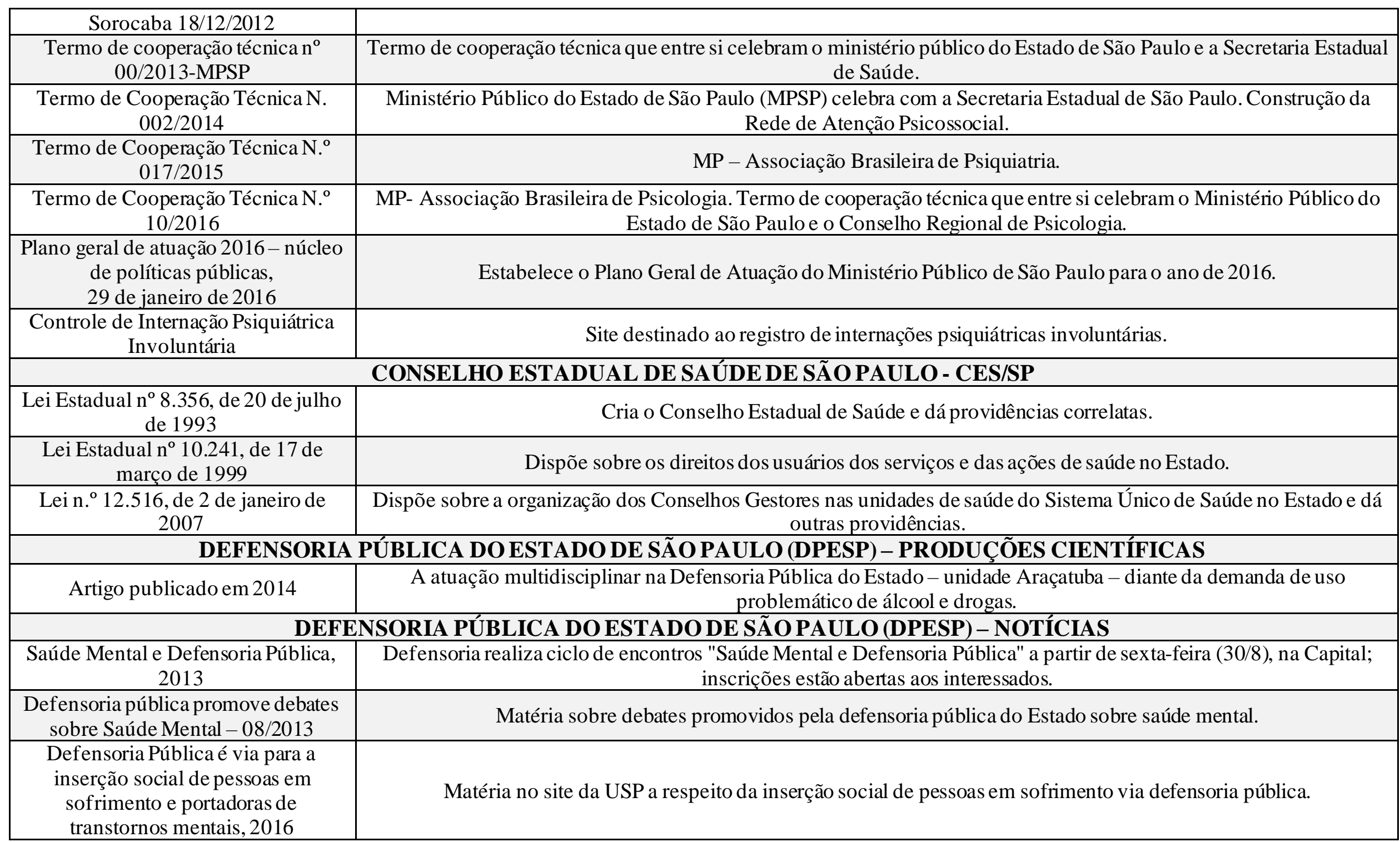


Em relação à legislação nacional apresentada, é importante destacar que alguns documentos formam o aparato legal e normativo do processo de desinstitucionalização das pessoas com transtornos mentais internadas em hospitais psiquiátricos e que devem ser seguidos pelos gestores:

- Portaria $\mathrm{n}^{\circ}$ 106, de 11 de fevereiro de 2000, que institui os Serviços Residenciais Terapêuticos;

- Lei $n^{\circ} 10.216$, de 06 de abril de 2001, que dispõe sobre a proteção e os direitos das pessoas portadoras de transtornos mentais e redireciona o modelo assistencial em saúde mental;

- Portaria $\mathrm{n}^{\mathrm{o}}$ 251, de 31 de janeiro de 2002, que estabelece diretrizes e normas para a assistência hospitalar em psiquiatria, reclassifica os hospitais psiquiátricos, define a estrutura, a porta de entrada para as internações psiquiátricas na rede do SUS e institui o Programa Nacional de Avaliação dos Serviços Hospitalares (PNASH/Psiquiatria);

- Portaria 2391, de 26 de dezembro de 2002, que regulamenta o controle das internações psiquiátricas involuntárias (IPI) e voluntárias (IPV) de acordo com o disposto na Lei 10.216, de 06 de abril de 2002, e os procedimentos de notificação da Comunicação das IPI e IPV ao Ministério Público pelos estabelecimentos de saúde, integrantes ou não do SUS;

- $\quad$ Portaria $\mathrm{n}^{\circ}$ 336, de 19 de fevereiro de 2002, que estabelece as modalidades de CAPS e equipe mínima;

- Lei $n^{\circ} 10.708$, de 31 de julho de 2003, que institui o auxílio-reabilitação psicossocial para pacientes acometidos de transtornos mentais egressos de internações "De Volta para Casa";

- Decreto $\mathrm{n}^{\mathrm{o}}$ 7.179, de 20 de maio de 2010, que institui o Plano Integrado de Enfrentamento ao Crack e outras Drogas, cria o seu Comitê Gestor, e dá outras providências;

- Portaria $\mathrm{n}^{\mathrm{o}} 3.088$, de 23 de dezembro de 2011, que estabelece diretrizes para a organização da Rede de Atenção à Saúde no âmbito do Sistema Único de Saúde (SUS);

- Portaria 2840, de 29 de dezembro de 2014, que cria o Programa de Desinstitucionalização, integrante do componente: Estratégias de desinstitucionalização da RAPS. 
Cabe evidenciar o ano de 2014, que se caracterizou pelo interstício em que o Estado de São Paulo adaptou-se no que preconiza a Portaria n. 2.840, de 29 de dezembro de 2014, que cria o "Programa de Desinstitucionalização integrante do componente Estratégias de Desinstitucionalização da RAPS, no âmbito do SUS, e institui o respectivo incentivo financeiro de custeio mensal" (Brasil, 2014), levando em consideração as recomendações da IV Conferência Nacional de Saúde Mental - Intersetorial, ocorrida entre 27 de junho e 01 de julho de 2010.

De acordo com o artigo $3^{\circ}$ da referida Portaria, o Programa de Desinstitucionalização tem como objetivos:

\begin{abstract}
I - apoiar e desenvolver ações de desinstitucionalização de pessoas com sofrimento ou transtorno mental e com necessidades decorrentes do uso de crack, álcool e outras drogas em situação de internação de longa permanência [aquela superior a 01 (um) a no, de forma ininterrupta ] em hospitais psiquiátricos no âmbito do SUS; e

II - apoiar e desenvolver ações e estratégias nos processos de reabilitação psicossocial no território das pessoas desinstitucionalizadas, favorecendo-se os percursos de produção de autonomia e da contratualida de social, de forma a garantir seus direitos e a efetiva participação e inclusão social, fortalecendo a RAPS (Brasil, 2014,p. 1).
\end{abstract}

No artigo $4^{\circ}$ fica estabelecida a necessidade da criação da equipe de Desinstitucionalização, cabendo, conforme o artigo 16 "às Secretarias Estaduais de Saúde promover o desenvolvimento de ações de articulação dos Municípios e de cooperação técnica e financeira, quando couber, objetivando-se a desinstitucionalização das pessoas com internação de longa permanência em hospitais psiquiátricos e implantação e qualificação da RAPS".

A Legislação do Estado de São Paulo publicada pela SES/SP, COSEMS/SP, MPSP, CES/SP e Defensoria Pública/SP, à desinstitucionalização das pessoas com transtornos mentais dos hospitais psiquiátricos, após a realização do Censo Psicossocial (2008), é de fundamental importância, pois entendemos que a partir do referido Censo, a SES/SP e demais instituições nominadas se dispõem a realizar as devidas ações de desinstitucionalização.

Com o objetivo de identificar as ações de desinstitucionalização efetivadas pela SES/SP, após a realização do Censo Psicossocial de 2008, realizamos a pesquisa documental na Base de Dados LEGSES-SP da SES/SP, para complementar com a análise temática das entrevistas com os sujeitos participantes.

Para melhor visualização, demonstramos (Figura 6) a Base de Dados de Legislação em Saúde LEGSES-SP (São Paulo, 2017b). 
Figura 6 - Página inicial da Base de Dados de Legislação em Saúde

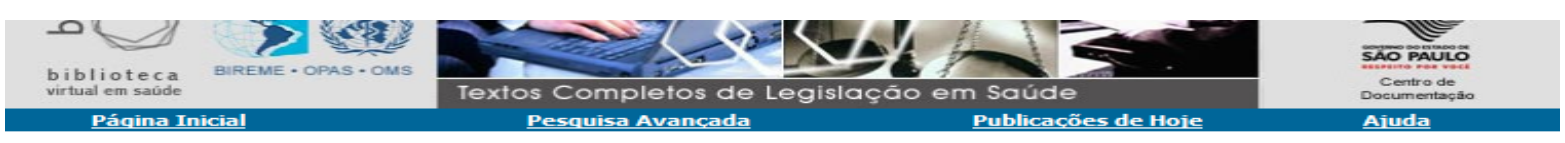

Texto Completo de Legislação em Saúde

Não é necessário preencher todos os campos.

campo para ver o texto de ajuda.

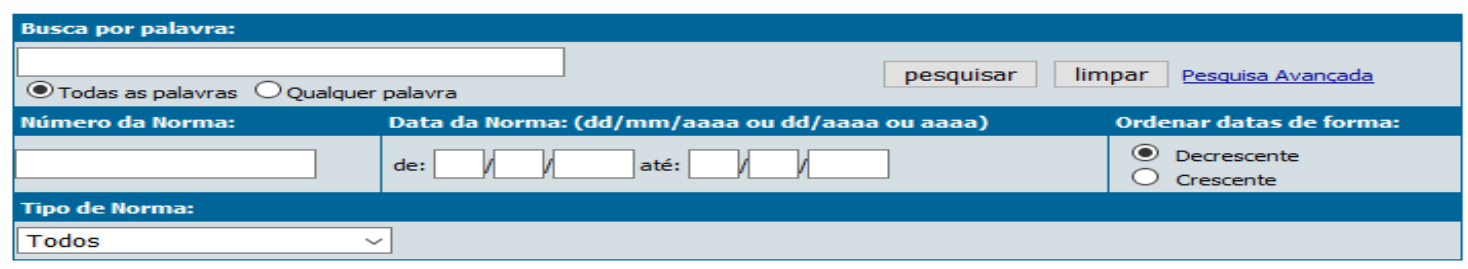

Notas

- Publicacốes de Hoie.

- O desenvolvimento do LEGSES-SP é uma parceria entre a SES, através do seu Centro de Documentação, e a BIREME.

- O LEGSES-SP utiliza a metodologia e a tecnologia de Textos Completos em Legislação da Biblioteca Virtual em Saúde (BVS), desenvolvidas em

parceria entre a ANVISA e a BIREME por meio do projeto VISALEGIS.

- Esta base de dados contempla, atualmente, a legislação relacionada à saúde no âmbito do Estado de São Paulo com relevância e prioridade às

- Para alguns anos, estão disponíveis apenas as referências dos atos normativos, por não possuírem ainda o texto completo em formato

- Para demais atos normativos, consulte: Imprensa Oficial do Estado de São Paulo, Imprensa Nacional e Planalto.

Secretaria de Estado da Saúde/ Coordenadoria de Controle de Doenças/Centro de Documentação:

Av. Dr. Arnaldo, 351 - Anexo 3 - Telefones:(11) 3065-4701/4702/4707 FAX: 30654706 - São Paulo / SP - CEP 01246-901 Copyright \& 2003 SES/CTD \& BIREME/OPAS/OMS

Fonte: São Paulo, 2017b.

Na Base de Dados LEGSES-SP da SES/SP, a busca ocorreu por meio das palavraschaves: Hospitais Psiquiátricos, Censos, Desinstitucionalização e Saúde Mental. Desta maneira, utilizando como palavra de busca "desinstitucionalização", foram encontradas 06 (seis) ocorrências (Resultado da pesquisa: "Palavras do texto" "desinstitucionalização" Tipo de Norma "\$" encontrou "06" normas legislativas), sendo que a sexta é a Resolução SS no 294, de 29 de agosto de 2007, que "Institui Grupo de Trabalho para construção de proposta de desinstitucionalização de pacientes de longa permanência dos hospitais psiquiátricos do Estado de São Paulo" (São Paulo, 2017b).

A seguir, em ordem crescente por data, citam-se as ocorrências na legislação do Estado de São Paulo que tratou da questão da desinstitucionalização no Estado:

- Resolução SS n ${ }^{\circ}$ 181, de 10 de dezembro de 2009 - estabelece a transferência de recursos do Fundo Estadual de Saúde para os Fundos Municipais de Saúde, referentes ao Plano Estadual de Apoio à Desinstitucionalização, de pessoas internadas há mais de um ano nos hospitais psiquiátricos do Estado de São Paulo que define os valores do repasse único de incentivo Estadual aos Fundos Municipais de Saúde, a serem utilizados exclusivamente para implantação de SRT e CAPS, que deveriam ser implementados em até três meses após o recebimento do recurso 
financeiro nos municípios de Adamantina, Osvaldo Cruz, Jaboticabal, Monte Alto, Espírito Santo do Pinhal Cedral, Guapiaçu, Santa Fé do Sul, Sorocaba e São Miguel Arcanjo;

- Resolução SS no 81, de 21 de junho de 2010 (Versão Republicada) - estabelece a transferência de recursos do Fundo Estadual de Saúde para os Fundos Municipais de Saúde, referentes ao Plano Estadual de Apoio à Desinstitucionalização de pessoas internadas há mais de um ano nos hospitais psiquiátricos do Estado de São Paulo, e dá outras providências - que destina para os municípios de Avaré, Iperó, Itapeva, Itápolis, Itararé, Junqueirópolis, Mococa, Pindamonhangaba, Pirapozinho, Porto Ferreira, Rio das Pedras, São Bernardo do Campo e São José do Rio Pardo, repasse de recursos para implantação de SRT e CAPS;

- Resolução SS no 251, de 27 de dezembro de 2010 - estabelece a transferência de recursos do Fundo Estadual de Saúde para os Fundos Municipais de Saúde, referentes ao Plano Estadual de Apoio à Desinstitucionalização de pessoas internadas há mais de um ano nos hospitais psiquiátricos do Estado de São Paulo estabelecido o repasse único de incentivo Estadual aos Fundos Municipais de Saúde a serem utilizados exclusivamente para implantação de SRT e CAPS para os municípios de Botucatu, Porto Feliz e Casa Branca;

- Resolução SS nº 22, de 20 de março de 2012 - estabelece a transferência de recursos do Fundo Estadual de Saúde para os Fundos Municipais de Saúde, referentes ao Plano Estadual de Apoio à Desinstitucionalização, de pessoas internadas há mais de um ano nos hospitais psiquiátricos do Estado de São Paulo, e dá outras providências - a serem utilizados exclusivamente para implantação de SRT e CAPS para os municípios de Barueri, Boituva, Ibiúna e Ourinhos.

Assim, verificamos que no período de 2008 até o ano de 2010, ou seja, após o Censo Psicossocial (2008) e de suas recomendações, que a SES/SP publicou resoluções visando a desinstitucionalização, como a transferência de recursos financeiros do Fundo Estadual de Saúde para os Fundos Municipais de Saúde, referentes ao Plano Estadual de Apoio à Desinstitucionalização, de pessoas internadas há mais de um ano nos hospitais psiquiátricos do Estado de São Paulo, em comparação com o ano de 2012, em que constatamos apenas uma publicação com o mesmo objetivo.

Em relação aos Planos Estaduais de Saúde (PES), a partir de 2008, demonstrados no quadro demonstrativo e de fácil acesso na web para leitura, com o objetivo de efetivar as 
ações do PES, a Comissão Intergestores Bipartite do Estado de São Paulo, publicou deliberações, nas quais homologa a criação e implantação de CAPS I e II; a criação e implantação de SRT em diversos municípios do Estado (STR Tipo I e II); além do Credenciamento do Serviço Hospitalar de Referência para atenção a pessoas com transtorno mental e com necessidades de saúde decorrentes do uso de álcool, crack e outras drogas, do Componente Hospitalar da RAPS. É importante destacar que nos PES todas essas propostas de ações de saúde mental devem ser realizadas pelos gestores estadual e municipais, já que são eles que são os formuladores e executores da política descrita (São Paulo, 2017).

Também verificamos que a SES/SP publicou uma nota técnica importante de orientações para desinstitucionalização a serem realizadas pelos hospitais psiquiátricos/especializados em psiquiatria no Estado de São Paulo. Na Nota Técnica, compete ao Estado por meio da SES/SP, apoio à implementação, coordenação do Grupo Condutor Estadual da RAPS, financiamento, contratualização com os pontos de atenção à saúde sob sua gestão, monitoramento e avaliação da RAPS no território estadual de forma regionalizada e ao Município compete por meio da Secretaria Municipal de Saúde, implementação, coordenação do Grupo Condutor Municipal da RAPS, financiamento, contratualização com os pontos de atenção à saúde sob sua gestão, monitoramento e avaliação da RAPS no território municipal; obrigações reafirmadas na Deliberação CIB 87 de 03 de dezembro de 2012 (São Paulo, 2017, s/d).

Destaca-se, ainda, a publicação em 28 de julho de 2016 da Nota Técnica Conjunta de Orientações para Desinstitucionalização a serem realizadas pelos hospitais psiquiátricos/ especializados em psiquiatria no Estado de São Paulo, que tinha por

\footnotetext{
Objetivo oferecer aos Departamentos Regionais de Saúde instrumentos técnicos de apoio para esclarecimentos de dúvidas, uniformização de procedimentos e otimização de processos de desinstitucionalização de moradores de Hospitais Psiquiátricos/ Especializados em Psiquiatria no Estado de São Paulo, além de oferecer parâmetros técnicos para o acompanhamento dos Hospitais Psiquiátricos/ Especializados em Psiquia tria contratualizados com a Secretaria de Estado da Saúde (São Paulo, 2017c, p. 1).
}

De acordo com essa Nota Técnica Conjunta entre a Assessoria Técnica de Saúde Mental, Coordenadoria de Serviços de Saúde, Coordenadoria das Regiões de Saúde e a Coordenadoria de Gestão Orçamentária e Financeira, caberia aos hospitais a elaboração de um Projeto Técnico Institucional para a Desinstitucionalização que deveria ser encaminhado para o DRS, contemplando as transformações do desenho organizativo institucional objetivando a reabilitação psicossocial a serem implementadas, bem como o Projeto Terapêutico Singular 
(PTS) visto como uma estratégia que deveria buscar a integralidade do cuidado e deveria orientar ações da equipe multiprofissional, na busca da autonomia dos indivíduos e construção de projetos de vida com vistas à desinstitucionalização, sendo que para tanto, os indivíduos, família e recursos territoriais deveriam ser convidados para contribuir (São Paulo, 2017c).

Ainda, enfatiza-se que é fundamental a reafirmação de que "toda pessoa moradora de Hospital Psiquiátrico/Especializado em Psiquiatria independente do diagnóstico tem direito a Residência Terapêutica", ou seja, "toda pessoa com mais de um ano de internação, desinstitucionalizada, deve ser acompanhada pela Rede de Atenção Psicossocial evitando novas institucionalizações" (São Paulo, 2017c).

$\mathrm{Na}$ pesquisa documental realizada no site do Conselho de Secretários Municipais COSEMS/SP encontramos dois documentos elaborados pelo Conselho para auxiliar os secretários municipais de saúde do Estado de São Paulo em relação ao planejamento, implantação, execução, avaliação, monitoramento e o financiamento das RRAPS: Redes Regionais de Atenção Psicossocial - Documento Norteador do COSEMS/SP e; Redes de Atenção Psicossocial (RAPS) - Orientações do COSEMS/SP sobre a implantação de residências terapêuticas no Estado de São Paulo.

No documento Redes Regionais de Atenção Psicossocial - Documento Norteador COSEMS/SP, o mesmo traça as diretrizes que norteiam a questão da atenção à saúde pública nos municípios, descrevem-se os serviços que integram a Rede de Assistência à Saúde Mental; a organização do trabalho e processos de trabalho; e as especificações para a gestão das RAPS (COSEMS/SP, 2017a).

No documento Redes de Atenção Psicossocial (RAPS) orientações do COSEMS/SP sobre a implantação de residências terapêuticas no Estado de São Paulo, descreve inicialmente os aspectos históricos da Assistência à Saúde Mental no Brasil, é definida a atuação do COSEMS/SP e a Política Nacional de Saúde Mental, evidenciando a Portaria No 3.088, de 23 de dezembro de 2011, que é fundamental que as três esferas da gestão garantam e cumpram com sua responsabilidade, cabendo à União responsável, por intermédio do Ministério da Saúde, ao apoio à implementação, financiamento, monitoramento e avaliação da RAPS em todo território nacional (COSEMS/SP, 2017b).

Os resultados apontaram que o CES/SP e a Defensoria Pública do Estado de São Paulo também foram tímidos na produção e publicação de documentos que pudessem, nesse estudo, embasar ações de desinstitucionalização, pois não encontramos na página oficial destas instituições tais documentos específicos na época da coleta de dados, e nem a pedido desta pesquisadora aos sujeitos participantes destas instituições durante as entrevistas, apenas 
encontramos os documentos descritos no quadro anterior, apesar de termos convicção que ambas as instituições realizam estratégias de saúde mental, pois em relação o CES/SP,

Os Conselhos da Saúde são definidos como órgãos permanentes e deliberativos com representantes do Governo, dos prestadores de serviço, profissionais de saúde e usuários. Atuam na formulação de estratégias e no controle da execução da política de saúde, inclusive nos a spectos econômicos e financeiros (São Paulo, 2019).

Em relação à Defensoria Pública do Estado de São Paulo têm-se que,

\begin{abstract}
A Defensoria Pública do Estado de São Paulo é uma instituição permanente cuja função, como expressão e instrumento do regime democrático, é oferecer, às pessoas necessitadas, de forma integral e gratuita, a orientação jurídica, a promoção dos direitos humanos e a defesa, em todos os graus, judicial e extrajudicial, dos direitos individuais e coletivos (São Paulo, 2019).
\end{abstract}

A última pesquisa documental realizada neste estudo foi referente aos documentos do Ministério Público Estadual (MPSP) sobre as políticas públicas de desinstitucionalização e nesse caso, encontramos alguns termos de cooperação técnica com a SES/SP, Associação Brasileira de Psiquiatria, Conselho Regional de Psicologia, o Termo de Ajustamento de Conduta de Sorocaba (TAC Sorocaba), e o site destinado ao registro de internações psiquiátricas involuntárias, na qual é obrigatório em 72 horas as informações de internamento e alta hospitalar pelas instituições hospitalares, justamente com o intuito de evitar a institucionalização das pessoas com transtornos mentais nesses locais.

O Ministério Público é o responsável por esse sistema, conforme o Art. $6^{\circ}$. “Estabelecer que ao Ministério Público caberá o registro da notificação das internações psiquiátricas involuntárias (IPI), bem como das voluntárias que se tornam involuntárias (IPVI), para controle e acompanhamento destas até a alta do paciente" (Brasil, 2002c).

Sendo assim, esta pesquisadora solicitou informações durante a entrevista para o representante do MPSP em relação a como se dá o funcionamento do referido sistema, após os estabelecimentos de saúde comunicarem essas internações pelas Autorizações de Internação Hospitalares (AIH), porém não obtivemos a informação de como ocorre esse controle de internações e altas de pessoas com transtornos mentais no Estado de São Paulo.

Em relação ao Termo de Cooperação Técnica com a SES/SP, o MPSP celebrou o Termo de Cooperação Técnica $n^{\circ}$ 002/2014, tomando como premissa que "a construção da RAPS é essencial para o exercício da cidadania e que o Ministério Público é instituição responsável pela defesa dos cidadãos, na perspectiva dos direitos coletivos, e da fiscalização do cumprimento da lei, em causas em que haja interesse público”, firmado então para a 
“conjugação de esforços visando à prestação mútua de informações e dados relativos à construção da RAPS no âmbito do SUS”, através do qual, o MPSP se propôs a acompanhar o processo de implantação das 63 RAPS, por meio dos Núcleos da Rede Protetiva de Direitos Sociais (RAPDS), o monitoramento das iniciativas municipais (São Paulo, 2014).

O MPSP também celebrou o Termo de Cooperação Técnica N. ${ }^{\circ}$ 017/2015 com a Associação Brasileira de Psiquiatria (ABP), tendo como objetivo o estabelecimento de cooperação mútua entre as duas instituições, "visando à fiscalização e à promoção de medidas para a adequada prestação das ações e serviços de saúde mental e o respeito aos direitos das pessoas com transtornos mentais, nas suas respectivas áreas de atuação", sendo atribuições do MPSP, sempre que solicitado, "fornecer subsídios para a realização de ações conjuntas, visando, sempre, a adequação das ações e serviços de saúde mental e a melhoria no atendimento das pessoas com transtornos mentais", assim como "indicar membros e serviços para participarem de ações conjuntas visando à discussão de questões que envolvam ações e serviços de saúde mental, bem como direitos das pessoas portadoras de transtornos mentais" (São Paulo, 2015, p. 3).

Ao seu lado, as atribuições da ABP referem-se à prestação de apoio técnico, inclusive através de perícias, para a apuração de fatos que possam ser configurados como violação dos direitos das pessoas com transtornos mentais, seja no plano individual ou coletivo, assim como fatos que configurem a inadequada prestação de ações e serviços de saúde mental, cabendo-lhe a obrigação de comunicar a ocorrência de qualquer violação a direitos difusos (São Paulo, 2015).

Atribuições semelhantes foram firmadas entre o MPSP e o Conselho Regional de Psicologia, por meio do o Termo de Cooperação Técnica N. ${ }^{\circ}$ 10/2016 escrito com igual teor (São Paulo, 2016).

Em relação ao TAC, como resultado da pressão dos grupos de luta antimanicomial, deflagrada por uma reportagem mostrando as atrocidades cometidas nos hospitais psiquiátricos da região de Sorocaba, o MPSP propôs a SES/SP, às Prefeituras Municipais de Sorocaba, Salto de Pirapora e Piedade juntamente com o Ministério da Saúde, uma pactuação do TAC, tendo como objetivo descrito no art. $1^{\circ}$,

Em especial, a partir de um processo contínuo de desinstitucionalização dos atuais pacientes moradores nos 07 (sete) hospitais psiquiátricos existentes na região de Sorocaba, no Estado de São Paulo, garantindo a integralidade da assistência terapêutica em todos os componentes da rede de atenção psicossocial, nos termos da Portaria 3.088/2011 do Ministério da Saúde (art. $7^{\circ}$, inciso 11, da Lei Orgânica da Saúde Lei no 8.080, de 19 de setembro de 1990 ; e arts. $9^{\circ}$ e 10 , do Decreto $\mathrm{n}^{\circ} 7.508$, 
de 28 de junho de 2011) começando, contudo, pelo Hospital Vera Cruz (São Paulo, 2012).

A seguir, apresentamos os resultados das categorias empíricas elencadas a partir dos temas depreendidos nas entrevistas com os sujeitos participantes, intituladas: "Categorias Empíricas".

\subsection{CATEGORIAS EMPÍRICAS}

Apresentamos, a seguir, as categorias empíricas elencadas após a identificação das frases temáticas, agrupadas a partir de afinidades entre os temas.

\subsubsection{Categoria 1 - A Instituição Manicomial}

4.2.1.1 O conceito de Hospital Psiquiátrico

4.2.1.2 A Curatela

4.2.1.3 As Internações Involuntárias

4.2.1.4 As Internações Compulsórias

4.2.1.5 Os mortos vivos

4.2.2 Categoria 2 - A Desinstitucionalização no Estado de São Paulo

4.2.2.1 As Recomendações do Censo Psicossocial (2008) para a Desinstitucionalização

4.2.2.2 Resistência a Desinstitucionalização

4.2.2.3 Caminhos para Desinstitucionalização

4.2.2.4 O Planejamento das Políticas Públicas

4.2.2.5 Destinação de Recursos Financeiros para Desinstitucionalização

4.2.2.6 Retrocesso para Desinstitucionalização

4.2.2.7 Ações do Ministério Público

4.2.3 Categoria 3 - Redes de Atenção Psicossocial (RAPS) do Estado de São Paulo: A Desinstitucionalização

4.2.3.1 As necessidades da RAPS

4.2.3.2 Os Serviços Residenciais Terapêuticos para a Desinstitucionalização

4.2.3.3 A inserção das Comunidades Terapêuticas na RAPS 


\subsubsection{A Instituição Manicomial}

\subsubsection{O conceito de Hospital Psiquiátrico}

As pessoas com transtornos mentais eram vistas pela sociedade como uma ameaça à segurança pública, e para tanto, deveriam ser asiladas, excluídas do convívio social, tendo seus direitos humanos violados, privadas de sua liberdade, e tendo seus direitos civis, políticos, sociais e culturais negados (Ventura, 2011).

A participação da família no tratamento à pessoa com transtorno mental institucionalizada era restrita a visitas pré-determinadas pelo médico psiquiatra do hospital, resultando em poucas oportunidades de relacionamento com os profissionais de saúde mental e com o próprio paciente (Marcon, Oliveira, 2006).

Saraceno (2001, p. 62) define o hospital psiquiátrico como um lugar que reproduz a doença e corroborando com o autor, inspirado na concepção basagliana, o hospital psiquiátrico é uma instituição total que nunca é modificada, pois é um locus atemporal, que nunca modificará sua estrutura funcional. O tema "O conceito de Hospital Psiquiátrico" foi abordado pelos entrevistados, reforçando a precariedade dessa forma de assistência em saúde, que resulta na segregação, na exclusão da pessoa com transtorno mental do convívio em comunidade, pela família, que não poucas vezes, os colocam sob a forma asilar, sob a curatela do Estado.

Nas frases temáticas dos entrevistados, é evidenciada a crença de que ao serem institucionalizadas e abandonadas por seus familiares (sempre havia exceções), esses pacientes não mais de lá sairiam, estando destinados a morrer nesses locais, principalmente porque, ocorria uma tendência à cronificação das pessoas internadas a longo tempo nos hospitais psiquiátricos.

"É você tirar ela do convívio. Eu acho que ainda a cultura é tirar a pessoa do convívio. Eaí, tirar do convívio significa você mandar ele pra outra cidade, você colocar no hospital psiquiátrico". (EI11)

"Eles colocam ali, o hospital psiquiátrico pode ser considerado um morredouro, você põe lá pra morrer. Dure o tempo que durar, mas vai morrer lá dentro”. (EJ5)

Gadelha Junior (2002, p. 89) afirma que o hospital psiquiátrico favorece o processo de cronificação dessas pessoas, ou seja, o embotamento afetivo, o isolacionismo, os hábitos 
grotescos e a dificuldade na realização de ações práticas, o que justificaria sua tutela, sendo que,

o cronificar o sujeito, a instituição psiquiátrica o condena a o internamento por toda a vida, ou podemos dizer, à morte em vida, pois impossibilita qualquer possibilidade de retorno a o convívio social, pela totalfalta de resolutividade nas ações terapêuticas e pelo desconhecimento do fenômeno estudado.

\subsubsection{A Curatela}

Outro fato muito importante identificado durante a realização do Censo de 2008 foi o caso das curatelas. Conforme Barros e Bichaff, (2008, p. 91),

1.976 (hum mil, novecentos e setenta e seis) moradores, um número considerável, tinham curador, o que representa $31,12 \%$ da população pesquisada. Quando não possuem curador, existem situações em que se estabelece um procurador, com muita frequência entre os próprios funcionários da equipe, com a finalidade específica de administrar a renda do morador.

Para Barros e Bichaff (2008), as evidências encontradas no Censo suscitam a necessidade de revisão das ações relacionadas à interdição e à curatela dos moradores em hospitais psiquiátricos, para que se torne possível à reversão do processo de institucionalização que leva a pessoa a uma progressiva perda de cidadania resultante também dos processos de interdição.

Nas frases temáticas dos entrevistados que vivenciaram essas descobertas na época, com o sequestro do indivíduo a curatela do Estado, a corrupção permeava as relações no interior dos hospitais psiquiátricos com a curatela dada a familiares e até para diretores de hospitais que não prestavam contas.

"A coisa mais difícil que acho que o censo nos deu, e que nós aprofundamos, mas na minha forma de avaliar muito pouco, porque a gente descobriu as curatelas. Então, família que era curadora do paciente, nunca participava de nad a e ficava com o dinheiro do paciente". (EJ13)

"E o dono do hospital, que era curador de noventa e tinha uma única conta, não tinha noventa cartõezinhos, era uma coisa horrível. E eu fico assim: "Cadê o juiz? Cadê a justiça? Como que ele presta conta disso?". (EJ14)

"Tinha essa questão da curatela, que foi uma coisa que chamou muito a nossa atenção. Porque isso foi meio que observado pela área técnica e isso traz mais 
argumento pra gente poder até pautaro Ministério Público pra ficar em cima. Porque a gente chegou a pegar situações de um bom tanto assim de familiar que recebe o benefício, né?". (EL7)

"O diretor do hospital era nomeado judicialmente como curador da pessoa, né? Então, além de receber pelo SUS, recebia também os benefícios previdenciários dessa mesma pessoa e administrava sem prestação de contas, né? Sem prestação de contas". (EF5)

De acordo com o artigo 1.767 do Código Civil Brasileiro “os incapazes estarão sujeitos à interdição total ou parcial, fins de terem seus direitos e interesses protegidos pelo Estado através da figura do curador que os representará ou assistirá legalmente”, definindo como dever do curador, "reger a pessoa do interditado, zelando por seus interesses, provendo necessidades básicas como alimentação, saúde, defesa de seus direitos e educação, bem como administrar seus bens".

Ferronatto (2012, p. 31) destaca que o Ministério Público deve ajuizar uma ação de prestação de contas, buscando a apuração da responsabilidade do curador, no caso de indícios de mau uso ou desvio dos recursos financeiros do curatelado, dito incapaz, uma vez que,

caso haja indícios de mau uso ou desvio dos recursos financeiros do Atuando nas ações relativas à incapacidade, tutela e curatela, o MP busca a proteção jurídica e social do incapaz, assegurando que seus direitos, sejam exercidos corretamente pelo curador, de acordo com o preceito maior da dignida de da pessoa humana.

\subsubsection{As Internações Involuntárias}

Outro tema identificad o foi "internações involuntárias". Esta modalidade de internação era (e ainda é) um recurso utilizado em grande escala nos casos de pessoas com transtorno mental ou ainda em casos de pessoas com deficiências que não apresentavam transtorno mental, mas que mesmo assim eram abandonadas nos hospitais psiquiátricos.

“(...) E sequestram, levam pra lá. O psiquiatra assina um laudo de internação. $\mathrm{Na}$ internação involuntária”. (EF2)

"Não são pessoas que estavam fora do controle das suasfaculdades mentais de jeito nenhum. Da sua consciência. Então, essas pessoas eram levadas, muitas vezes, a força, ou eram pessoas que iam espontaneamente por solicitação da família, mas que depois não podiam sair". (EF7) 
De acordo com Cléve (2017), quando a pessoa consente com a internação ou toma a iniciativa de forma expressa, é considerada voluntária. Quando ocorre por ato médico definido quando o paciente se encontra em momento crítico, através do pedido de terceiro, mas sem o consentimento da pessoa, se caracteriza como internação involuntária. No caso da internação compulsória, ocorre sob a decisão exclusiva de um juiz competente, que não pode interferir no tratamento definido em laudo médico obrigatório, não havendo o consentimento do paciente, desde que exista perigo iminente ou risco à sua integridade física ou de terceiros.

\subsubsection{As Internações Compulsórias}

Temos comprovado nos últimos anos, um retorno às práticas de internação compulsória, principalmente quando se trata de pessoas dependentes do uso de álcool e/ou outras drogas, seja pelo pedido da família à Defensoria Pública ou por meio dos poderes públicos o que tem acirrado novamente as discussões por se caracterizar em um retrocesso nas políticas de desinstitucionalização implementadas no Estado de São Paulo.

"A pessoa entra, a gente não tem um mecanismo de acompanhamento da internação involuntária. Agora, com a compulsória, piorou. Porque São Paulo tá aumentando as compulsórias". (EA16)

"Aí a internação é muito mais longa, porque agora se você só pode manter o dito louco, 90 dias, de cara você pode manter por seis meses, um ano o usuário de álcool e drogas, com apoio do judiciário”. (EA23)

"Esse sistema é constantemente desrespeitado. Eu can sei de ver internação de psiquiatria sem laudo médico, cansei de ver ordem judicial, apesar da alta médica, o poder judiciário não deixava a pessoa sair do local”. (ED8)

“Eu sei que o Poder Judiciário e o Ministério Público que atuamnesse processo estão lutando contra isso, porque querem internar todo mundo. Porque o pedido é sempre de internar". (ED17)

"Não são pessoas que estavam fora do controle das suasfaculdades mentais de jeito nenhum. Da sua consciência. Então, essas pessoas eram levadas, muitas vezes, a força, ou eram pessoas que iam espontaneamente por solicitação da família, mas que depois não podiam sair". (EF7)

Conforme Sarlet (2016, p. 1) 
a internação psiquiátrica, em qualquer das modalidades, somente se mostra cabível quando os recursos não hospitalares forem tidos como insuficientes e houver risco à integridade física, à saúde ou à vida dos portadores de transtorno mental ou a terceiros.

Assim que cesse o estado de crise, a pessoa com transtorno mental deve ser reinserida em seu meio social.

Todos esses resultados até aqui, servem de pano de fundo para que possamos trazer, sob a ótica dos entrevistados, a discussão sobre a efetividade das Políticas Públicas de Desinstitucionalização desenvolvidas no Estado de São Paulo, para buscar formas de garantir o desenvolvimento no Estado de políticas de saúde mental, de assistência e de promoção de ações de saúde às pessoas com transtornos mentais, com a participação tanto da família quanto da sociedade, sendo que "o tratamento visará, como finalidade permanente, à reinserção social do paciente em seu meio, e à internação, em qualquer de suas modalidades, só será indicada quando os recursos extra-hospitalares se mostrarem insuficientes" (Veloso, Carlos, 2009, p. 104).

\subsubsection{Os mortos vivos}

Durante a realização da coleta de dados para o Censo Psicossocial (2008) um dos indicadores referia-se à Cidadania e Suporte Social, e foram identificados 1.312 (um mil trezentos e doze) moradores que não possuíam documentos pessoais e, portanto, deveriam ser alvo de ações estratégicas, para que pudessem ser identificados, e ter respaldados os seus direitos a obter benefícios da Previdência Social e acesso ao Auxilio de Reabilitação do Programa "De Volta Para Casa" do Ministério da Saúde.

Os entrevistados trazem essa questão da falta de documentos que identificassem essas pessoas, que, aos olhos da lei, não existiam, eram invisíveis, eram "mortos civis" e era importante a realização do Registro tardio dessas pessoas, conforme a recomendação do Censo 2008.

"No município, as pessoas tinham documento, a maioria. No Estado, a maioria não tinha nome, não tinha documento, não tinha nada”. (EB29)

"Hoje a gente tem a Defensoria Pública junto, com papel específico. Então a gente já aciona quando não tem documento”. (EB30)

"Uma das questões são as pessoas que tão chegando nas RTs e não têm histórico, nome e sobrenome”. (EG13) 
"Nós não sabíamos quem era. Esse que é o grande trunfo do Censo. Uma coisa é você ver números. Nós temos 06 mil, 6349 moradores. Moradores. Quem são essas pessoas? Eaí começou. Quem são? São mortos civis, ninguém sabe, ninguém viu”. (EJ10)

"A gente ainda encontra resistência com relação a isso, por conta de independência funcional, de Ministério Público e dos próprios hospitais que não ajudam. Porque vocêpoderia só com a informação do hospital, pedir essa certidão tardia”. (EI27)

\subsubsection{A Desinstitucionalização no Estado de São Paulo}

\subsubsection{As Recomendações do Censo Psicossocial (2008) para a Desinstitucionalização}

O projeto da desinstitucionalização coincide com a reconstrução da complexidade do objeto que o modelo clínico e asilar haviam simplificado. O enfoque não é mais a cura, a reparação, mas a produção da vida e a reprodução social das pessoas. É preciso "reinventar a instituição" para que se identifiquem situações de sofrimento e opressão, rearticulando-as ao corpo social, a partir de trocas, novos papéis, encontrando "outros modos materiais de ser para o outro, aos olhos do outro" (Rotelli, 1990, p. 94). Esta invenção só poderá ser viabilizada se considerada a singularidade das pessoas e sua articulação com as práticas sociais.

O Censo Psicossocial de 2008 foi extremamente importante para dar visibilidade aos moradores de hospitais psiquiátricos de longa permanência. A partir de sua publicação, as ações implementadas pela SES/SP e pelo COSEMS/SP, tomaram como referência os números de moradores, o perfil socioeconômico e demográfico, entre tantos outros achados, para a implantação e implementação das políticas de desinstitucionalização e de fortalecimento das redes extra-hospitalar no Estado de São Paulo, buscando a efetivação da reabilitação psicossocial dessas pessoas com o resgate de sua cidadania, de seus direitos. Nas frases temáticas, a seguir, reforça-se essa importância:

"Porque o Censo me deu uma fotografia. Como é que eu faço pra não ter que fazer um outro censo em 2020? Porque o PNASH de psiquiatria, o último também não envolveu os atores sociais. O primeiro envolveu vários atores, o movimento ia junto. No último, já nãofoi mais. Foram só técnicos que entraram nos hospitais”. (EA39) 
"Essa equipe entra dentro do hospital e vai olhar os prontuários, vai conversar com as pessoas. Porque o Censo é uma porta. Ele me diz uma coisa, um olhar. Mas ele não me diz daquela pessoa. Então a gente tem que entrar. Olhar, de novo, conversar. Ver se tem referência, ver da onde veio... Se tem documento, se não tem documento. Dá um geral naquelas pessoas. A gente fez um instrumento. Avalia as pessoas. A partir daí a gente define pra onde elas vão”. (EB2)

"Então teve o Censo de 2008, pra gente foi muito importante. Eu acho que, principalmente, porque é uma exposição saudável do Estado. Eu acho que foi o primeiro documento onde o Estado assume que tem uma divida social e que ele tem que criar alguma alternativa pra cumprir essa divida social”. (EB5)

"Eu acho que a publicação do primeiro censo, ela chacoalhou o Estado como um todo, né? As recomendações são pertinentes e atuais. Eu acho que não tem nada ali que a gente não diga: "Olha, estamos fazendo até hoje..." Ou "Con sideramos aquilo ultrapassado". (EB6)

"Esse conjunto de recomendações, na realidade, eles norteiam qualquer ação em saúde mental, né? Então, de uma forma geral, acho que, assim, você não consegue pensar em processos de desinstitucionalização sem pensar em fortalecimento de RAPS". (EC2)

"Pensando nas recomendações, elas se organizavam no sentido da necessidade de fortalecimento e implantação da rede psicossocial, falava da importância de estratégias de estímulos aos municípios pro desenvolvimento dos serviços, falava da questão da documentação, da necessidade da retirada de doc umentação, das revisões das questões das curatelas". (EC1)

"Era importante que gente retomasse a visibilidade do censo pra dizer: "Olha, o Censo de 2008 não concluiu. Ele só levantou um processo. E se a gente enquanto gestor não olhar pra esse processo, a gente paralisa. Então é importante a gente reolhar pra isso tudo. (EC29)

"Acho que ele foi muito importante pra dar esse diagnóstico de como que era a situação. E ele serve de instrumento pra gente, agora já o de 2014, pra que o município se organize, não só pra resolvero problema dos hospitais de Sorocaba, mas pra colher todos os pacientes moradores que estão espalhados em ho spitais no Estado de São Paulo”. (EI5) 
"Depois com o Censo, você sabe que é um número muito maior”. (EI22)

"Todos esses resultados, essas conquistas, eu tenho certeza que se não fo sse o Censo, o Censo de 2008, 2014 também, a gente não teria tido a re solutividade e mesma eficácia que a gente teve. Porque o TAC, quando ele imprimiu uma ordem jurídica”. (EJ16)

"A gente sabia, pelos PNASH, que existia um grande número de moradores. Mas era sempre assim "Existe muita gente internada morando no hospital". "Existe muita gente". Mas quantos? Aonde? Quem são? Por que tão lá? Há quanto tempo tão lá, né?". (EK1)

"As recomendações não eram nem um pouco humildes, vamos dizer assim. Considerando todos esses cenários, onde a gente estava, toda a contradição do interior da política a da própria reforma. A gente tinha grandes metas". (EK6)

"Umas das grandes características do Censo é, que é assim, mesmo quem é contra a reforma, não tem coragem de dizer que uma pessoa tem que se manter internada, né? Isso era politicamente incorreto ". (EK8)

\subsubsection{Resistência à Desinstitucionalização}

No Brasil, com a aprovação da Lei n. 10.216, de 06 de abril de 2001, a Lei da Reforma Psiquiátrica, busca-se um novo modelo de assistência, direcionando-a para uma rede de base comunitária de atenção à saúde mental, seja, buscando a redução do número de hospitais psiquiátricos e a aplicação dos CAPS para atender as pessoas com transtornos mentais, definidos como serviços substitutivos ao hospital psiquiátrico, cabendo a promoção da desinstitucionalização, tornando o tratamento extra hospitalar e comunitário, sendo a família a principal cuidadora, todos apoiados pelas equipes de saúde no território.

A "resistência a desinstitucionalização" foi outro tema identificado, pois alguns entrevistados relataram que a pessoa com transtorno mental precisa ser assistida como qualquer outro cidadão, em hospitais gerais, nos CAPS, nos componente da RAPS, longe do estigma e da segregação, porém, apesar de ser possível, ainda encontra muita resistência por parte de vários atores da sociedade, sejam gestores, grupos políticos, proprietários de hospitais, dentre outros.

“Esses psiquiatras são formados dentro de manicômios. (...) a gente faz um esforço em formar pessoas numa direção, pra ter um conceito antimanicomial. Porém, 
toda residência de psiquiatria pública do Estado de São Paulo, ele é formado dentro de hospital psiquiátrico para manutenção de hospital psiquiátrico”. (EA10)

"Eu acho que a lógica estadual ainda é questão dos grandes hospitais, né? Então você ainda tem uma resistência muito grande". (EC27)

"Qual é a articulação que vocês fizeram pra convencer o gestor? Vamos abrir residência? Vamos aderir ao programa do Ministério?" Por isso que eu falo é uma resistência da própria sociedade civil. Só que como elesficam, aqui no caso do Estado de São Paulo existe muito forte aqui a questão política partidária. Muito forte". (EE11)

"Nós estávamos descobrindo um caminho pra promover a desinstitucionalização daqueles pacientes e contando com muita resistência da sociedade, do poder público, de uma ala da psiquiatria, enfim, de alguns médicos, dos próprios proprietários dos hospitais”. (EH8)

"Mas existe as cidades aqui, hoje, atualmente conservadoras, que estão contra, totalmente, à Rede de Atenção Psicossocial”. (EJ2)

Para os entrevistados fica evidente a convicção de que no Estado de São Paulo, a Reforma Psiquiátrica apesar de já ter gerado muitas transformações à superação do antigo paradigma, ainda está arraigado nas convicções de muitos daqueles atores políticos e profissionais atuantes na área de Saúde Mental, uma verdadeira resistência à desinstitucionalização.

\subsubsection{Caminhos para Desinstitucionalização}

Tratando-se de Políticas de Saúde no Brasil, Machado, Baptista e Lima (2014) analisam a relação entre a institucionalidade da política e sua continuidade, mesmo diante de alterações na conjuntura política. De acordo com as autoras, a trajetória histórica, as regras e os canais formais, os procedimentos informais acordados e a solidez da base de apoio social sustentam as políticas de saúde. Nesse sentido, é importante o esforço e consenso dos atores sociais para ampliar e transformar o contexto de saúde pública.

Com a Reforma Psiquiátrica em movimento no Brasil e no Estado de São Paulo, a luta pela desinstitucionalização dos moradores de longa permanência nos hospitais psiquiátricos foi presente nas frases temáticas, pois ocorreram mudanças no direcionamento das políticas 
públicas de desinstitucionalização no Estado, ou seja, outros caminhos à desinstitucionalização de acordo com alguns entrevistados.

"Surgiria também uma organização dos técnicos da saúde mental no sentido de sustentar uma prática que dispensava radicalmente o hospital psiquiátrico. Não a internação psiquiátrica”. (EJ6)

"Fica difícil do gestor dizer que essa pessoa precisa de atendimento no hospital. Ninguém precisa. Não tem mais argumento e mesmo psiquiatra pra dizer que as pessoas precisam morarno hospital”. (EI24)

“Eu acho que já existe, agora, uma compreensão de que não deu certo ter tudo isso de hospital psiquiátrico. Porque ver o número de quatro dígitos de paciente moradores, eu acho que não deu certo, porque o Estado não consegue fiscalizar o atendimento nesses hospitais. (...) acho que os gestores estadual já têm essa compreensão de que esse modelo não deu certo”. (EI29)

De acordo com Silva e Rosa (2014), desde a década de 1990 a Política de Saúde Mental no Brasil passou a tomar novos rumos, visando à substituição do modelo centrado nas internações e medicalização, para a priorização do sujeito em sua totalidade no contexto social no qual deveria estar inserido, caracterizando-se assim em um novo modelo de atenção à pessoa com transtorno mental, compactuando com os ideais da Reforma Psiquiátrica e do SUS, além da Luta Antimanicomial.

A tentativa de mudança do modelo hospitalocêntrico para o modelo comunitário, de atenção psicossocial, fica evidente em relação à convicção de que no Estado, a Reforma Psiquiátrica e a luta antimanicomial apesar de já terem gerado muitas transformações, tem sido um árduo processo resultante de muitas lutas, enfrentamentos e desafios para a superação do antigo paradigma como identificamos na frase temática que segue:

“A questão da luta antimanicomial não era só fechar manicômio. Nunca foi só isso" e ainda no relato de outro entrevistado: EJ8 "Houve um certo comodismo depois que as leis foram publicadas, como se isso fosse naturalmente conseg uir mudança de paradigma, de modelo. Não. Era uma coisa... A política é cotidiana ”. (EA32)

\subsubsection{O Planejamento das Políticas Públicas}

Conforme Mota (2014), as políticas públicas são a forma como o Estado atua para amenizar os conflitos e as desigualdades sociais, sendo delineadas para o atendimento dos 
diferentes interesses das diversas camadas da sociedade, sendo fundamental nesse processo a participação dos atores políticos para a definição e a destinação de recursos públicos para a consecução da política pública a ser implementada.

Nas frases temáticas que desvelam (a falta de) planejamento das políticas públicas de desinstitucionalização que deveriam ser promovidas na esfera da gestão estadual, notamos que durante todos esses anos, de acordo com um dos entrevistados, poucas coisas efetivamente mudaram e foram implementadas pela SES/SP, o que contradiz o que foi definido nos objetivos, metas e ações estratégicas nos Plano Estadual de Saúde para o quadriênio 2008-11:

"Diferente de qualquer outra área da saúde, a Lei 10.216, ela não está implantada na saúde. Nunca foi implantada e nunca foi cobrada na saúde suplementar. Então, assim, os planos dos municípios nunca foram obrigados a cumprir a 10.216”. (EA11)

"O plano estadual também é uma coisa que a gente conversou, que ele tá escrito de uma forma muito ampla, não especifica. É como se fosse assim: "Que metas eu posso por pra dar certo de eu cumprir para o governador não brig ar comigo?". Não dizem as formas mesmo de fazer aquilo". (EA38)

No Estado de São Paulo, o Plano Estadual de Saúde (PES) deve ser compreendido como a "síntese das propostas e ações estratégicas do Governo do Estado de São Paulo na área de saúde" (Souza et al., 2008a, p. 11). Ainda, conforme Souza et al. (2008a, p. 16) , o PES foi dividido em Eixos Prioritários e suas diretrizes estratégicas, tendo como objetivo "facilitar o processo de planejamento, o entendimento e a realização de ações por parte dos agentes, órgãos técnicos e administrativos estaduais", sendo que dentro de cada uma das diretrizes estratégicas foram estabelecidos objetivos, seguidos da definição de suas "ações estratégicas propostas para intervenção nos problemas e modificação dos padrões de saúde existentes no Estado de São Paulo, além das metas/resultados esperados para o quadriênio".

No PES, para o quadriênio 2008-2011, a questão da Saúde Mental foi tratada no Eixo VI: "Desenvolvimento de serviços e ações de saúde para segmentos da população mais vulneráveis aos riscos de doença ou com necessidades específicas", sendo que dentre as diretrizes estratégicas ficou definida a "necessidade de ampliação e garantia à saúde mental”, visto que a alta prevalência dos transtornos mentais e comportamentais na população em geral refletia-se em diversos impactos tanto sobre os indivíduos, as famílias e as comunidades, mesmo porque o país estava passando nas últimas décadas, por um período de "complexa 
transformação no campo de conhecimentos e práticas em saúde mental”, tendo como “pressupostos a reorientação do modelo de atenção em saúde mental e a proteção aos direitos das pessoas com transtornos mentais" (Souza et al., 2008b, p. 110).

O PES para o quadriênio 2008-2011 contemplou quatro objetivos específicos para atender ao Eixo VI, no que se refere especificamente à questão do Objetivo 01: Garantir atenção integral à saúde mental da população em serviços extra-hospitalares; Objetivo 02: Promover e apoiar articulações intersetoriais para a atenção à saúde mental; Objetivo 03: Promover a avaliação e reestruturação da assistência psiquiátrica hospitalar; e, Objetivo 04: Promover a implantação e implementação de programas de educação permanente e qualificação de serviços da rede de atenção em saúde mental extra-hospitalar.

Reforçando ainda em relação ao que está evidenciado no PES do Estado de São Paulo, no PES para o quinquênio 2012-2015, as diretrizes, objetivos e metas foram citadas. A questão da Saúde Mental foi tratada no Eixo 1 - aperfeiçoamento e qualificação do acesso aos serviços e ações de saúde, tendo como diretriz "integrar os serviços de saúde do Estado de São Paulo em Redes Regionais de Atenção à Saúde (RRAS), cujo objetivo era "reorganizar e ampliar a rede de atenção à saúde mental/álcool e outras drogas", ainda enfatizando como objetivo específico, “apoiar a implantação de RTs, CAPS e leitos em Hospital Geral de acordo com a pactuação regional feita com os gestores municipais nas RRAS, na Comissão Intergestores Bipartite e aprovada pelo Conselho Estadual de Saúde”, tendo-se então como meta, “organizar a rede temática de saúde mental/álcool e outras drogas em 100\% das RRAS (Teixeira et al., 2012, p. 121).

Finalmente, o último PES quadriênio 2016-2019, define em seu EIXO II Desenvolvimento de programas e ações para segmentos específicos da população, os objetivos e metas para o alcance da diretriz "aprimorar a atenção à saúde mental", os quais observa-se no Quadro 3. 
Quadro 3 - Objetivos e Metas do Eixo II do PES/SP quadriênio 2016-2019

\begin{tabular}{|c|c|}
\hline $\begin{array}{l}\text { Desenvolver processo de planejamento e } \\
\text { implementação da Rede de Atenção Psicossocial } \\
(\text { RAPS })^{3} \text {. }\end{array}$ & $\begin{array}{l}\text { 1-100\% das Regiões de Saúde com RAPS } \\
\text { aprovadas na Comissão Intergestores Bipartite } \\
\text { (CIB). } \\
\text { 2-100\% dos leitos e serviços de saúde mental do } \\
\text { estado de São Paulo regulados. } \\
\text { 3-Implantar a Linha de Cuidado da Saúde Mental } \\
\text { no estado de São Paulo prioritariamente nas } \\
\text { cinco regiões de saúde definidas no Programa } \\
\text { Saúde em Ação (Vale do Ribeira, Vale do } \\
\text { Jurumirim, Vale do Paraíba, Região } \\
\text { Metropolitana de Campinas e Itapeva). } \\
\text { 4- Apoiar financeiramente em parceria com os } \\
\text { municípios a ampliação das Residências } \\
\text { Terapêuticas (RT). } \\
\text { 5- Apoiar tecnicamente os Departamentos } \\
\text { Regionais de Saúde (DRS) por meio de } \\
\text { estratégias de educação permanente na } \\
\text { implantação das RAPS no estado de São Paulo. }\end{array}$ \\
\hline $\begin{array}{l}\text { Promover ações de prevenção, tratamento e } \\
\text { reabilitação psicossocial aos usuários de } \\
\text { substâncias psicoativas por meio do Programa } \\
\text { "Recomeço". }\end{array}$ & $\begin{array}{l}\text { 1- Ampliar em } 7 \% \text { a cobertura de Centros de } \\
\text { Atenção Psicossocial (CAPS). }\end{array}$ \\
\hline $\begin{array}{l}\text { Promover a desinstitucionalização dos moradores } \\
\text { de hospitais psiquiátricos do estado de São Paulo. }\end{array}$ & $\begin{array}{l}\text { 1- Desinstitucionalizar } 100 \% \text { dos moradores de } \\
\text { hospitais psiquiátricos no estado de São Paulo. } \\
\text { 2- Implementar as comissões revisoras das } \\
\text { internações involuntárias em 70\% dos } \\
\text { Departamentos Regionais de Saúde (DRS). }\end{array}$ \\
\hline
\end{tabular}

Fonte: Adaptada de Mendes, Cruz e Portas. (2015, p. 162)

Assim, neste contexto é contraditório o que um dos sujeitos participantes neste estudo refere:

"O próprio Estado não colocou no seu plano estadual uma política. Se for analisar. Porque é isso, o gestor público só pode fazer o que tá na lei”. (EA27)

Por outro lado, no caso da implementação de políticas públicas municipais de desinstitucionalização, os entrevistados enfatizam a importância das políticas públicas municipais e de seus gestores para a efetivação de parte do processo de fechamento dos hospitais psiquiátricos, da criação das RAPS, de acolher pessoas que passaram suas vidas

\footnotetext{
${ }^{3}$ Objetivo definido com base na Portaria no 3.088/GM/MS, de 23 de dezembro de 2011, que institui a Rede de Atenção Psicossocial (RAPS) para pessoas com sofrimento ou transtorno mental, e com necessidades decorrentes do uso de crack, álcool e outras drogas, no âmbito do SUS, republicada em 21 de maio de 2013.
} 
como moradores de longa permanência nestes hospitais, lutando contra o estigma e a segregação que os acompanha, porém, os discursos são contraditórios:

"A gente ia discutir com gestor e ele falava: "Mas eu vou ter que fechar a quele hospital? Vou ter que botar os doidos tudo na rua? Ai, meu Deus, o meu município!". (EB22)

"Ele tá lá esperando, o município já tá atrasado há anos pra acolher esses pacientes. E aí a dificuldade que tem de abrir serviço e aí a dificuldade que tem de cada município ter as suas prioridades, as suas urgências". (EI9)

"Tem a questão cultural. O município, ele vê muito do ponto de vista do cartão de visita deles, também, né? Então, assim, o que que pode dar voto, o que pode dar eleitorado". (EL9)

"O gestor não fica muito interessado em montar uma RT. Ele monta por pressão. Quando você usa o apelo do argumento da divida social”. (EL10)

A questão da desinstitucionalização das pessoas com transtornos mentais encontrou várias resistências conforme os relatos de alguns entrevistados. Os entraves não eram poucos, começando com a mudança da cultura que apregoava que "lugar de louco é no hospício", de que eles representavam riscos às pessoas, também toda a questão eleitoreira, para não perder os votos daqueles que não desejavam "loucos em sua vizinhança", bem como a questão dos recursos financeiros e humanos que muitos municípios não tinham para o custeio de todo esse processo.

Entretanto, também tiveram municípios que "abraçaram" o processo de desinstitucionalização, conforme destacaram os entrevistados, dando a possibilidade dessas pessoas de se tornarem visíveis, de serem acolhidas, de terem uma oportunidade de reescrever suas histórias.

[Sobre o município de Orindiúva.] "É um município bem interessante, porque é um município muito pequeno, mas que fez uma opção, porque é um município que tem recurso. Então é um município de menos de dez mil habitantes, mas que tem CAPS e optou em abrir uma residência terapêutica totalmente solidária". (EA2)

"A gente trabalha com vaga solidária. Então o cara vai montar uma residência e tem sete moradores. Sobraram três vagas. Se o município aceitar, ele acolhe três dessas pessoas que não tem referência”. (EB4) 
Entretanto, para que se tornasse possível a articulação de qualquer política pública de desinstitucionalização, era essencial a alocação de recursos financeiros tanto oriundos da esfera federal, quanto estadual e também do próprio município que possibilitasse todo o aparato extra hospitalar.

\subsubsection{Destinação de Recursos Financeiros para Desinstitucionalização}

A questão de financiamento público é exatamente uma das recomendações propostas pelo Censo Psicossocial realizado em 2008 no Estado de São Paulo. Se olharmos o levantamento das leis, portarias, decretos e resoluções levantadas, é possível perceber que a maior parte delas trata-se da destinação de recursos financeiros à criação de CAPS e de SRT, porém insuficientes ainda para manter toda a estrutura necessária à reinserção dessas pessoas na sociedade identificado nas frases temáticas.

"Na saúde mental, como em vários outros grupos, a questão do financiamento é uma questão marcante. Então, assim, a maioria dos municípios do Estado de São Paulo já subiram de 25\% do gasto dos municípios com saúde, pra 27\%. Então, assim, se a lei diz que os municípios devem gastar pelo menos $15 \%$ em saúde, no Estado de São Paulo nós estamos em 27\%”. (EA5)

“A gente não tem recurso do tesouro estadual sendo colocado priorita riamente com isso. O Estado, ele ajuda na medida de antecipar seis meses o recurso de abertura pra CAPS e residências terapêuticas". (EA19)

"O recurso, defato, cobriu o custo de uma residência terapêutica. Porque isso dava uma tranquilidade pro pessoal de que vai dar. Hoje, como custo do alu guel em São Paulo, na maioria das regiões, o dinheiro que vem do Ministério não cobre o custo". (EA25)

"A falta do recurso federal pra custeio de RT foi determinante. No final de 2011, quando saíram às portarias e que aí previa a questão do recurso financeiro, o cenário era outro". (EB13)

"A Secretaria de Estado solta uma deliberação CIB que incentiva os municípios com mais dez mil reais por residência e dá mais vinte mil reais por CAPS, se tiver vinculado a uma residência. Isso ajudou”. (EB15)

"A questão financeira, foi uma proposta do primeiro censo, um apoio. Tanto que, a partir dali, saiu uma resolução que passava dez mil reais de incentivo de 
implantação pra RT, e vinte mil reais pra incentivo de implantação de CAPS se viesse agregado a uma RT”. (EC24)

"A gente passou a custear nos mesmos valores da tabela do Ministério a residência terapêutica por seis meses. Issofoi, assim, umfator fundamental pro avanço das negociações de uma forma geral e, principalmente, no TAC de Sorocaba”. (EC26)

“A Secretaria de Estado tem recursos, capacitação técnica e tem que ajudar os municípios na implementação dos serviços previstos na Política Nacional de Saúde Mental”. (ED3)

"É um problema econômico. O recurso que o Ministério da Saúde encaminha pra fazer as políticas de saúde mental é ínfimo, é muito pequeno”. (ED15)

“A gente já tinha mapeado os pacientes, a gente já sabia o destino deles. E aí começou um outro processo árduo, também, de negociação com os municípios pra instalação dessas residências terapêuticas. Dentro da rede de atenção psicossocial. E era uma negociação difícil, porque havia o compromisso do Ministério da Saúde em mandar o dinheiro, eles tinham que cadastrar o equipamento. Mas era um processo burocrático”. (EH14)

\subsubsection{Retrocesso para Desinstitucionalização}

O cenário atual para os entrevistados tende a se tornar mais disforme na medida em que passamos a enfrentar as imposições de uma nova Política para a Saúde Mental, com o incentivo ao fortalecimento dos hospitais psiquiátricos em detrimento de todas as mudanças ocorridas nas últimas décadas.

A participação de toda a sociedade e instituições se torna a principal forma de articulação para que não se repita no Brasil as atrocidades que foram constatadas nos hospitais psiquiátricos. Entretanto, entre os entrevistados, em suas frases temáticas observamos uma visão pessimista quanto ao futuro da Reforma Psiquiátrica. Evidenciamos nas frases temáticas que se caminha para um retrocesso, mesmo que alguns deles ainda creiam que não haverá um retorno ao processo asilar.

"Acho que o momento político tem mostrado isso pra gente, é que as relações, às vezes, do Ministério Público, do Executivo e do Legislativo não são exatamente aquelas que deveriam ser." (EA17) 


\title{
“É. Precisa mudar a gestão do Estado, né? Precisa de uma gestão mais voltada pra distribuição de recursos e atendimento de direitos sociais". (EG19)
}

Novamente há que se falar em retrocesso na política de desinstitucionalização, não somente em São Paulo, mas no país todo, uma vez que conforme a NOTA TÉCNICA N ${ }^{\circ}$ 11/2019-CGMAD/DAPES/SAS/MS, que traz "Esclarecimentos sobre as mudanças na Política Nacional de Saúde Mental e nas Diretrizes da Política Nacional sobre Drogas", aponta que,

\begin{abstract}
Após nove anos, o valor pago pelas internações em Hospitais Psiquiátricos foi atualizado, medida que visa garantir atendimento adequado nas internações indicadas. O Hospital Psiquiátrico, incluído na RAPS, deve ser modernizado e seguir protocolos e padrões modernos vigentes. Vale ressaltar que a desinstitucionalização dos pacientes moradores de Hospitais Psiquiátricos continua sendo incentivada pelo Governo Federal, que não entende esses Serviços como locais de moradia de pacientes. Entretanto, a desinstitucionalização não será mais sinônimo de fechamento de leitos e de Hospitais Psiquiátricos (Brasil, 2019a).
\end{abstract}

As mudanças que estão em curso no país na Política Nacional de Saúde Mental reflete os impasses nas políticas públicas de desinstitucionalização sentidas pelos entrevistados no decorrer das mudanças suscitadas pela Lei da Reforma Psiquiátrica, que está sendo colocada em xeque na atual administração federal, e que, consequentemente, reflete nas políticas do Estado de São Paulo e em todos os Estados da Federação.

\subsubsection{Ações do Ministério Público}

A mais efetiva ação realizada pela Secretaria de Saúde do Estado de São Paulo, mas que não partiu de uma proposta por sua equipe planejada como apresentado anteriormente na pesquisa documental, e sim como resultado da pressão dos grupos de luta antimanicomial, deflagrada por uma reportagem que foi veiculada mostrando as atrocidades cometidas nos hospitais psiquiátricos da região de Sorocaba, foi a pactuação do Termo de Ajustamento de Conduta (TAC) proposto pelo Ministério Público às SES/SP.

No TAC, todos os moradores internados nos sete hospitais psiquiátricos da região de Sorocaba que recebiam verba do SUS deveriam ser desinstitucionalizados para a RAPS gerida pelo poder público e os hospitais seriam descredenciados (São Paulo, 2012).

Identificamos nas frases temáticas dos entrevistados, as percepções sobre o que foi o TAC, as ações implementadas e as consequências do processo de desinstitucionalização dos moradores dos sete hospitais psiquiátricos na região de Sorocaba. 
"Porque o TAC não foi só Sorocaba. Quando o TAC era de três municípios, ela transformou o TAC num TAC do Estado de São Paulo. Na medida de que responsabilizou todo mundo”. (EA30)

"Sete hospitais [região de Sorocaba] que detin ham metade dos moradores do Estado e, praticamente, maior quantidade concentrada do país”. (EB28)

"Sorocaba se tornou um polo de hospitais psiquiátricos, de internação de longo prazo e lá, pra lá ficar, realmente, centenas de pessoas. Muitas delas vindas de famílias pobres que não tinham condições de manter. A rede de apoio não existia ou era insuficiente, não de agora, mas de muito tempo". (EF3)

"O objetivo é o fortalecimento da rede comunitária e aberta. A gente também vai participar na questão das residências terapêuticas a partir de uma conversa que fizemos com o Ministério Público Federal que tem um Termo de Ajustamento de Conduta para a desinstitucionalização de todos os leitos do polo manicomial de Sorocaba”. (EG11)

“O TAC foi escrito há muitas mãos, não, é? Não foi o Ministério Público que redigiu o TAC. Ele foi pactuando o TAC com a Secretaria Estadual de Saúde, com o Ministério da Saúde, com as prefeituras". (EH6)

“O TAC impulsionou também o movimento, na própria Secretaria, de fortalecimento da Rede de Atenção Psicossocial. Então, eles conseguiram, por conta própria, sem TAC nenhum, o próprio Estado conseguiu fechar mais dez hospitais. Fora desses sete em Sorocaba”. (EH14)

Ainda Duarte (2018, p. 21) faz um depoimento sobre sua experiência enquanto participante do processo de luta contra o que acontecia nos hospitais psiquiátricos da região de Sorocaba.

Não posso deixar de lembrar a importância e representatividade do movimento social antimanicomial na mudança de paradigma que não se deu por leis e normativas, mas sim por agentes sociais que problematizaram as práticas psiquiátricas e a desassistência promovida no âmbito dessas instituições asilares. Assim, dentre os títulos possíveis para eu me apresentar, o de militante da luta antimanicomial me afeta e é motivo de muito orgulho, pois exige, tal qual a luta pelos direitos humanos, conquistar essa condição diariamente, empenhando-me numa prática política concreta de cuidado ao sujeito excluído e vítima de uma estrutura perversa da indústria da loucura. 
O TAC e todo o processo de fechamento dos hospitais psiquiátricos na Região de Sorocaba foram resultados da participação de vários segmentos da sociedade nas discussões para livrar aquelas pessoas dos sofrimentos que lhes eram impostos, da desumanização pela qual passavam. Qualquer ação implementada pela SES/SP, só se torna possível, com a articulação com o Ministério Público Federal e Estadual, o COSEMS/SP, a Defensoria Pública e toda a sociedade. Para tanto, os entrevistados destacam em suas frases temáticas suas crenças de que tudo só se torna possível através da participação, da criação de conselhos, da composição de grupos condutores, de comissões especializadas e da participação popular.

\subsubsection{Redes de Atenção Psicossocial (RAPS) do Estado de São Paulo: A Desinstitucionalização}

\subsubsection{As necessidades da RAPS}

Analisando as frases temáticas dos entrevistados, notamos que, mesmo aqueles atores que fizeram e fazem parte de toda a construção do processo de desinstitucionalização no Estado de São Paulo, trazem em suas concepções a falta de uma efetiva transformação na política de Saúde Mental. Mudanças ocorreram com o início da implantação da RAPS, não se pode negar, mas, ainda muito aquém das necessidades das pessoas com transtornos mentais de forma a que fossem garantidos os seus direitos fundamentais enquanto pessoas humanas e enquanto cidadãos.

Para os entrevistados, fica evidente as crenças e percepções da importância da estruturação da RAPS, buscando assegurar a qualidade assistencial apoiada no modelo comunitário para a preservação da cidadania das pessoas com transtornos mentais, após as políticas voltadas para a redução dos leitos psiquiátricos, porém, o modelo de acordo com eles ainda está longe de ser o ideal:

“A gente não ficou na questão de desinstitucionalização. A gente falou na reorganização e reestruturação da rede de saúde mental. Então, assim, você tem que fazer RT, mas você tem que ter CAPS, vocêtem que ter os outros serviços que dão conta do atendimento territorial”. (EB21)

“A gente reconhece que a rede de apoio é muito precária, muito falha". (EF17) 
“A gente percebe como uma falha muito grande no sistema de apoio, sistema da rede de apoio, é que elas não trabalham a família. Elas trabalham exclusivamente a pessoa, quando trabalham". (EF19)

"Hoje você pode dizer que o Estado de São Paulo tem uma rede constituída. Talvez ainda seja insuficiente porque esse município é um absurdo também de gente. Nunca será suficiente”. (EK11)

A proposta à organização da RAPS, está conceituada como "uma teia que engloba todos os serviços de saúde, mecanismo que pode promover autonomia e cidadania das pessoas com transtornos mentais" (Oliveira, Martinhago, Moraes, 2009, p. 39). Contribuíram para tal organização as portarias que, juntamente com a Lei n. 10.216/2001, instituíram as experiências institucionais, como os CAPS, SRT; o Programa "De Volta para Casa", centros de convivência e outros, além de equipamentos voltados para potencializar o cuidado comunitário e a produção de laços sociais da pessoa com transtorno mental na sociedade.

Os CAPS, regulamentados pela Portaria n. 336/GM, de 19 de fevereiro de 2002, constituem o principal equipamento do processo de Reforma Psiquiátrica no País. São destinados a acolher as pessoas com transtornos mentais severos e persistentes, de forma a inseri-las na vida comunitária e familiar, buscando a sua autonomia. Funcionam como porta de entrada aos serviços para ações relacionadas à saúde mental, sendo um articulador com outras redes que oferecem serviços a este público, como o Programa de Saúde da Família, Núcleos de Apoio à Saúde da Família, ambulatórios, SRT, abertura de leitos em saúde mental/atenção psicossocial em hospitais gerais, entre outros (Brasil, 2002a).

Para a melhoria da RAPS, os entrevistados apontam a necessidade de apoio técnico para a sua implementação nos municípios principalmente da SES, que conta com pessoas com conhecimentos especializados na condução das políticas de planejamento público, que vai além da questão dos recursos financeiros.

"Que seria o papel do Estado, da Secretaria de Estado de um apoio técnico. Esse apoio técnico, não existe. Não existiu. Então nós perdemos, vamos perder mais quatro anos. Talvez daqui três anos, no próximo início de gestão municipal, a gente faça. Agora, essa condição de planejamento público, não houve”. (EA26)

"Os municípios não tão nem pedindo, tão implorando um apoio técnico. Pra quem montou residência terapêutica, pro CAPS, como é que eu acompanho isso tecnicamente? A gente tá falando com Estado, quer dizer, tem recurso em caixa da educação permanente”. (EA28) 
"Saúde Mental é isso. É formação permanente ali no lugar e supervisão. A gente tem pedido. E a gente se pergunta porque que a gente não conseg ue fazer is so. Tem universidade, tem quadros aptos a fazer isso, teria parceiros que poderiam fazer". (EA35)

"Rede de Atenção Psicossocial ainda é muito deficitária, muito ruim e precisa ser aperfeiçoada”. (ED1)

"Não podemos fechar o leito psiquiátrico e colocá-las ou mesmo no CAPS ou mesmo numa residência sem estrutura. Eu acho que tem que ter um profissional capacitado, nós temos um problema de falta de capacitação do s profissionais ". (EE7)

“A nossa participação, agora, seria mais no âmbito da discussão mais a mpla da RAPS e também numa intervenção no âmbito das residências, instalação das residências terapêuticas aqui na cidade de São Paulo". (EG12)

“Tinha que fazer todo o apoio técnico, toda discussão de montagem dessa rede pra não só montar a residência, mas montar a rede compatível ao acolhimento desse sujeito nesse território”. (EK10)

Ressaltamos que a RAPS não reduz as instituições substitutivas aos hospitais psiquiátricos, mas envolve as instituições mencionadas, incluindo, também, os vínculos familiares, as associações e comunidades que, de forma compartilhada, contribuem para o cuidado e reinserção das pessoas com transtorno mental no convívio social principalmente as Residências Terapêuticas.

\subsubsection{Os Serviços Residenciais Terapêuticos para a Desinstitucionalização}

Como uma das estratégias definidas pela Política Nacional de Saúde Mental do Ministério da Saúde, tomando por base a Lei da Reforma Psiquiátrica, o SRT se configurava como o substitutivo ao modelo manicomial asilar de assistência às pessoas com transtornos mentais, sendo que a orientação é a redução progressiva e o fechamento dos leitos psiquiátricos, visando assim o fortalecimento e a ampliação da RAPS.

Barioni (2013, p. 9), afirma que

Ainda na conjuntura de redireciona mento das ações em saúde, mais especificamente a respeito da Saúde Mental, o Ministério da Saúde pública a Portaria MS 106/2000, que cria o Serviço Residencial Terapêutico (SRT) no âmbito do SUS. Este serviço torna-se responsável pelo acolhimento das pessoa com sofrimento psíquico in ten so 
e persistente que, anteriormente, foram moradoras de hospitais psiquiátricos ou instituições asilares similares, devido às internações psiquiátricas de longa permanência, e que perderam os vínculos com os familiares e/ou vínculos sociais, culturais, trabalhistas, econômicos.

Para Bastos (2011), a possibilidade de viver em liberdade, de poder habitar em uma casa com toda a estrutura de um lar, tendo acesso a um território tal qual qualquer ser humano, após passar longos anos de permanência em hospitais psiquiátricos, cerceado de sua cidadania, poder reconstruir relações de convívio do cotidiano, configura-se como uma reconquista de seus direitos mais fundamentais, além da possibilidade de assumir a responsabilidade por sua própria vida, tendo autonomia.

Entretanto, conforme alguns entrevistados, apesar de ser um lugar de transformação dos egressos de hospitais psiquiátricos, outros entrevistados relatam que o número de SRT é muito inferior à necessidade no Estado de São Paulo para atender a demanda, mesmo porque muitos municípios ainda apresentam restrições a sua implantação, fruto do preconceito culturalmente arraigado no Estado.

"É inacreditável a mudança das pessoas [em residências terapêuticas]. Você olha no espaço hospitalar, você põe na residência terapêutica, você vai um mês depois". (EB9)

"Foram 16 hospitais que fecharam nesse meio tempo. Então, hoje, quando um município negocia a montagem da sua residência, ele não monta só pra Sorocaba. Ele monta pra todos os seus moradores que estão em diferentes hospitais do Estado. Então isso proporcionou uma saída muito grande de pessoas pra residência terapêutica”. (EC22)

"Não é só implantar a residência. Eu acho que a residência faz parte do pacote de desinstitucionalização”. (EC7)

"Não tem como obrigar o município a ter uma residência terapêutica. Ela faz uma articulação boa na hora de pactuar, nas reuniões da CIB, da CIR, que é onde tem que pactuar isso com 645 municípios. Mas não avança justamente porcausa desse preconceito. Existe um preconceito. Ninguém vai querer uma residência terapêtica”. (EE1)

"O município chega lá fala "Não'. Nós vamos abrir uma residência terapêutica." Eles meio que se esquivam. Se você pegar de 2011 até agora é muito pouco a quantidade de residências. É muito pouco". (EE4) 
"Não basta você alugar uma casinha e enfiar os caras lá. Por quê? Você tem que trabalhar com essa comunidade, você tem que trabalhar com esses trabalhadores que vão ter que assumir esse desafio". (EK14)

"São 15 residências terapêuticas aqui em São Paulo, pra abrigar esses 150 pacientes são de São Paulo. A prefeitura se comprometeu já fazer, mas não sai do papel. Eque, pra São Paulo, vocêfala. Eles falam, quando vocêfala que tem que fazer a residência terapêutica, nossa o administrador já fica, ele já dá um malestar". (EH17)

\title{
4.2.3.3 A inserção das Comunidades Terapêuticas na RAPS
}

$\mathrm{Na}$ esteira dos retrocessos na Reforma Psiquiátrica, além dos poucos recursos financeiros à manutenção efetiva das residências terapêuticas, um dos entrevistados evidencia que esse recurso está sendo destinado para comunidades terapêuticas:

"O recurso pela lei dá transparência pra comunidade terapêutica. Este recurso que sai do tesouro, ele é o recurso que poderia e deveria, a meu ver, estar implementando e ajudando a implementar a RAPS no Estado”. (EA18)

Na definição de Costa (2009, p. 2), as comunid ades terapêuticas são entendidas como,

\begin{abstract}
Instituições de atendimento ao dependente químico, não governamentais, em ambiente não hospitalar, com orientação técnica e profissional, onde o principal instrumento terapêutico é a convivência entre os residentes, surgiram no cenário brasileiro, ao longo dos últimos quarenta anos, antes mesmo de existir qualquer política pública de atenção à dependência química no país. Elas cresceram, multiplicaram-se e ocuparam espaços na medida em que inexistiram programas e projetos de caráter público que oferecessem alternativas para o atendimento às pessoas dependentes de substâncias psicoativas (SPAs), desejosas de tratamento.
\end{abstract}

As comunidades terapêuticas desenvolvem propostas de atendimento levando-se em consideração "a visão de mundo e perspectiva política, ideológica e religiosa dos diferentes grupos e instituições, governamentais e não governamentais, atuantes nesta área" (Costa, 2009, p. 2).

No entanto, o posicionamento dos entrevistados é enfático em considerar, as comunidades terapêuticas, uma forma de retorno ao sistema de internação, ainda mais as involuntárias ou compulsórias, como observamos nas frases temáticas a seguir.

"Graças a Deus, a gente tem Programa Recomeço. Porque, bem ou mal... acho certo”. (EB23) 
“Quando o Programa 'Recomeço' regula e organiza isso, a gente também não tá dando muita margem pra essas comunidades clandestinas $e$ picaretas que a gente tem por aî”. (EB24)

“O Estado oferta a comunidade que, bem ou mal, tem que tá legalmente constituída, tem fiscalização pública. Então, não que eu acredite que aquele modelo é resolutivo. Mas a gente tem o mínimo de controle em cima do que tá sendo ofertado." (EB25)

“A questão das comunidades terapêuticas que vêm reproduzindo a lógica manicomial, de um jeito muito grave, no Estado de São Paulo. E que tem um apoio grande de muitos operadores de direito. Então, che vê comunidades que, muitas vezes, são ilegais, tendo pessoas cumprindo 'ordens judicial' de internação em espaços”. (EC18)

“O Programa Recomeço, que é um programa intersetorial pra questão da dependência química e que trabalha muito diferente do que a gente costuma trabalhar com a saúde mental de uma forma geral. Então é um programa que tem a comunidade terapêutica. Mas, por um outro lado, ela exige da comunidade uma organização e uma legalidade que tira ela desse espaço clandestino que é muito pior dela estar, né?”. (EC19)

“Comunidade não pode internar ninguém. Eu já vi até ordem judicial mandando internar em comunidade. A comunidade terapêutica é um lugar que as pessoas voluntariamente resolvem morar". (ED11)

“Eu não tenho dúvida que essa questão das comunidades terapêuticas, na medida em que as pessoas ficam muito tempo lá e depois perdem, depois vem sem nenhuma referência, [?], isso aí é exclusão”. (EJ18)

"Alguém tá ganhando dinheiro com isso. E se eles forem, se eles produzirem moradores de comunidade terapêutica, os seus filhos, seus netos estarão aqui discutindo a mesma coisa, como é que a gente vai fazer pra tirar esse povo que foi internado?”. (EJ19)

"As comunidades terapêuticas, elas têm essa introdução na Rede de Atenção Psicossocial bastante discutida, bastante discutível por conta do 
desvirtuamento do equipamento desde seu início teórico que era um”. (EG4)

"Não dá para ignorar que isso tá acontecendo e, em alguns casos, com recursos públicos, tá? Então acho que a gente vai ter que pensar como é que vão ficar, como é que vai ficar essa questão de comunidade terapêtica”. (EI33)

Devemos, ainda, enfatizar que na Nota Técnica $N^{\circ} 11 / 2019$, uma das diretrizes é o aumento do financiamento público das Comunidades Terapêuticas, entidades privadas que ganham cada vez mais espaço dentro das discussões sobre as políticas públicas sobre Saúde Mental, Álcool e outras Drogas.

Os resultados da pesquisa documental e das entrevistas com os sujeitos participantes apontam que, apesar do aparato legal empreendido pela SES/SP é possível afirmar que as recomendações propostas pós-Censo Psicossocial (2008), não foram efetivamente implementadas no Estado de São Paulo, não atendendo aos princípios do processo de desinstitucionalização de pessoas com transtornos mentais internadas há longo tempo em hospitais psiquiátricos do Estado, como apresentamos no capítulo a seguir da Discussão. 


\section{DISCUSSÃO}




\section{DISCUSSÃO}

Dos resultados encontrados na análise documental, a partir da identificação e da análise das ações relatadas por documentos e das instituições pesquisadas frente às recomendações propostas pelo Censo Psicossocial (2008) de moradores em hospitais psiquiátricos do Estado de São Paulo, categorizamos de acordo com as dimensões estrutural, particular e singular intituladas sequencialmente: Categoria 01: A Política Nacional de Saúde Mental; Categoria 02: As Instituições e as Normatizações (ações) para a Desinstitucionalização no Estado de São Paulo e; Categoria 03: Os posicionamentos e ações das Instituições à Desinstitucionalização no Estado de São Paulo.

Da análise temática das entrevistas com os sujeitos participantes emergiram as três categorias: Categoria 01: A Instituição Manicomial, Categoria 02: A Desinstitucionalização no Estado de São Paulo e, Categoria 03: Redes de Atenção Psicossocial (RAPS) do Estado de São Paulo: A Desinstitucionalização, as quais possibilitaram a discussão que se segue.

Nas frases temáticas dos entrevistados é possível evidenciar que o hospital psiquiátrico é o local em que é retirada do convívio social daqueles que são considerados loucos e a eles está reservado o papel de excluídos do meio familiar. Não poucas vezes, a própria família os coloca nos hospitais psiquiátricos, por não ter condições de cuidar dos seus entes, ou então, por serem vistos como perigosos e/ou um risco às pessoas ditas "normais".

As pessoas com transtornos mentais, na sua grande maioria, são relegadas a viverem o resto de suas vidas dentro dos "depósitos de gente", denominação dada por vários personagens envolvidos na luta antimanicomial no Brasil iniciada nos idos de 1970, no combate ao sistema asilar, que usavam métodos de tratamentos cruéis e desumanos, como o tratamento com intervenções físicas, como eletrochoques e lobotomia, medicalização permanente, entre outros.

Conforme Barros e Egry (2001, p. 35),

O primeiro asilo paulista para alienados foi o Hospital Provisório de Alienados da Cidade de São Paulo, inaugurado em 1952 [...]. Nos primeiros anos, apenas nove doentes ali foram recolhidos, mas logo depois, seu administrador denunciava em seus rela tórios a superlotação, as epidemias, a alta mortalidade, as revoltas, as fuga s e a precariedade das instalações [...]" 
Se nos primeiros anos após a fundação do primeiro asilo paulista a situação dos pacientes já se caracterizava em um cenário hediondo, de superlotação, há que se olhar para os dados obtidos no Censo Psicossocial realizado em 2008. Para Barros e Bichaff (2008, p. 12),

\begin{abstract}
Esta crueldade torna-se mais dolorosa e triste quando se reveste de ciência que estaria sendo utiliza da em defesa da saúde do homem. Infelizmente, a Medicina deu uma enorme contribuição à violação do direito de pessoas que, em determinado momento de suas vidas, foram considera das como uma a meaça, já que destoa vam dos padrões sociais ou de comportamento. Em todo o mundo e no Brasil, disto resultou uma prática socialmente a ceita de retirar essas pessoas do convívio de sua s famílias e de suas comunidades. No Estado de São Paulo esta história não foi diferente. O mais grave é que muitos foram "esquecidos" nos manicômios e se tornaram um desafio para o Estado e a sociedade, de como possibilitar a essas pessoas retomarem suas vidas. É claro que esta retomada será sempre limitada pela impossibilidade de reconstrução da história e de recuperação do tempo não vivido.
\end{abstract}

É fato que as pessoas institucionalizadas em hospitais psiquiátricos vivenciaram (e vivenciam) situações injustas, desumanas, as quais, sob o signo da cura da loucura alimentaram a discriminação, o preconceito, a estigmatização e a marginalização daqueles que não se adaptavam aos padrões de normalidade impostos pela sociedade. Esta lhes impingia o isolamento, como se o transtorno mental fosse algo contagioso, indigno e até imoral, discurso que ajudava a alimentar a "indústria da loucura".

O estigma e o preconceito em relação aos pacientes ocorriam não somente na família, na comunidade, mas dentro das próprias institucionais produzindo, conforme Moscovici (2003, p. 10), representações sociais que “[...] impregnam a maioria de nossas relações estabelecidas, os objetos que nós produzimos ou consumimos e as comunicações que estabelecemos", estigmatizando-o como alguém perturbado, alienado, desajuizado, sempre trazendo inerentemente a visão negativada de sua subjetividade, que trazem em seu bojo uma visão discriminatória da loucura que a sociedade traz até a atualidade, mesmo com todo o processo de Reforma Psiquiátrica,

[...] é perceptível, também, que a loucura é uma produção social histórica, mediada em grande medida por discursos, práticas e produções de representações sobre o estado de saúde mental dos pacientes. A Reforma Psiquiátrica, partindo dessa concepção, tem como foco as intervenções e trabalhos específicos, equipes multi e interdisciplinares; e a mudança do conceito/visão de loucura e de hospitais psiquiátricos como manicômios, apontando uma melhoria na qualidade de vida e conquista ao que se refere em termos de cidadania aos pacientes psiquiátricos (RAMMINGER, 2002). Tal movimento trata-se, também, de uma produção social marcada pelas demandas atuais da saúde e sociedade em nosso tempo presente (Figueiredo, Delevati, Tavares, 2014,p. 123). 
Os entrevistados trazem a questão da cronificação das pessoas nos hospitais psiquiátricos, conceituando-os como "morredouro", como o local onde os ditos loucos "vão para morrer". Essa tendência de cronificação se dá em virtude de que o transtorno mental é visto como incurável, justificando o fato de muitos pacientes não receberem alta dos hospitais psiquiátricos.

Kinoshita (2001) faz uma profunda reflexão, a partir de suas vivências práticas pontuando que "quem não teve a experiência de entrar em um corredor de um hospital psiquiátrico e ser assediado por uma turba de pacientes pedindo qualquer coisa que pudesse lembrar, a ele e a nós, que aind a eram humanos?" [Grifo do autor] (Kinoshita, 2001, p. 84).

As pessoas com transtornos mentais, chamados de crônicos, anteriormente às políticas de desospitalização, de acordo com Kinoshita (2001, p. 70), "eram os pacientes internados" em instituições para crônicos, nesse sentido, continua afirmando, que "era o lugar de tratamento que definia o seu estatuto de crônico", e como, era o hospital psiquiátrico o único local no qual essas pessoas tinham tratamento, e, "uma internação costumava durar longo tempo, senão a vida inteira, não se buscava maiores distinções, pois havia apenas um critério para cronicidade: a hospitalização". Assim, era o longo período de permanência no hospital psiquiátrico que tornava o conceito de cronicidade um consenso. Foi a partir do movimento de desinstitucionalização que passou a se suscitar a necessidade do deslocamento no padrão e no locus de cuidado dessas pessoas.

Para tanto, são necessárias ampliações de políticas públicas que contemplem as ações que visam à promoção, prevenção e reabilitação contínua dos usuários da área de saúde mental na busca por aumentar sua autonomia social e, nesse contexto, a parceria da SES/SP, com o MPSP é fundamental.

Conforme o Código de Processo Civil Brasileiro, em seu artigo 82, incisos I e II, cabe ao Ministério Público atuar nas causas em que haja interesses de incapazes e nas que envolvam curatela e interdição, considerando-se que nos termos do artigo $3^{\circ}$, incisos II e III do Código Civil, aqueles considerados absolutamente incapazes, por enfermidade ou deficiência mental que não possuam discernimento para decisões de seus atos de vida civil ou até não puderem exprimir sua vontade por causa transitória, é totalmente proibido do exercício de direitos, o que somente será possível através de seu representante legal (representação).

No caso dos relativamente incapazes, considerados no Código Civil, em seu artigo $4^{\circ}$, incisos II a IV, "os ébrios habituais; os viciados em tóxicos; os que, por deficiência mental, tenham o discernimento reduzido; os excepcionais, sem desenvolvimento mental completo e 
os pródigos", estes podem praticar atos da vida civil, desde que assistidos pelo representante legal (assistência).

Nesse contexto jurídico, os incapazes (interditados de forma total ou parcial) têm seus direitos assegurados e protegidos pelo Estado por meio da figura do curador, que será seu representante ou o assistirá legalmente, conforme o artigo 1767 do Código Civil, tendo como dever reger a pessoa do interditado, zelando por seus interesses, provendo necessidades básicas como alimentação, saúde, defesa de seus direitos e educação, assim como lhe cabe à administração de seus bens.

Nas frases temáticas dos entrevistados e nos resultados do Censo Psicossocial (2008), constatou-se que $31,12 \%$ dos moradores dos hospitais psiquiátricos tinham um curador. É exatamente na questão das curatelas que se estabelece um grande esquema de corrupção dentro dos hospitais psiquiátricos. Quando não eram os familiares que realizavam a administração dos recursos financeiros dos pacientes, eram os diretores, funcionários ou terceiros ligados a alguém dentro do hospital que tinham a curatela de muitos pacientes, sem, no entanto, tais recursos serem destinados ao cuidado do próprio paciente.

Assim, um marco para assegurar as pessoas com transtornos mentais foi a Lei Brasileira de Inclusão das Pessoas com Deficiência (Lei Federal nº 13.146/2015), em vigor a partir de janeiro de 2016, que rompe com a condição de incapacidade absoluta antes atribuída a estas pessoas, tornando como exceção o regime de curatela e a restrição de direitos existenciais e de personalidade, como os direitos ao voto, ao casamento, à educação, ao trabalho, à adoção, à sexualidade e ao próprio corpo, conforme traz o artigo 85:

\footnotetext{
A curatela afetará tão somente os atos relacionados aos direitos de natureza patrimoniale negocial.

$\S 1^{\circ}$ A definição da curatela não a lcança o direito ao próprio corpo, à sexualidade, ao matrimônio, à privacida de, à educação, à saúde, a o trabalho e a o voto.

$\S 2^{\circ}$ A curatela constitui medida extraordinária, devendo constar da sentença as razões e motivações de sua definição, preservados os interesses do curatelado.

$\S 3^{\circ}$ No caso de pessoa em situação de institucionalização, a o nomear curador, o juiz deve dar preferência a pessoa que tenha vínculo de natureza familiar, afetiva ou comunitária com o curatelado (Brasil, 2015).
}

A curatela não permite a existência da cidadania do sujeito, o qual é menos cidadão na medida em que não tem o direito de decidir nada sobre como conduzir seus próprios desejos, tornando-se essencial após todo o processo de desospitalização a noção de que, 
Considerar que o sujeito-cidadão não seja 'curatelado', mas 'ajudado' pelos profissionais que o acompanham na gestão do próprio dinheiro, é imprescindível. Assim, urge a construção de documentos norteadores que garantam que os profissionais de saúde possam compreender a cidadania desse usuário e que orientem sobre como este pode administrar o seu dinheiro sem a necessidade de que o outro responda por sua curatela (Roza Junior, Loffredo, 2019, p. 292).

Deve haver um processo de mudanças para que as pessoas institucionalizadas em hospitais psiquiátricos possam ser reinseridas na sociedade, assegurando-lhes o exercício pleno de seus direitos enquanto cidadãos, por uma rede de assistência e cuidados, que não o excluam como acontecia atrás dos muros dos hospitais psiquiátricos.

Outros temas intrínsecos na categoria “A Instituição Manicomial” são as internações involuntárias e compulsórias das pessoas com transtornos mentais, em que ambas somente devem ocorrer em casos em que todos os recursos extra-hospitalares tenham sido esgotados, ou ainda quando existam riscos que se configurem em gravidade ou emergência, tais como de auto-agressão, de hetero-agressão, ou incapacidade grave de auto-cuidado.

$\mathrm{Na}$ análise temática das entrevistas é evidenciada a questão do "sequestro", da “emissão de laudo pelo psiquiatra”, pessoas que eram "levadas à força”, descrevendo que o processo de hospitalização involuntária muitas vezes é revestido de formas de violência velada contra esses sujeitos que são cerceados de sua dignidade enquanto um ser de escolhas, porque para eles não haviam escolhas.

Nos documentos analisados na pesquisa documental evidenciou-se que o MPSP firmou termos de cooperação técnica com a ABP e com o CRP, para apuração de fatos que possam ser configurados como violação dos direitos das pessoas com transtornos mentais, seja no plano individual ou coletivo, assim como fatos que configurem a inadequada prestação de ações e serviços de saúde mental, cabendo-lhe a obrigação de comunicar a ocorrência de qualquer violação a direitos difusos (São Paulo, 2015; 2016).

Essas ações do MPSP vão ao encontro das recomendações $n^{\circ} 7,8$ e 9 do Censo Psicossocial (2008), porém, de forma parcial, uma vez na prática, como relataram os entrevistados, a maioria das pessoas com transtornos mentais continuam com seus direitos violados, sem exercício pleno da cidadania.

Para as internações em hospitais psiquiátricos, a Lei n. 10.216/2001 que dispõe sobre a proteção e os direitos das pessoas com transtornos mentais, prevê as modalidades de internação psiquiátrica voluntária, involuntária e compulsória. Com a aplicação da Lei, é importante destacar o site destinado ao registro de internações psiquiátricas voluntárias e involuntárias ao Ministério Público pelos estabelecimentos de saúde integrantes ou não do 
SUS, denominado “Comunicação de Internação Psiquiátrica Involuntária”, que regulamenta o controle das internações psiquiátricas involuntárias (IPI) e voluntárias (IPV) pelo Ministério Público, que conforme o artigo $5^{\circ}$ da Portaria n. ${ }^{\circ}$ 2391/2002 cita,

Art. $5^{\circ}$ Estabelecer que a Comunicação de Internação Psiquiátrica Involuntária deverá ser feita, no prazo de 72 horas, às instâncias referidas no artigo anterior, observado o sigilo das informações, em formulário próprio (Termo de Comunicação de Internação Psiquiátrica Involuntária, modelo constante do Anexo desta Porta ria ), que deverá conter laudo de médico especialista pertencente ao quadro de funcionários do estabelecimento de saúde responsável pela internação (Brasil, 2002c).

O intuito do referido Termo de IPV e IPI é justamente para evitar a institucionalização das pessoas com transtornos mentais e usuários de álcool e outras drogas em qualquer estabelecimento de saúde devendo no Art. 10 da referida Portaria,

Art.10. Estabelecer que o gestor estadual do SUS constituirá uma Comissão Revisora das Internações Psiquiátricas Involuntárias, com a participação de integrante designado pelo Ministério Público Estadual, que fará o acompanhamento dessas internações, no prazo de setenta e duas horas após o recebimento da comunicação pertinente (Brasil, 2002c).

A Recomendação $n^{0} 7$ do Censo Psicossocial (2008) pontua que "há articulação do gestor estadual do SUS com o Ministério Público para a criação de Comissão Revisora de Internações Psiquiátricas Involuntárias, de acordo com a Portaria GM n. 2391/2002" (Barros, Bichaff, 2008). Diante disso, discorremos que a solicitação de informações, durante a entrevista com representante do MPSP, em relação a como se dá o funcionamento do referido Termo de IPV e IPI e sobre a Comissão Revisora de Internações Psiquiátricas Involuntárias, porém não obtivemos a informação de como ocorre esse controle de internações e altas de pessoas com transtornos mentais no Estado de São Paulo, ou seja, não constatamos a efetividade total da Recomendação n 7 do Censo Psicossocial (2008).

A internação compulsória, como destacam os entrevistados, tem sido uma prática recorrente as pessoas com transtornos mentais e principalmente, os dependentes do uso de álcool e outras drogas, sob o discurso de que o transtorno mental interfere na autonomia do indivíduo o que justifica a aplicação de pena restritiva de direito.

A Lei 13.840 publicada em Diário Oficial no dia 05 de julho de 2019 autoriza a internação em instituições de saúde "especializadas" e hospitais gerais, com o aval de um médico e prazo máximo de 90 dias, tempo considerado necessário à desintoxicação, não sendo mais obrigatória a autorização judicial para a internação compulsória de dependentes químicos, podendo ser feito pela família ou responsável legal, ou na falta destes, por servidor 
da área da saúde, assistência social ou de órgãos integrantes do Sistema Nacional de Políticas Públicas sobre Drogas (Sisnad). Também pode ocorrer internação em comunidades terapêuticas, porém, após o tempo definido na lei, o usuário deve manifestar por escrito sua vontade de ficar de forma voluntária (Brasil, 2019).

Assim, as recomendações $n^{\circ} 8$ e $n^{\circ} 9$, que propõem a articulação com as instâncias do Poder Judiciário e com o Ministério Público para a elaboração de proposições objetivando a revisão de interdições judiciais, bem como, a análise da situação de moradores de hospitais psiquiátricos do Estado de São Paulo com internação compulsória, mais uma vez não estão sendo totalmente efetivas, devido aos contextos nacional e estadual e com o aumento da judicialização na Saúde Mental, aliada a Lei 13.840 de 2019, que vai contra as políticas públicas de desinstitucionalização (Brasil, 2019).

O tema "os mortos vivos", outra problemática em relação à instituição manicomial, refere-se à falta de documentação das pessoas com transtornos mentais de longa internação em hospitais psiquiátricos no Estado de São Paulo e no Brasil. Nas frases temáticas extraídas das entrevistas, percebemos que apesar da melhora na obtenção e acesso à documentação pessoal básica realizada após o Censo Psicossocial em 2008, ainda há muitas pessoas sem quaisquer documentos como certidão de nascimento, identidade e CPF, que são indispensáveis para o exercício de qualquer direito civil, e sem os documentos, um cidadão "não existe", a pessoa é um "morto vivo" perante o Estado e a sociedade.

O Programa "De Volta para Casa", criado pela Lei Federal n 10.708 de 31 de julho de 2003, que destina uma bolsa de auxílio-reabilitação, visa contribuir para o processo de reinserção dos egressos de longa permanência do sistema manicomial. Com a documentação básica, esse sujeito pode ser beneficiado, pois,

\footnotetext{
O benefício aumenta a rede de inclusões dos portadores, garante o bem-estar integra 1 e instiga o exercício dos direitos civis, políticos e de cidadania. O benefício é depositado em conta bancária, mediante convênio entre o Ministério da Saúde e a Caixa Econômica Federal, e pode ser renovado ou não, de acordo com a necessidade do portador. "O município de residência do beneficiário deve, para habilitar-se ao Programa, ter assegurada uma estratégia de acompanhamento dos beneficiários e uma rede de atenção à saúde mental capaz de dar uma resposta efetiva às demandas de saúde mental" (Brasil, 2005, p. 17).
}

Conforme Barros e Bichaff (2008, p. 99) aprofundar-se na história dos moradores de longa permanência que não possuíam documentos, "identificadas como ignoradas" tornava-se fundamental "para reverter esse cenário que não condiz com o preconizado nas políticas públicas de saúde mental e com as diretrizes da Secretaria de Estado da Saúde”, sendo que 
Essa população de 1.312 (hum mil, trezentos e doze) moradores denominados ignorados deve ser alvo de um "Projeto Cidadania" visando à recuperação da documentação original ou à obtenção da Certidão Tardia de Nascimento, promovendo o resgate de histórias, de identidades e vínculos, e as condições para o acesso a os benefícios e a os direitos previstos na legislação.

Assim, o Projeto "Cidadania" possibilitou a recuperação da documentação original e a emissão da Certidão Tardia de Nascimento, trazendo aos ex-internos de hospitais psiquiátricos o direito de cidadania, os direitos ao acesso às políticas de proteção, seguridade social e saúde, o acesso a benefícios, o resgate de suas histórias de vida. De qualquer forma, é incontestável a necessidade de regularizar a situação documental daqueles que continuam moradores de hospitais psiquiátricos no Estado de São Paulo.

Neste contexto, trazemos a recomendação $n^{\circ} 5$, proposta pelo Censo Psicossocial (2008) que visa à recuperação da documentação original ou à obtenção da Certidão Tardia de Nascimento dos moradores denominados "ignorados", bem como propõe uma série de articulações entre as equipes dos hospitais psiquiátricos, dos articuladores de Saúde Mental dos respectivos DRS, das equipes das redes municipais de atenção psicossocial, do Ministério Público e da Ordem dos Advogados do Brasil para que as pessoas com transtornos mentais possam obter o resgate de suas histórias, identidades e vínculos e promovendo as condições para o acesso aos benefícios e aos direitos previstos na legislação, como Programa "De Volta para Casa".

As recomendações do Censo Psicossocial (2008) à desinstitucionalização foi um dos temas identificados neste estudo, pois, propõe-se um conjunto de ações estratégicas para fundamentar a condução das políticas públicas de desinstitucionalização para o resgate da cidadania e reabilitação psicossocial dessas pessoas. Concordamos com Rotelli (1990, p. 33) quando afirma que:

\footnotetext{
Desinstitucionalização é, sobretudo um trabalho terapêutico voltado para a reconstituição das pessoas, enquanto pessoas que sofrem, como sujeitos. Talvez nã o se "resolva" por hora, não se "cure" agora, no entanto, seguramente "se cuida", sendo o cuidar o se ocupar, aquie agora, de fazercom que se transformem os modos de viver e sentir o sofrimento do "paciente" e que, a mesmo tempo, se transforme sua vida concreta e cotidiana, que alimenta este sofrimento.
}

A desinstitucionalização não se restringe à redução de leitos nos hospitais psiquiátricos, mas ao desenvolvimento de serviços comunitários adequados ao atendimento das pessoas com transtornos mentais e suas famílias. Entretanto, observamos muita resistência à desinstitucionalização das pessoas com transtornos mentais de longa internação no Estado de São Paulo, mediante ao não seguimento do que foi proposto pelas recomendações do 
Censo Psicossocial (2008), principalmente por entraves políticos decorrentes das mudanças de gestões administrativas, que ora eram formadas por pessoas que comungavam dos ideais da Reforma Psiquiátrica, ora por pessoas que viam no modelo hospitalocêntrico, o caminho para a solução dos problemas (e que colocavam resistência para o processo de desinstitucionalização).

Ainda, por aqueles que não tinham como objetivo central de suas políticas públicas a atenção à Saúde Mental, visto que o posicionamento ideológico desses gestores influenciava na destinação de recursos financeiros, na participação em discussões, apoio técnico, para a construção de uma RAPS forte e atuante nos municípios, como observamos nas frases temáticas dos entrevistados, já expostas.

De acordo com Del Priore (1991),

[...] a substituição de controles sociais velhos por novos torna-se impossível quando os velhos são satisfatórios na maioria dos a spectos e, quando não se altera o foco de percepção do poder da instituição pelos clientes. Com o novo o que irá acontecer será uma nova linguagem como forma de garantia à inatividade perfeitamente ajustávela uma opção de política econômica específica (Del Priore, 1991).

Entendemos que em todos os espaços existem relações de poder e formas de dominação e opressão, lógica presente em diversos manicômios, que necessitam, muitas vezes, serem visibilizadas para poderem ser transformadas. Mesmo após a homologação da Lei Federal no 10.216, de 06 de abril de 2001 que "Dispõe sobre a proteção e os direitos das pessoas portadoras de transtornos mentais e redireciona o modelo assistencial em saúde mental", muitos são os atores que, com suas ideologias, perspectivas e práticas diferentes constituem um cenário conflitante, de enfrentamento e que conferem o principal campo das tensões na área da saúde mental e psiquiátrica no Brasil.

Em um plano geral, os conflitos referentes à questão do louco e da loucura se tornam mais evidentes entre os setores que estão localizados em campos antagônicos: os antimanicomialistas versus os manicomialistas (Lüchmann, Rodrigues, 2007).

Conforme Pitta (2011, p. 4580-1), “entre os grupos contra e a favor da Reforma, nos governos, na sociedade civil e na população em geral, o estigma contra o louco persiste e de vários modos, explícitos ou sutis", uma vez que "evidências disso são localizadas na não escuta e não credibilidade da palavra dessas pessoas, gerando uma crônica postergação de suas demandas". Como relatou um dos entrevistados, "os médicos são formados dentro dos manicômios" e muitos deles defendem a hegemonia médica no campo da atenção básica, 
tendo como pedra fundamental do tratamento das pessoas com transtornos mentais, os tratamentos biológicos e medicamentosos, em detrimento à dimensão psicossocial do cuidado.

Ao analisarmos as frases temáticas extraídas das entrevistas e compararmos com as leis, decretos e portarias e com a literatura sobre o tema, não podemos ser radicais em dizer que nada mudou, ou que não ocorreram tentativas de ações de desinstitucionalização no Estado de São Paulo, ou seja, caminhos para a desinstitucionalização.

Trinta anos do processo de Reforma Psiquiátrica Brasileira, observamos com otimismo nas frases temáticas dos entrevistados, todo esse caminho de mudanças, os avanços na transformação do modelo tradicional centrado no modelo médico e hospitalocêntrico, para o modelo de atenção psicossocial, conquistas da Reforma Psiquiátrica, conquistas da luta antimanicomial, ou seja, "nunca mais Sorocaba".

Os resultados deste estudo também apontaram a importância da implementação na prática do Plano Estadual de Saúde (PES) que é a "síntese das propostas e ações estratégicas do Governo do Estado de São Paulo na área de saúde” (Souza et al., 2008a, p. 11).

Silva et al. (2017, p. 37) afirmam que

\begin{abstract}
A fase da implementação contém a aplicação da política através do Governo. É a etapa em que se busca combinar e conciliar o tempo para a implantação da política com os recursos financeiros e humanos disponíveis para seu cumprimento. Sua implantação deve estar constantemente atendendo aos objetivos previamente estabelecidos. Ao final do processo, os resultados alcançados caracterizam o impacto da política implementada. A implementação da política pública, por sua vez, sucede a tomada de decisões e antecede o processo de avaliação. É nesta fase onde os planejamentos, regras, rotinas, métodos e processos sociais são colocados em prática.
\end{abstract}

Neste percurso, enquanto se realizava o Censo Psicossocial (2008), a SES/SP apresentou os PES para o quadriênio 2008-2011, para o quadriênio 2012-2015 e para o quadriênio 2016-2019. Todos com objetivos e metas claras para "facilitar o processo de planejamento, o entendimento e a realização de ações por parte dos agentes, órgãos técnicos e administrativos estaduais" conforme Souza et al. (2008a, p. 16) no caso da área de Saúde Mental, para a desinstitucionalização das pessoas com transtornos mentais dos hospitais psiquiátricos para o cuidado extra-hospitalar e de atenção psicossocial.

Observamos, na análise da pesquisa documental, que no PES para o quadriênio 20082011, os objetivos para o processo de Reforma Psiquiátrica foram mais profundos, visando a contemplar diversas áreas, em que tinha um espectro de políticas públicas mais abrangentes, motivado pela implementação da Lei n. 10.216/2001, pela realização do Psicossocial (2008) e observada posteriormente a realização do referido Censo, pela produção de legislação voltada 
à desinstitucionalização das pessoas com transtornos mentais e um movimento na prática das ações de Saúde Mental.

No entanto, apesar dos demais PES também apresentarem ações estratégias com objetivos semelhantes, estas ações desinstitucionalizantes da SES/SP juntamente com o COSEMS/SP foram tornando-se mais superficiais na prática, não se estabelecendo exatamente o que e quando deveriam ser efetivadas, em grande medida pelo declínio nos recursos financeiros oriundos do Ministério da Saúde que, os direcionava ao retrocesso para outras políticas públicas consideradas prioritárias no país, contra os princípios da Reforma Psiquiátrica e em muitos casos por falta de motivação ou interesse dos municípios em receber essas pessoas com transtornos mentais novamente na comunidade, também em muitos casos, por insuficiência de recursos para manter a estrutura necessária para a reinserção na comunidade, justificativa dada por gestores para a não desinstitucionalização das pessoas com transtornos mentais dos hospitais psiquiátricos no Estado.

A questão da destinação dos recursos financeiros para a desinstitucionalização é um grande entrave às políticas públicas no Estado de São Paulo, apesar de que no decorrer dos anos, diversas portarias federais foram sancionadas tendo em vista a distribuição de recursos financeiros para o fortalecimento da RAPS.

As portarias federais destinam recursos financeiros principalmente para a operacionalização da criação de CAPS e de SRT pelos municípios, tais como a Portaria n. 412, de 15 de março de 2013, que redefine as orientações para operacionalização das transferências de recursos federais aos Estados, ao Distrito Federal e aos Municípios, a serem repassados de forma automática, sob a modalidade fundo a fundo, em conta única e específica para cada bloco de financiamento de que trata a Portaria $n^{\circ}$ 204/GM/MS, de 29 de janeiro de 2007, a Portaria n. 615 de 15 de abril de 2013 que dispõe sobre o incentivo financeiro de investimento para construção de CAPS e Unidades de Acolhimento, em conformidade com a RAPS para pessoas com transtorno mental, incluindo aquelas com necessidades decorrentes do uso problemático de crack, álcool e outras drogas no âmbito do SUS, além do apoio para a criação dos SRT dado aos municípios, em que é garantido um apoio financeiro em dinheiro para que essas pessoas não retornem aos hospitais psiquiátricos, com a Bolsa do Programa Federal "De Volta Para Casa" com a Lei no 10.708, de 31 de julho de 2003 (como mencionado na discussão sobre “Os mortos-vivos") que, em muitos municípios, está em pleno vigor (Brasil, 2003, 2013a, 2013b).

Entretanto, em relação à insuficiência na distribuição de recursos financeiros para o fortalecimento da RAPS de acordo com Campos (2019, p. 2), 
Em 2015, uma revisão apontava que alguns progressos podiam ser constatados em relação à integração entre serviços e na articulação de rede. Como, por exemplo, o fato da saúde mental a presentar mecanismos de integração nas áreas macrosistêmica, meso (institucional) e micro (clínica). Apontava-se expansão da rede de atenção e novas formas de organização e de treinamento. No entanto, o sistema persistia subfinanciado e precisando de melhorias na atenção primária e nos mecanismos de avaliação. Práticas integradas relacionadas às equipes de urgência e a o apoio matricial eram avaliadas como melhoras. Assim como as experiências de supervisã o e de equipes multidisciplinares.

Para Vasconcelos (2014), nos últimos anos tem ocorrido uma grande mobilização "pelos serviços de reabilitação psicossocial onde cada usuário é inserido, de oportunidades educacionais, culturais, de trabalho, vida comunitária, sociabilidade e esporte, bem como de inserção nos serviços locais de assistência social, saúde, educação pública, etc" (Vasconcelos, 2014, p. 43), porém para a efetivação de qualidade da RAPS, os recursos financeiros destinados são insuficientes para manter as estruturas comunitárias segundo a maioria dos gestores municipais, conforme relatou um dos entrevistados.

Neste contexto, em relação a implantação e a implementação de CAPS, a partir da Portaria n. ${ }^{\circ} 3.089$, de 23 de dezembro de 2011, a quantidade de repasse financeiro do nível federal para os municípios, se tornou fixo, por tipo de CAPS. Dessa forma, de acordo com o Levantamento realizado junto aos Secretários Municipais de Saúde no período de setembro a dezembro/2018, o Estado de São Paulo tem enfrentado o problema da falta de custeio federal tanto para os CAPS, quanto para SRT (COSEMS/SP, 2019).

Conforme Silva e Vicentin (2017, p. 197),

As Residências Terapêuticas (RT) ou Serviços Residenciais Terapêuticos são casas para pessoas com transtornos mentais ou uso abusivo de álcool e outras drogas, para os quais a falta de moradia e a precariedade da rede social são questões prioritárias em seus projetos de vida. Recebem principalmente ex-internos dos hospitais psiquiátricos, posicionando-se a ssim como um dos instrumentos fundamentais para a política de redução de leitos psiquiátricos.

O Censo Psicossocial (2008) foi fundamental para o balizamento de muitas das ações desenvolvidas pela SES/SP, mesmo que, dentre as 17 recomendações apontadas pelo Grupo de Trabalho que realizou o Censo, poucas foram efetivamente implementadas em sua essência, tais como o aporte de subsídios de governo estadual para os municípios criassem os SRT, na mesma proporção ofertada pelo MS.

As recomendações $n^{\circ} 01$ e $n^{\circ} 02$ do Censo Psicossocial (2008) propõem a articulação entre os três níveis de gestão do SUS à construção do conjunto de condições sanitárias, institucionais, técnicas, econômicas, jurídicas, políticas, bem como à criação de incentivo estadual para os municípios que acolherem os moradores desinstitucionalizados, visando a 
apoiar a implementação de SRT, à efetivação da desinstitucionalização das pessoas moradores de hospitais psiquiátricos do Estado de São Paulo, o que assegura o direito, a moradia e a garantia de cuidado e de reabilitação psicossocial nas redes locais de atenção psicossocial.

Entretanto, tanto a SES/SP, quanto o COSEMS/SP não chegam a um consenso sobre a efetividade desta recomendação, comprometendo a desinstitucionalização das pessoas com transtornos mentais dos hospitais psiquiátricos. No que tange à SES/SP, o adiantamento do recurso e o valor disponibilizado aos municípios é suficiente para a desinstitucionalização dos moradores de hospitais psiquiátricos com a implantação dos SRT, porém para a maioria dos municípios, além de serem insuficientes os recursos financeiros tanto do MS, quanto da SES/SP, o tempo de adiantamento por seis meses que a SES/SP disponibilizou até que o MS faça o repasse aos municípios, não cobrem as despesas à ampliação da RAPS e assim, esse impasse reflete no lado mais fraco, o morador de hospital psiquiátrico no Estado de São Paulo, que continua abandonado, esquecido, sem expectativas de liberdade para a cidadania e a sua consequente Reabilitação Psicossocial.

Estes impasses entre a SES/SP e o COSEMS/SP avançam para o retrocesso nas ações de desinstitucionalização, e assim, concordamos com Barros (1998), em consonância com as ideias de Rotelli, ao afirmar que: "é necessário desconstruir não apenas as instituições manicomiais, mas também as ideias, as noções e os preconceitos que as acompanham e modelam, e que são parte do imaginário mesmo daqueles que, conscientemente, desejam destruí-la” (Barros, 1998, p. 191).

É fato também que o número de internações vem aumentando, ao revés do ideal do processo de desinstitucionalização. Esse cenário é fortalecido pelo aumento, em 2018 do financiamento de hospitais psiquiátricos, sem reajuste dos valores para os CAPS, que foram congelados por 20 anos com a aprovação da PEC 241/16 e a Emenda Constitucional 95 que congelou os recursos destinados à saúde e à educação (Brasil, 2016b).

Um sinal de retrocesso no processo de desinstitucionalização se refere à falta de leitos para internação de casos agudos na visão dos gestores municipais. Conforme dados da Reunião do COSEMS/SP (2019), em que cerca de 40\% das AIHs em Saúde Mental são relativas a internações de longa permanência e aproximadamente $70 \%$ dos leitos estão em hospitais psiquiátricos de grande porte, reafirmando a tendência observada por nossos entrevistados de que o modelo de Saúde Mental ainda é centrado no modelo hospitalocêntrico, o que compromete o processo de desinstitucionalização no Estado de São Paulo (COSEMS/SP, 2019). 
Entretanto, aqui podemos apontar um grande retrocesso que marca esse processo de desinstitucionalização no ano de 2019, que traz o redirecionamento dos recursos orçamentários para os hospitais psiquiátricos, que voltam a fazer parte da RAPS, tendência já advinda do Governo Temer, decisão tomada sem a participação social dos movimentos da “Luta Antimanicomial” e sem a aprovação do Conselho Nacional de Saúde, agravando esse cenário ainda, com a inclusão de leitos para crianças e adolescentes, o que fere o Estatuto da Criança e do Adolescente, instrumento que garante os direitos dessa população (Brasil, 2019).

O COSEMS/SP então traz como propostas para a SES/SP, visando melhorar a situação da Saúde Mental no Estado de São Paulo, com o apoio do CONASEMS,

\begin{abstract}
Cobrar do MS o custeio de SRT e CAPS e reajuste para acelerar o processo de desinstitucionalização das pessoas com transtornos mentais de longa internação; pactuar com a SES/SP cofinanciamento permanente para CAPS e SRT (além dos 6 meses) com recursos estaduais; pactuar junto à SES/SP a ampliação de leitos de Saúde Mental em Hospitais de Gerais de Gestão Estadual; solicitar à SES/SP as informações sobre as ações judicia is obtidas junto à Central de Regulação de Of erta de Serviços de Saúde (CROSS/SP) e; pactuar a regularização do abastecimento dos medicamentos da Rede de Saúde Mental(COSEMS/SP, 2019).
\end{abstract}

Entretanto, tais reivindicações, talvez se tornem inviáveis, pois, com a proposta pelo Governo Federal da Nova Política Nacional de Saúde Mental e nas Diretrizes da Política Nacional sobre Drogas, explicada pela Nota Técnica $N^{\circ} 11 / 2019$, publicada em 02 de setembro de 2019, marca um ponto de ruptura com todo o processo de desinstitucionalização, com todos os avanços da Reforma Psiquiátrica e da luta antimanicomial, colocando todo o modelo de atenção psicossocial em xeque, na medida em que destina maiores recursos financeiros aos hospitais psiquiátricos, defende a internação compulsória e as comunidades terapêuticas e o uso de eletroconvulsoterapia como alternativa de tratamento para as pessoas com transtornos mentais.

A Lei 10.216/2001, que estabeleceu um redirecionamento no modelo assistencial em Saúde Mental, traz que são direitos da pessoa com transtorno mental, em seu artigo $2^{\circ}$, parágrafo único, incisos VIII e IX, "ser tratada em ambiente terapêutico pelos meios menos invasivos possíveis" e "ser tratada, preferencialmente, em serviços comunitários de saúde mental", sendo que, conforme o seu artigo $4^{\circ}$, só é indicada a internação do paciente, no caso dos recursos extra-hospitalares serem insuficientes, sendo que o serviço de internação deverá ser estruturado para oferecer assistência integral, com serviços médicos, de assistência social, psicológicos, ocupacionais, de lazer e outros. 
Entretanto, durante muito tempo, observamos um movimento de mercantilização do tratamento de saúde, em que o sujeito é transformado em mercadoria e a doença em fonte de lucro para o setor privado, o que estimula a perpetuação dos hospitais psiquiátricos.

Observamos que o Ministério Público é o responsável pela fiscalização das internações compulsórias, além de realizar vistorias nos hospitais psiquiátricos. Posteriormente à Lei n. 10.216/2001, o cenário de maus tratos, torturas, atrocidades diversas nos hospitais psiquiátricos, quando os "loucos" eram submetidos a condições sub-humanas, ainda se constata novas internações e novos moradores, e surgem novos questionamentos, entre eles: Por que levou anos para que o Ministério Público atuasse na DRS de Sorocaba? O mesmo perguntamos em relação ao CES/SPe Defensoria Pública.

Após muitas denúncias e ampla divulgação da mídia sobre as atrocidades ocorridas nos manicômios na DRS de Sorocaba, O MPSP interviu de forma radical, articulando com a SES/SP, COSEMS/SP, CES/SP e Defensoria Pública, a elaboração e assinatura do TAC (2012) que iniciou o processo de desinstitucionalização dos moradores de longa permanência e o fechamento dos manicômios na região de Sorocaba, que se configurava como a região de maior concentração de pessoas com transtornos mentais hospitalizadas, com cerca de 4.000 pacientes (São Paulo, 2012).

Ainda Duarte (2018, p. 21) faz um depoimento sobre sua experiência enquanto participante do processo de luta contra o que acontecia nos hospitais psiquiátricos da região de Sorocaba.

\footnotetext{
Não posso deixar de lembrar a importância e representatividade do movimento social antimanicomial na mudança de paradigma que não se deu por leis e normativas, mas sim por agentes sociais que problematizaram as práticas psiquiátricas e a desassistência promovida no âmbito dessas instituições asilares. Assim, dentre os - títulos possíveis para eu me apresentar, o de militante da luta antimanicomial me afeta e é motivo de muito orgulho, pois exige, tal qual a luta pelos direitos humanos, conquistar essa condição diariamente, empenhando-me numa prática política concreta de cuidado ao sujeito excluído e vítima de uma estrutura perversa da indústria da loucura.
}

O TAC e todo o processo de fechamento dos hospitais psiquiátricos na DRS de Sorocaba foram resultados da participação de vários segmentos da sociedade nas discussões para livrar aquelas pessoas dos sofrimentos que lhes eram impostos, da desumanização pela qual passavam. Qualquer ação implementada pela SES/SP, só torna-se possível, com a articulação com o MPSP, o COSEMS/SP, a CES/SP, a Defensoria Pública e toda a sociedade. Para tanto, os entrevistados destacam em suas frases temáticas suas crenças de que tudo só se 
torna possível através da participação, da criação de conselhos, da composição de grupos condutores, de comissões especializadas e da participação popular.

Constatamos, assim, que por meio do TAC, houve o fechamento do maior polo manicomial do País, na DRS de Sorocaba, decorrente da articulação entre todos os órgãos responsáveis já nominados acima, porém esta articulação deu-se somente por pressão dos grupos de luta antimanicomial, deflagrada por reportagem em âmbito nacional que mostrou as atrocidades cometidas nos hospitais psiquiátricos da região de Sorocaba.

Esta discussão permeia todas as recomendações propostas pelo Censo Psicossocial (2008), mas principalmente as recomendações $n^{\circ} 3, n^{\circ} 4$ e $n^{\circ} 5$, em relação à Política Nacional de Saúde Mental em contraponto as novas legislações que o Governo Federal tem imposto, que reflete nas demais recomendações do referido Censo, pois prejudica a articulação de todos os atores sociais responsáveis pela execução e controle das políticas públicas desinstitucionalizantes de direitos, cidadania e Reabilitação Psicossocial.

Assim, as recomendações propostas pelo Censo Psicossocial (2008) apresentam cada uma, estratégias à desinstitucionalização das pessoas com transtornos mentais há muito tempo internadas em hospitais psiquiátricos no Estado de São Paulo, e neste cenário o SRT é o equipamento assistencial ideal juntamente com o CAPS, como os principais dispositivos da RAPS, para que os sujeitos com transtornos mentais tornem-se protagonistas de sua história, de terem um lar, do seu direito de ir e vir.

O avanço da Reforma Psiquiátrica Brasileira depende de muitos fatores, principalmente da vontade política no Governo Federal, dos Estados e dos municípios. Dessa maneira, com a Reforma Psiquiátrica e a Política Nacional de Saúde Mental foram criados vários equipamentos assistenciais mantidos pelas esferas tripartite e bipartite, serviços substitutivos em Saúde Mental, como hospital-dia, CAPS, entre outros e principalmente, o repasse de recursos federais para que os municípios implantassem os serviços residenciais terapêuticos (SRT), cuja prioridade é receber os usuários que foram moradores desses hospitais. Ainda conforme cita a Lei $n^{\circ} 10.216 / 2001$,

Art. 5: O paciente há longo tempo hospitalizado ou para o qual se caracterize situação de grave dependência institucional, decorrente de seu quadro clínico ou de ausência de suporte social, será objeto de política específica de alta planejada e reabilitação psicossocial assistida, sob responsabilidade da autoridade sanitária competente e supervisão de instância a ser definida pelo Poder Executivo, assegurada a continuidade do tratamento, quando necessário.

Instituídos por meio da Portaria no 106/2000 do Ministério da Saúde, os Serviços Residenciais Terapêuticos (SRT) têm como objetivo, de acordo com França et al. (2017), 
“contribuir para a redução dos leitos em hospitais psiquiátricos ocupados pelos 'moradores do hospital' que, apesar de terem o perfil clínico para residir na comunidade, apresentavam laços familiares e sociais comprometidos ou mesmo rompidos por decorrência da associação perversa entre o transtorno mental e longos anos de reclusão e distanciamento dos seus pares".

De acordo com o Ministério da Saúde (2004):

O Serviço Residencial Terapêutico (SRT) - ou residência terapêutica ou simplesmente "mora dia" - são ca sas localiza das no espaço urbano, constituídas para responder às necessidades de mora dia de pessoas portadoras de transtornos m en tais graves, institucionalizadas ou não (Brasil, 2004, p. 6).

As pessoas em geral não gostam do impacto negativo que sentem ao ver em documentários, os hospitais psiquiátricos tão diferente do modelo idealizado pela sociedade que para Roza Junior e Loffredo (2018) é,

\begin{abstract}
Um hospital limpo, com comida de qualidade, colchões para dormir, cadeiras para se sentar, equipe disponível 24 horas por dia, pronta para o 'cuidado'. Para uma grande parcela da população, a não violência seria um hospital isolado, mas de qualidade. Poucos reconhecem que a existência do hospital psiquiátrico - um lugar de onde o louco jamais poderia sair - já é violenta por si.
\end{abstract}

Saraceno (2001) considera que a reabilitação psicossocial é o princípio norteador da atuação dos CAPS e dos SRT após o processo de desinstitucionalização das pessoas com transtornos mentais dos hospitais psiquiátricos, que, para Goldberg (2001, p. 34) configura-se como um "processo articulado de práticas (sustentadas por uma trama de conceitos), que não se deteria até que a pessoa acometida por problemas mentais pudesse sedimentar uma relação mais autônoma com a instituição".

Os entrevistados evidenciam a importância dos SRT, entretanto, destacam a falta da ampliação no número de residências, além do apoio da gestão municipal (e em todas as esferas que devem rever a política de repasse de recursos financeiros), e, principalmente, da sociedade que precisa mudar a visão de segregação social que tem das pessoas com transtornos mentais, pois,

Por que queremos esta desinstitucionalização? Porque, a nosso ver, o objeto da Psiquiatria não pode nem deve ser a periculosidade ou a doença (entendida como algo que está no corpo ou no psiquismo de uma pessoa). Para nós, o objeto sempre foi a "existência-sofrimento dos pacientes e sua relação com o corpo social". O mal obscuro da Psiquiatria está em haver constituído instituições sobre a separação de um objeto fictício - a doença - da existência global, complexa e concreta do paciente e do corpo da sociedade (Rotelli, 1990, p. 88). 
Os resultados da pesquisa documental e das entrevistas apontam que a Dimensão Estrutural intitulada “A Política Nacional de Saúde Mental”, reflete o contexto econômico, político e social para a Cidadania, Direitos e Reabilitação Psicossocial das pessoas com transtornos mentais e caracteriza-se como o norte para que Estados e municípios implantem e implementem as políticas públicas desinstitucionalizantes.

Na Dimensão Particular, em que as práticas e ideologias em saúde ocorrem conforme a TIPESC (Egry, 1996), ou seja, as ações que a SES/SP e demais instituições realizam para a desinstitucionalização das pessoas de longa internação, mostram, nos resultados, diversas normatizações, notas técnicas conjuntas entre os órgãos responsáveis deste estudo, termos de cooperação técnica para garantir que não ocorra a violação dos direitos humanos das pessoas com transtornos mentais em hospitais psiquiátricos, TAC que com a articulação entre as instituições possibilita o fechamento de hospitais psiquiátricos no Estado e o encaminhamento das pessoas com transtornos mentais para os SRT, a destinação de recursos financeiros para efetivar a implantação dos SRT nos municípios e todas as orientações necessárias para a desinstitucionalização destes sujeitos de longa internação a serem realizadas pelos hospitais psiquiátricos.

Ainda na dimensão particular, intitulada "As Instituições e as Normatizações (ações) para a Desinstitucionalização no Estado de São Paulo", após a realização do Censo Psicossocial (2008), os objetivos e metas dos PES/SP desde o quadriênio 2008-2011 até os dias atuais, estabelece que as ações devem ser realizadas pelos órgãos responsáveis pela formulação, execução e controle das políticas públicas de Saúde Mental, conforme o que está posto pela Política Nacional de Saúde Mental, que tem como finalidade consolidar um modelo de atenção aberto e de base comunitária (Brasil, 2001, 2011, 2014).

A proposta da Reforma Psiquiátrica Brasileira é garantir a livre circulação das pessoas com transtornos mentais pelos serviços, pela comunidade e pela cidade, ou seja, dar as pessoas com transtornos mentais, os mesmos direitos de qualquer outro cidadão brasileiro, promovendo a cidadania, o exercício dos direitos e a Reabilitação Psicossocial das pessoas com transtornos mentais, corroborando com Saraceno (1999, p. 18), em que "a cidadania do paciente da Saúde Mental não é a simples restituição de seus direitos formais, mas a construção de seus direitos substanciais, e é dentro de tal construção (afetiva, relacional, material, habitacional, produtiva) que se encontra a Reabilitação possível”.

O fortalecimento da RAPS se faz imprescindível à efetivação do processo de desinstitucionalização das pessoas com transtornos mentais dos hospitais psiquiátricos no Estado de São Paulo, o que foi verificado nas documentações que orientam para 
desinstitucionalização a serem realizadas pelos hospitais psiquiátricos/especializados em psiquiatria no Estado de São Paulo (São Paulo, 2017c), no TAC entre o MPSP, a SES/SP, às Prefeituras Municipais de Sorocaba, Salto de Pirapora e Piedade (São Paulo, 2012), com a criação do GT RAPS (COSEMS/sd) e com as orientações do COSEMS/SP sobre a implantação de residências terapêuticas no Estado de São Paulo (COSEMS/SP, 2017b). Esses documentos, discutidos no decorrer deste capítulo, demonstram que com a articulação dos órgãos responsáveis pela formulação, execução e controle da Política Pública Estadual, as recomendações do Censo Psicossocial (2008) podem ser efetivas na sua totalidade.

Por fim, a Dimensão Singular intitulada: “Os posicionamentos e ações das Instituições para a Desinstitucionalização no Estado de São Paulo", foi identificada nas frases temáticas dos entrevistados com as posições que assumem e em suas ações para a efetividade da política estadual de Saúde Mental relacionadas aos direitos, à cidadania e à reabilitação psicossocial dos sujeitos com transtornos mentais, verificadas nas Categorias Empíricas desta pesquisa.

Apesar de todas as conquistas advindas do processo da Reforma Psiquiátrica, com a implantação e implementação da RAPS, que mesmo sem recursos suficientes para sua estruturação e fortalecimento ainda resiste, mais uma vez nos deparamos na esteira dos retrocessos na Reforma Psiquiátrica, com um novo dispositivo da RAPS que foi inserido ao longo dos anos, as comunidades terapêuticas, que no nosso entendimento, são a nova configuração dos manicômios, pois,

\footnotetext{
Elas têm a mesma lógica dos manicômios, de tirar o sujeito de circulação e segregálo, afastá-lo das relações sociais. Isso vai contra tudo o que se pensou para a saúde mental, porque compreendemos que aquele que sofre psiquicamente, ele precisa estar nas suas relações sociais porque a sua diferença não impede de estar trabalhando, fazendo suas atividades, trocando com sés familiares. Além disso, vivemos num estado laico, e essas comunidades na sua maioria têm viés religioso, sem o cuidado com saúde, e se oferece o culto em busca da cura. Se isso não for a barbárie, é pelo menos uma vergonha. Isso não sói vai contra os princípios da Reforma Psiquiátrica, mas a té da Constituição bra sileira, já que vivemos num estado laico de direito (Antunes, 2014,p. 1).
}

Com a Nova Política de Saúde Mental, devemos enfatizar que na Nota Técnica ${ }^{\circ}$ 11/2019, uma das diretrizes é o aumento do financiamento público das comunidades terapêuticas, entidades privadas que ganham cada vez mais espaço dentro das discussões sobre as políticas públicas de Saúde Mental e de Álcool e outras Drogas (Brasil, 2019b).

Logo, corroboramos com Amarante (1995) ao pontuar que "esses serviços seguem uma lógica de mais admissões, mais tempo de internação e menos recursos técnicos e medicamentosos, visando a manter a lucratividade, o que explica o termo "indústria da 
loucura", uma semelhança do que é o conceito de hospital psiquiátrico para o referido autor e que hoje retorna na mesma perspectiva com as comunidades terapêuticas. Também concordamos com Goffman (1987) que considera a instituição total [...] como um local de residência e trabalho onde um grande número de indivíduos com situação semelhante, separados da sociedade mais ampla por considerável período de tempo, levam uma vida fechada e formalmente administrada (Goffman, 1987, p. 11).

Entendemos que as comunidades terapêuticas são um triste destino para as pessoas com transtornos mentais, que ainda tem chances de vivenciarem a liberdade, o respeito, a dignidade e a cidadania e que só com uma RAPS estruturada, com os legítimos serviços extrahospitalares propostos pela Reforma Psiquiátrica, entre eles, os CAPS e os SRT, que são as chaves que podem trancam os manicômios de vez, para nunca mais o horror ocorrido nos manicômios de Sorocaba existir.

Após a apresentação dos resultados e da discussão das fontes de pesquisa, a partir da identificação e da análise das ações relatadas por documentos e entrevistados frente às recomendações propostas pelo Censo Psicossocial (2008) de moradores em hospitais psiquiátricos do Estado de São Paulo, categorizamos de acordo com as dimensões estrutural, particular e singular intituladas sequencialmente: A Política Nacional de Saúde Mental; Os Sujeitos Participantes e suas normatizações (ações) para a Desinstitucionalização no Estado de São Paulo e; Categoria 03: Os posicionamentos e ações das Instituições para a Desinstitucionalização no Estado de São Paulo, conforme apresentamos no quadro a seguir: 
Quadro 4 - Quadro demonstrativo da análise das ações relatadas por documentos e entrevistados frente às recomendações propostas pelo Censo Psicossocial (2008) de moradores em hospitais psiquiátricos do Estado de São Paulo

\begin{tabular}{|c|c|}
\hline $\begin{array}{l}\text { CATEGORIAS } \\
\text { TEMÁTICAS }\end{array}$ & RESULTADOS \\
\hline \multirow[t]{2}{*}{$\begin{array}{l}\text { A Política Nacional de } \\
\text { Saúde Mental }\end{array}$} & 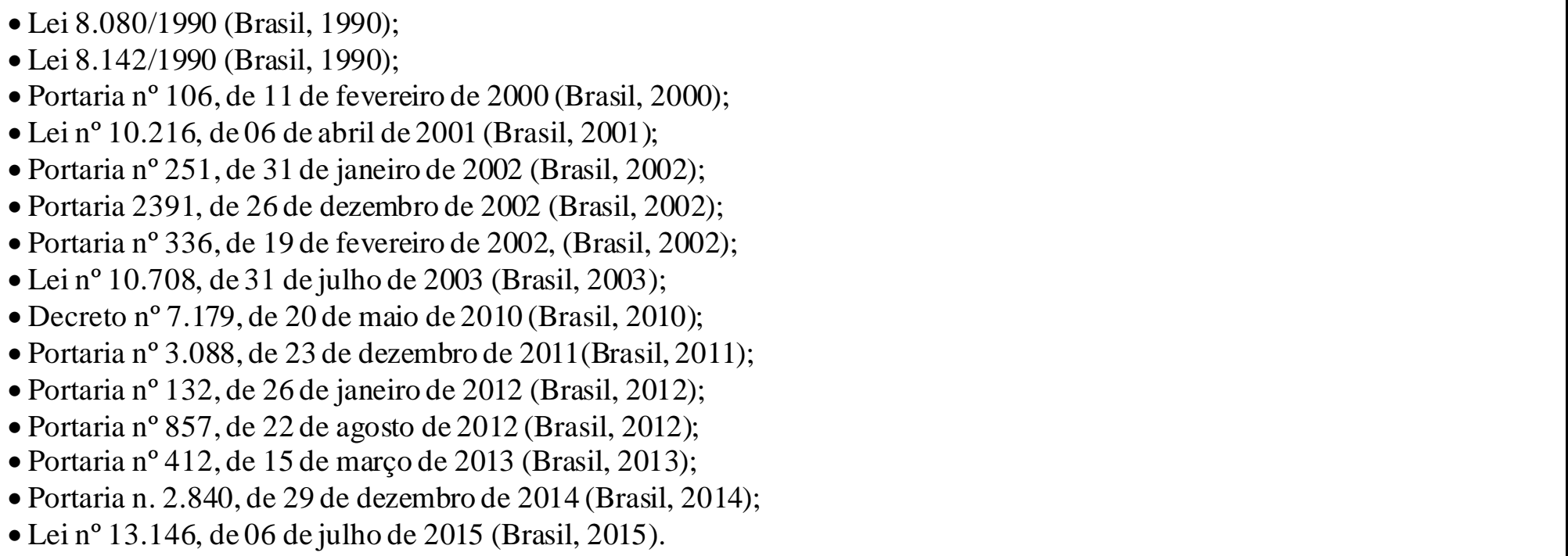 \\
\hline & $\begin{array}{l}\text { SES/SP } \\
\text { - Censo Psicossocial (2008) (Barros, Bichaff, 2008); } \\
\text { - Censo Psicossocial (2014) (Cayres et al., 2015); } \\
\text { - Planos Estaduais de Saúde (PES) 2008-2011; 2012-2015, 2016-2019; } \\
\text { - Resolução SS nº 294, de 29 de agosto de 2007 (São Paulo, 2017b); } \\
\text { - Resolução SS no 181, de } 10 \text { de dezembro de 2009; Resolução SS no 81, de } 21 \text { de junho de } 2010 \text { (Versão Republicada); } \\
\text { Resolução SS no 251, de 27 de dezembro de 2010; Resolução SS no 22, de 20 de março de 2012 (São Paulo, 2009, 2010, 2012); } \\
\text { - Nota técnica - Orientações para desinstitucionalização a serem realizadas pelos hospitais psiquiátricos/especializados em } \\
\text { psiquiatria no Estado de São Paulo (São Paulo, 2017, s/d); } \\
\text { - Deliberação CIB 87 de 03 de dezembro de 2012. (São Paulo, 2012); } \\
\text { - Nota Técnica Conjunta entre a Assessoria Técnica de Saúde Mental, Coordenadoria de Serviços de Saúde, Coordenadoria das } \\
\text { Regiões de Saúde e a Coordenadoria de Gestão Orçamentária e Financeira - Orientações para Desinstitucionalização a serem }\end{array}$ \\
\hline
\end{tabular}




\begin{tabular}{|c|c|}
\hline \multirow{3}{*}{$\begin{array}{c}\text { As Instituições e as } \\
\text { Normatizações (ações) } \\
\text { para a } \\
\text { Desintitucionalização no } \\
\text { Estado de São Paulo }\end{array}$} & $\begin{array}{l}\text { realizadas pelos hospitais psiquiátricos/ especializados em psiquiatria no Estado de São Paulo (São Paulo, 2017c). } \\
\text { - Plano de Ação das RAPS aprovadas em CIB (São Paulo, s/d); } \\
\text { • Portaria nº } 1.727 \text {, de } 24 \text { de novembro de } 2016 \text { (São Paulo, 2016). }\end{array}$ \\
\hline & $\begin{array}{l}\text { COSEMS/SP } \\
\text { - GT RAPS - Grupo Condutor Estadual da Rede de Atenção Psicossocial (COSEMS/sd); } \\
\text { - Redes Regionais de Atenção Psicossocial - Documento Norteador COSEMS/SP (COSEMS/SP, 2017a); } \\
\text { - Redes de Atenção Psicossocial (RAPS) Orientações do COSEMS/SP sobre a implantação de residências terapêuticas no Estado } \\
\text { de São Paulo (COSEMS/SP, 2017b). } \\
\text { - Carta de São Paulo (COSEMS/SP, 2016). }\end{array}$ \\
\hline & $\begin{array}{l}\text { MPSP } \\
\text { - Controle de notificação das internações psiquiátricas voluntárias e involuntárias (IPVI), para controle e acompanhamento destas } \\
\text { até a alta do paciente" (Brasil, 2002c); } \\
\text { - Termo de Cooperação Técnica no 002/2014 com a SES/SP (São Paulo, 2014); } \\
\text { - Termo de Cooperação Técnica N. }{ }^{\circ} \text { 017/2015 entre MPSP e Associação Brasileira de Psiquiatria (ABP) (São Paulo, 2015); } \\
\text { - Termo de Cooperação Técnica N. }{ }^{\circ} \text { 10/2016 entre MPSP e Conselho Regional de Psicologia (CRP/SP) } \\
\text { - Termo de Ajustamento de Conduta de Sorocaba (TAC) entre o MPSP, a SES/SP, às Prefeituras Municipais de Sorocaba, Salto de } \\
\text { Pirapora e Piedade (São Paulo, 2012). }\end{array}$ \\
\hline $\begin{array}{l}\text { Os posicionamentos e ações } \\
\text { das Instituições para a } \\
\text { Desinstitucionalização no } \\
\text { Estado de São Paulo }\end{array}$ & - Entrevistas dos sujeitos participantes deste estudo: Categorias Empíricas - p. 81 a p. 106 deste estudo. \\
\hline
\end{tabular}

Fonte: A pesquisadora. 
Diante do panorama apresentado acima, podemos verificar que as recomendações do $1^{\circ}$ Censo Psicossocial de 2008, foram parcialmente atendidas pela SES/SP, COSEMS/SP e MPSP, exceto as sob $n^{\circ} 13, n^{\circ} 14, n^{\circ} 15$ e $n^{\circ} 16$, nas quais não foram encontradas documentações relacionadas às referidas recomendações nas instituições pesquisadas, além de que estas recomendações não foram abordadas pelos sujeitos participantes durante as entrevistas, o que sinaliza possível desconhecimento ou, até mesmo, resistência em relação à adoção das recomendações do Censo Psicossocial (2008) por parte destes órgãos responsáveis.

Diante disso, verificam-se contradições que desvelam as restrições relacionadas à implementação das recomendações em questão neste estudo, dentre elas: aumenta-se o número de SRT, porém são insuficientes para abrigar, em meio à sociedade, todos os moradores dos hospitais psiquiátricos; outro problema é a insuficiência de número de CAPS no Estado, pois sabe-se que há a necessidade de ampliação para se adequar a Portaria $n^{\circ}$ 336/2002 e isso é constatado com a irregular taxa de concentração dos CAPS entre as diferentes regiões de saúde do Estado de São Paulo, sendo as regiões pobres as mais prejudicadas neste sentido; o financiamento desigual e em desacordo com as diretrizes do SUS entre as três esferas do poder, o que prejudica a equidade entre as regiões com criação de convênios ou implantação de serviços substitutivos aos hospitais psiquiátricos; e, por último e mais grave, o aumento do número de pessoas em instituições asilares e, ao mesmo tempo, o não acompanhamento que discrimine as reinternações ou as novas internações por parte dos órgãos responsáveis.

Assim, nesta pesquisa, percebemos a tímida contribuição do CES/SP e da Defensoria Pública do Estado para a deliberação e construção de estratégias, controle da execução da política de saúde e defesa dos direitos das pessoas com transtornos mentais para a desinstitucionalização, evidenciando que há muito que se fazer para ir ao encontro das finalidades da Política Nacional de Saúde Mental, no que tange à Reabilitação Psicossocial por meio do exercício pleno da Cidadania e da Inclusão Social destes sujeitos no Estado de São Paulo, visto que o modelo psiquiátrico ainda rege as concepções de muitas pessoas da sociedade, inclusive de políticos e juristas, prejudicando a implementação das estratégias de desinstitucionalização da RAPS no Estad o de São Paulo. 
6 LIMITACÕES DO ESTUDO 


\section{LIMITAÇÕESDO ESTUDO}

A primeira limitação deste estudo se refere à coleta de dados, tanto da pesquisa documental, quanto das entrevistas com os sujeitos participantes, realizadas no início do ano de 2018, em uma época de transição política e de mudanças de políticas sociais, hoje imposta pelo Governo Federal, que devem nortear as políticas públicas de saúde estaduais e municipais, que apontam para um retrocesso nos rumos de todo o processo de desinstitucionalização no Brasil.

Mesmo assim, alguns dos entrevistados já apontavam para esse cenário de mudanças retrógradas, mesmo que outros trouxessem o discurso de que os avanços na desinstitucionalização seriam irreversíveis. Entretanto, vemos um gradual abandono no modelo psicossocial para o retorno ao modelo asilar por parte da grande maioria dos gestores.

A segunda limitação se refere à dificuldade de acesso na página da SES/SP, que apresenta dados desatualizados, faltantes e /ou insuficientes que identifiquem e caracterizem dados sociodemográficos e clínicos das pessoas com transtornos mentais, a inexistência de informações atualizadas dos serviços da RAPS, ou seja, a transparência necessária para os que acessam a referida página, já que trata-se da Secretaria de Estado da Saúde de São Paulo a responsável pela formulação da Política Estadual de Saúde Mental.

Apesar destas limitações, esta pesquisa buscou contribuir para produção de informações que possam desencadear o debate e fomentar a discussão, acerca da revisão das políticas públicas desinstitucionalizantes de Saúde Mental no Estado de São Paulo, alcançando os objetivos a ela elencados. 


\section{CONSIDERACÕES FINAIS}




\section{CONSIDERAÇÕES FINAIS}

Este estudo objetivou analisar as políticas públicas de Saúde Mental relacionadas aos direitos, à cidadania e à reabilitação psicossocial dos sujeitos com transtornos mentais, derivadas do conjunto de recomendações propostas na obra resultante do Censo Psicossocial dos moradores em hospitais psiquiátricos (2008), com vistas a contribuir com a (re)formulação das políticas públicas de direitos e cidadania e reabilitação psicossocial.

Para tanto, realizamos a pesquisa documental e as entrevistas semi estruturadas com os atores sociais responsáveis pela formulação, execução e fiscalização destas políticas públicas no Estado, para identificar as ações propostas e implementadas pelas SES/SP e para caracterizar e analisar as políticas públicas de desinstitucionalização das pessoas com transtornos mentais de longa internação.

Os principais participantes deste estudo foram: a SES/SP e, no decorrer da pesquisa, consideramos, também, o COSEMS/SP e o MPSP, com igual responsabilidade pelas ações de Saúde Mental efetivadas no Estado que foram apresentad as nos Resultados e discutidas após a análise temática dos documentos e das entrevistas realizadas com os sujeitos participantes.

Com a realização das análises, as categorias temáticas identificadas na Pesquisa Documental foram: Categoria 01: A Política Nacional de Saúde Mental; Categoria 02: As Instituições e Normatizações (ações) para a Desinstitucionalização no Estado de São Paulo e; Categoria 03: Os posicionamentos e ações das Instituições para a Desinstitucionalização no Estado de São Paulo.

$\mathrm{Na}$ análise temática das entrevistas emergiram três categorias empíricas: Categoria 01 - A Instituição Manicomial na qual discutimos os temas: O conceito de Hospital Psiquiátrico; A Curatela; As Internações Involuntárias; As Internações Compulsórias e; Os mortos vivos; a Categoria 02 - A Desinstitucionalização no Estado de São Paulo, oportunizando a discussão das temáticas: As Recomendações do Censo Psicossocial (2008) para a Desinstitucionalização; Resistência à Desinstitucionalização; Caminhos para Desinstitucionalização; O Planejamento das Políticas Públicas; Destinação de Recursos Financeiros para Desinstitucionalização; Retrocesso para Desinstitucionalização; Ações do Ministério Público e, a Categoria 03 - Redes de Atenção Psicossocial (RAPS) do Estado de São Paulo: A Desinstitucionalização na qual discutimos as temáticas: As necessidades da 
RAPS; Os Serviços Residenciais Terapêuticos para a Desinstitucionalização e; A inserção das Comunidades Terapêuticas na RAPS.

Constatamos, neste estudo, que, há mais de uma década após a realização do $1^{\circ}$ Censo Psicossocial (2008) sistematizado e publicado no livro "Desafios para a desinstitucionalização: Censo Psicossocial dos moradores em hospitais psiquiátricos do Estado de São Paulo" (Barros, Bichaff, 2008), o cenário pouco mudou e o processo de desinstitucionalização das pessoas com transtornos mentais de longa internação se estagnou após 2014, refletindo a situação e a ideologia política do Governo Federal e do Governo Estadual paulista e evidenciado pela transição do conteúdo das publicações de leis e decretos de âmbitos nacional e estadual, bem como a diminuição do quantitativo de propostas no decorrer dos anos.

A Política Nacional de Saúde Mental determina a desinstitucionalização das pessoas com transtornos mentais de longa internação à Reabilitação Psicossocial e à cidadania de acordo com os princípios da Reforma Psiquiátrica há mais de trinta anos em processo no Brasil e a Lei 10.216 de 06 de abril de 2001.

A documentação em relação às políticas públicas desinstitucionalizantes, apresentada neste estudo, demonstrou que isso é possível, porém os resultados apontaram articulações enfraquecidas na prática, em que as recomendações do Censo Psicossocial (2008) foram parcialmente efetivadas, segundo os sujeitos participantes deste estudo, em grande parte por dificuldades em relação ao repasse de recursos financeiros que são insuficientes à implantação de SRT nos municípios, sabendo, no entanto, que, de acordo com os entrevistados, não se trata só de destinação de recursos para que a desinstitucionalização ocorra, mas de toda uma mobilização por parte destes atores sociais e de políticas governamentais efetivas à consecução das recomendações propostas pelo Censo Psicossocial (2008).

Entendemos que há dificuldades para a implantação de SRT pelos gestores municipais e gestor estadual, mas há possibilidades, comprovado com a publicação de documentos importantes advindos da articulação entre estes gestores, o MPSP e a Defensoria Pública, como o TAC que possibilitou o fechamento do maior polo manicomial do Estado, tendo em vista que as pessoas com transtornos mentais institucionalizadas nos hospitais psiquiátricos e que não têm familiares que possam assisti-las, contam com as ações destes gestores, para que possam ser reincluídas na sociedade e sejam protagonistas de sua história.

O processo de desinstitucionalização caracteriza-se por implicar novos contextos de vida para as pessoas com transtorno mental, bem como para seus familiares, e pretende modificar as relações de poder entre os usuários e as instituições. O paradigma da atenção 
psicossocial é o balizador das mudanças em curso, compreendido como sinônimo de cidadania (Saraceno, 1996), tendo três eixos estruturantes: a) o morar, ou seja, habitar conquistando territórios novos na cidade; b) o trocar identidade, multiplicando-a, combatendo e desconstruindo estigmas e mitos; e c) o produzir valores de trocas sociais, o que implica em ampliação de laços sociais, aumentando a contratualidade, a partir dos valores destacados pela sociedade, assegurando processos de geração de emprego e renda, potencializando as capacidades das pessoas com transtorno mental.

Entretanto, analisando as frases temáticas dos entrevistados, verificamos a fragilidade no que diz respeito à corresponsabilização e à articulação entre todos os órgãos responsáveis pela formulação, execução e controle das ações desinstitucionalizantes de Saúde Mental, observada, também, pelas ações tímidas do CES/SP em deliberar junto aos demais órgãos responsáveis e da Defensoria Pública em estar mais atuante, culminando na baixa resolubilidade de casos antigos e inexistência de barreiras efetivas que impeçam a institucionalização de novos sujeitos com transtornos mentais, nos hospitais psiquiátricos do Estado de São Paulo, o que impossibilita que as recomendações propostas pelo Censo Psicossocial (2008) sejam efetivadas na sua totalidade.

Diante do panorama alarmante evidenciado e na perspectiva de construção do projeto de intervenção na realidade objetiva, com a proposição de ações a serem desenvolvidas, se faz necessário que medidas urgentes sejam tomadas pautadas nas recomendações já estabelecidas pelo Censo Psicossocial (2008), que envolvam aspectos como educação permanente para profissionais atuantes na área de saúde mental, bem como a formação de novos profissionais baseado na atenção psicossocial do cuidado em saúde mental, rompendo com o padrão biologicista, monitoramento das novas internações compulsórias, fortalecimento da RAPS com fomento suficiente destinado a implementação e manutenção de SRT, Reabilitação Psicossocial por meio de providenciar a documentação para todos os usuários que não têm, apuração de curatela e punição para os que praticam corrupção e demais ações que fortaleçam a reinserção do sujeito com transtorno mental na sociedade.

Sabe-se que a estigmatização das pessoas com transtorno mentais, especialmente os usuários de longa internação em hospitais psiquiátricos, bem como os interesses dos donos dessas instituições são barreiras importantes para o avanço do processo de desinstitucionalização, barreiras que devem ser demolidas com urgência, pois enquanto nada se faz, pessoas continuam sujeitas a situações muitas vezes desumanas e reclusas do convívio em sociedade, abandonadas, esquecidas. Portanto, é emergencial o fortalecimento da luta 
antimanicomial e dos grupos pró Reforma Psiquiátrica para que situações como as encontradas nos hospitais psiquiátricos não se repitam.

Assim, suscita-se a necessidade da construção de uma forma de cuidado, que não seja de exclusão e isolamento, mas que, sobretudo, paute-se na democracia, solidariedade e tolerância em relação à diferença. Uma forma de cuidado que se revele uma atitude de colocar atenção, mostrar interesse, compartilhar e estar com o outro com prazer; pois, "pelo cuidado não vemos a natureza e tudo o que nela existe como objetos. A relação não é sujeito-objeto, mas sujeito-sujeito [...] A relação não é de domínio sobre, mas de com-vivência. Não é pura intervenção, mas inter-ação e comunhão" (Boff, 2001, p. 95).

O presente estudo nos permitiu ter uma visão da totalidade do processo de desinstitucionalização no Estado de São Paulo, a partir da realização do Censo Psicossocial (2008), à luz da Teoria de Intervenção Práxica da Enfermagem em Saúde Coletiva - TIPESC - desenvolvida por Egry (1996), nas dimensionais de práxis social - estrutural, singular e particular que nos guiou para atingir os objetivos propostos com a captação, interpretação e reinterpretação da realidade objetiva, em que analisamos as relações e formas político ideológicas dos sujeitos participantes deste estudo, tendo como norte a Política Nacional de Saúde Mental.

Portanto, a partir da análise das ações de desinstitucionalização, conforme as recomendações propostas pelo Censo Psicossocial (2008) de moradores em hospitais psiquiátricos do Estado de São Paulo, entendemos que o referido Censo Psicossocial (2008) é um instrumento imprescindível para a desinstitucionalização dessas pessoas de longa internação e diante de sua importância, demonstrada neste estudo, propomos que o mesmo seja incluído como componente da política pública de Saúde Mental, pois somente com políticas públicas efetivas de Saúde Mental relacionadas aos Direitos, Cidadania e Reabilitação Psicossocial, por meio, principalmente, do fortalecimento da RAPS e da desconstrução do estigma da loucura na sociedade, com a superação da violação de direitos, para o avanço da Reforma Psiquiátrica, é que possibilitará à pessoa com transtorno mental tornar-se verdadeiramente ser social com direitos assegurados. 
REFERENCIAS 


\section{REFERÊNCIAS}

Amarante P, coordenador. Loucos pela vida: a trajetória da reforma psiquiátrica no Brasil. 2. ed. Rio de Janeiro: Fiocruz; 1995.

Amarante, Oliveira MHB, Torre EHG, Coelho IP. Derechos humanos y salud mental en Brasil: una historia de lucha y militancia por la justicia social y el derecho a la vida: "la salud no se vende, la locura no se encierra". Átopos: Salud Mental, Comunidad y Cultura. 2016;(2):1-16.

Antunes A. Os manicômios hoje se chamam comunidades terapêuticas. [Entrevista a Fábio Belloni]. EPSJV/Fiocruz. 2014 maio 24. [citado 2018 ago. 4] Disponível em: http://www .epsjv.fiocruz.br/noticias/entrevista/os-manicomios-hoje-se-chamamcomunidades-terapeuticas

Atterbury K, Rowe M. Citizenship, Community Mental Health, and the Common Good. Behav Sci Law. 2017 Jul;35(4):273-87.

Barioni PM. Residências Terapêuticas no "Serviço de Saúde Dr. Cândido Ferreira": estratégia, avanços e desafios para as Políticas de Saúde Mental em Campinas [dissertação]. São Paulo: Secretaria de Estado da Saúde de São Paulo; 2013.

Barros DD. Cidadania versus periculosidade social: a desinstitucionalização como desconstrução de saberes. In: Amarante $\mathrm{P}$ organizador. Psiquiatria social e reforma psiquiátrica. Rio de Janeiro: Fiocruz; 1998. p. 171-94.

Barros S, Bichaff R, organizadoras. Desafios para a desinstitucionalização: censo psicossocial dos moradores em hospitais psiquiátricos do Estado de São Paulo. São Paulo: FUNDAP, Secretaria da Saúde; 2008.

Barros S, Egry EY. O louco, a loucura e a alienação institucional: O ensino de enfermagem psiquiátrica sub judice. Taubaté: Cabral Editora Universitária; 2001.

Boff L. Saber cuidar: ética do humano - compaixão pela terra. Petrópolis: Vozes; 2001.

Boyatzis RE. Transforming qualitative information: Thematic analysis and code development. Thousand Oaks, CA, US: Sage Publications, Inc; 1998. 
Brasil. Código Civil, Lei 10.406, de 10 de janeiro de 2002. São Paulo: Revista dos Tribunais, 2002.

Brasil. Código de Processo Civil Brasileiro. Lei no 13.105, de 16 de março de 2015. Brasília: Senado Federal, 2015. [citado 3 maio 2019]. Disponível em: https://www2.senado.leg.br/bdsf/ bitstream/handle/id/507525/CPC\%202015.pdf?sequence=3\&isAllowed=y

Brasil. Constituição, 1988. Constituição da República Federativa do Brasil. Brasília: Senado; 1988.

Brasil. Decreto Lei n. 10.216, de 6 de abril de 2001. Dispõe sobre a proteção e os direitos das pessoas portadoras de transtornos mentais e redireciona o modelo assistencial em saúde mental. Subchefia para Assuntos Jurídicos. Diário Oficial da União, Brasília, 9 abr. 2001. Seção 1, p. 2.

Brasil. Emenda Constitucional n. 95, de 15 de dezembro de 2016. Altera o Ato das Disposições Constitucionais Transitórias, para instituir o Novo Regime Fiscal, e dá outras providências. Diário Oficial da União. Brasília, 15 dez. 2016 a.

Brasil. Lei Federal n. 10.078 de 31 de julho de 2003. Institui o auxílio-reabilitação psicossocial para pacientes acometidos de transtornos mentais egressos de internações. Diário Oficial da União. Brasília, 1 ago. 2003.

Brasil. Lei Federal n. 13.146, de 6 de julho de 2015. Institui a Lei Brasileira de Inclusão da Pessoa com Deficiência (Estatuto da Pessoa com Deficiência). Diário Oficial da União. Brasília, 7 jul. 2015.

Brasil. Ministério da Saúde. Conselho Nacional de Saúde. Resolução 466, de 12 de dezembro de 2012. Dispõe sobre diretrizes e normas regulamentadoras de pesquisas envolvendo seres humanos. Diário Oficial da União. Brasília, 13 jun. 2013, Seção 1, p. 59.

Brasil. Ministério da Saúde. Lei n. 13.840, de 5 de junho de 2019. Altera as Leis nos 11.343, de 23 de agosto de 2006, 7.560, de 19 de dezembro de 1986, 9.250, de 26 de dezembro de 1995, 9.532, de 10 de dezembro de 1997, 8.981, de 20 de janeiro de 1995, 8.315, de 23 de dezembro de 1991, 8.706, de 14 de setembro de 1993, 8.069, de 13 de julho de 1990, 9.394, de 20 de dezembro de 1996, e 9.503, de 23 de setembro de 1997, os Decretos-Lei nos 4.048, de 22 de janeiro de 1942, 8.621, de 10 de janeiro de 1946, e 5.452, de $1^{\circ}$ de maio de 1943, para dispor sobre o Sistema Nacional de Políticas Públicas sobre Drogas e as condições de atenção aos usuários ou dependentes de drogas e para tratar do financiamento das políticas sobre drogas. Diário Oficial da União. Brasília, 2019a.

Brasil. Ministério da Saúde. Portaria GM/MS n. 2391, de 26 de dezembro de 2002. Regulamenta o controle das internações psiquiátricas involuntárias (IPI) e voluntárias (IPV) de acordo com o disposto na Lei 10.216, de 6 de abril de 2002, e os procedimentos de 
notificação da Comunicação das IPI e IPV ao Ministério Público pelos estabelecimentos de saúde, integrantes ou não do SUS. Diário Oficial da União. Brasília, 2002c.

Brasil. Ministério da Saúde. Portaria GM/MS n. 251, de 31 de janeiro de 2002. Estabelece diretrizes e normas para a assistência hospitalar em psiquiatria, reclassifica os hospitais psiquiátricos, define e estrutura, a porta de entrada para as internações psiquiátricas na rede do SUS e dá outras providências. Diário Oficial da União. Brasília, 20 fev. 2002 b.

Brasil. Ministério da Saúde. Portaria GM/MS n. 336, de 19 de fevereiro de 2002. Estabelece que os Centros de Atenção Psicossocial poderão constituir-se nas seguintes modalidades de serviços: CAPS I, CAPS II e CAPS III, definidos por ordem crescente de porte/complexid ade e abrangência populacional, conforme disposto nesta Portaria. Diário Oficial da União. Brasília, 20 fev. 2002a.

Brasil. Ministério da Saúde. Portaria n. 1.727, de 24 de novembro de 2016. Dispõe sobre a homologação do resultado final do Programa Nacional de Avaliação dos Serviços Hospitalares - PNASH/Psiquiatria 2012/2014. Diário Oficial da União. Brasília, 24 nov. 2016b. Seção 1, p. 134.

Brasil. Ministério da Saúde. Portaria n. 106, de 11 de fevereiro de 2000. Cria os Serviços Residenciais Terapêuticos em Saúde Mental, no âmbito do Sistema Único de Saúde, para o atendimento ao portador de transtornos mentais. Diário Oficial da União, Brasília, 24 fev. 2000. Seção 1, p. 23.

Brasil. Ministério da Saúde. Portaria n. 2.434, de 15 de agosto de 2018. Altera a Portaria de Consolidação $\mathrm{n}^{\circ}$ 6/GM/MS, de 28 de setembro de 2017, para reajustar o valor das diárias de internação hospitalar acima de 90 (noventa) dias do Incentivo para Internação nos Hospitais Psiquiátricos. Diário Oficial da União. Brasília, 2018.

Brasil. Ministério da Saúde. Portaria n. 2.840, de 29 de dezembro de 2014. Cria o Programa de Desinstitucionalização integrante do componente Estratégias de Desinstitucionalização da Rede de Atenção Psicossocial (RAPS), no âmbito do Sistema Único de Saúde (SUS), e institui o respectivo incentivo financeiro de custeio mensal. Diário Oficial da União, Brasília, 2014.

Brasil. Ministério da Saúde. Portaria n. 3.090, de 23 de dezembro de 2011. Altera a Portaria $n^{\circ}$ 106/GM/MS, de 11 de fevereiro de 2000, e dispõe, no âmbito da Rede de Atenção Psicossocial, sobre o repasse de recursos de incentivo de custeio e custeio mensal para implantação e/ou implementação e funcionamento dos Serviços Residenciais Terapêuticos (SRT). Diário Oficial da União, Brasília, 26 dez. 2011.b. Seção 1, p. 233-4.

Brasil. Ministério da Saúde. Portaria n. 412, de 15 de março de 2013. Redefine as orientações para operacionalização das transferências de recursos federais aos Estados, ao Distrito Federal e aos Municípios, a serem repassados de forma automática, sob a modalidade fundo a fundo, 
em conta única e específica para cada bloco de financiamento de que trata a Portaria $\mathrm{n}^{\circ}$ 204/GM/MS, de 29 de janeiro de 2007. Diário Oficial da União. Brasília, 16 mar. 2013a.

Brasil. Ministério da Saúde. Portaria n. 52, de 20 de janeiro de 2004. Institui o Programa Anual de Reestruturação da Assistência Psiquiátrica Hospitalar no SUS - 2004. Diário Oficial da União. Brasília, 20 jan. 2004.

Brasil. Ministério da Saúde. Portaria n. 615, de 15 de abril de 2013. Dispõe sobre o incentivo financeiro de investimento para construção de Centro de Atenção Psicossocial (CAPS) e Unidades de Acolhimento, em conformidade com a Rede de Atenção Psicossocial para pessoas com sofrimento ou transtorno mental incluindo aquelas com necessidades decorrentes do uso de crack, álcool e outras drogas no âmbito do Sistema Único de Saúde (SUS). Diário Oficial da União. Brasília, 16 abr. 2013b.

Brasil. Ministério da Saúde. Reforma Psiquiátrica e Política de Saúde Mental no Brasil. Conferência Regional da Reforma dos Serviços de Saúde Mental: 15 anos depois de Caracas. Brasília: OPAS. 2005. [citado 14 jun. 2018]. Disponível em: http://www.saude.gov.br/saúde mental

Brasil. Ministério da Saúde. SAS/DAPES. Coordenação Geral de Saúde Mental, Álcool e Outras Drogas. Saúde Mental em Dados - 8, ano VI, nº 8. Informativo eletrônico. Brasília: Ministério da Saúde;2011a.

Brasil. Ministério da Saúde. SAS/DAPES. Coordenação Geral de Saúde Mental, Álcool e Outras Drogas. Saúde Mental em Dados - 12, ano 10, nº 12. Informativo eletrônico. Brasília: Ministério da Saúde; 2015.

Brasil. Ministério da Saúde. Secretaria de Atenção à Saúde. Departamento de Ações Programáticas Estratégicas. Manual do programa "de volta para casa". Brasília: Ministério da Saúde; 2003.

Brasil. Ministério da Saúde. Secretaria de Atenção à Saúde. Departamento de Ações Programáticas Estratégicas. Saúde mental e economia solidária: inclusão social pelo trabalho. Brasília: Ministério da Saúde; 2005.

Brasil. Ministério da Saúde. Secretaria de Atenção à Saúde. Departamento de Regulação, Avaliação e Controle de Sistemas. Diretrizes para a programação pactuada e integrada da assistência à saúde. Brasília: Ministério da Saúde, 2006.

Brasil. Nota Técnica no 11/2019-CGMAD/DAPES/SAS/MS. Esclarecimentos sobre as mudanças na Política Nacional de Saúde Mental e nas Diretrizes da Política Nacional sobre Drogas. [citado 3 out. 2019b] .Disponível em: http://mds.gov.br/obid/nova-politica-nacionalde-saude-mental 
Brasil. PEC 241/16. Altera o Ato das Disposições Constitucionais Transitórias, para instituir o Novo Regime Fiscal. [citado 3 out. 2019]. Disponível em: https://www.camara.leg.br/ proposicoesWeb/fichadetramitacao?idProposicao $=2088351$

Brasil. Portaria n. GM/MS 204, de 29 de janeiro de 2007. Regulamenta o financiamento e a transferência dos recursos federais para as ações e os serviços de saúde, na forma de blocos de financiamento, com o respectivo monitoramento e controle. Diário Oficial da União. Brasília, 30 jan 2017.

Brasil. Portaria ${ }^{\circ}$ GM/MS 3.088, de 23 de dezembro de 2011. Institui a Rede de Atenção Psicossocial para pessoas com sofrimento ou transtorno mental e com necessidades decorrentes do uso de crack, álcool e outras drogas, no âmbito do Sistema Único de Saúde (SUS). Diário Oficial da União. Brasília, 26 dez. 2011.

Braun V, Clarke V. Using thematic analysis in psychology. Qual Res Psychol. 2006;3(2):77101.

Burti L. Italian psychiatric reform 20 plus years after. Acta Psychiatr Scand Suppl. 2001;104(410):41-6.

Burti L. Thirty-Five Years of Psychosocial Rehabilitation in Italy. Int J Ment Health. 2016;45(1):7-14.

Cayres AZF, Ribeiro MC, Elias R, Coutinho RA. Caminhos para a desinstitucionalização no Estado de São Paulo: censo psicossocial 2014. São Paulo: FUNDAP, Secretaria da Saúde; 2015.

Cléve CM. Análise constitucional da relação entre saúde pública e internação psiquiátrica compulsória. Revista Jus Navigandi [Internet]. 2017; [citado 2018 nov. 3];(5296). Disponível em: https://jus.com.br/artigos/62670.

Conselho de Secretários Municipais de Saúde do Estado - COSEMS/SP. Rede De Atenção Psicossocial (RAPS) - Orientações do COSEMS/SP sobre a implantação de residências terapêuticas no estado de São Paulo[Internet]. [citado 19 jul. 2017a]. Disponível em: http://www.cosemssp.org.br/downloads/NOTA-TECNICA-RAPS-Residencias-

Terapeuticas.pdf

Conselho de Secretários Municipais de Saúde do Estado - COSEMS/SP. Redes Regionais de Atenção Psicossocial - Documento Norteador do COSEMS/SP [Internet]. [citado 19 jul. 2017b]. Disponível em: http://www.cosemssp.org.br/downloads/Nota-Tecnicasa\%C3\%BAde-mental-Documento-Norteador.pdf 
Conselho de Secretários Municipais de Saúde do Estado - COSEMS/SP. Reunião Conselho de Representantes COSEMS/SP. Tema: Saúde Mental. São Paulo 21 ago. 2019. 33 slides.

Conselho de Secretários Municipais de Saúde do Estado - COSEMS/SP. Sobre [Internet]. s/d. [citado 4 nov. 2019]. Disponível em: http://www.cosemssp.org.br/quem-somos/sobre/

Controle de Comunicação de Internação Psiquiátrica Involuntária. [Internet]. [citado 21 nov. 2018]; Disponível em: https://sismpapp.mpsp.mp.br/interna/internacao.asp.

Costa SF. As Políticas Públicas e as Comunidades Terapêuticas nos Atendimentos à Dependência Química. Serviço Social em Revista [Internet]. 2009 [citado 2018 nov. 4];11(2). Disponível em: http://www.uel.br/revistas/ssrevista/c-v11n2.htm

Csipke E. Flach C, McCrone P, Rose D, Tilley J, Wykes, et al. Inpatient care 50 years after the process of deinstitutionalisation. Soc Soc Psychiatry Psychiatr Epidemiol. 2014 Apr;49(4):665-71.

Davidson L, Mezzina R, Rowe M, Thompson K. "A life in the community": Italian mental health reform and recovery. J Ment Health. 2010 Oct;19(5):436-43.

Del Priore M, organizadora. História das Crianças no Brasil. São Paulo: Contexto; 1991.

Duarte CG. Os (des)caminhos da interdição: cartografias dos territórios existenciais de sobreviventes dos manicômios de Sorocaba/SP [dissertação]. Campinas: Faculdade de Ciências Médicas, Universidade Estadual de Campinas; 2018.

Egry EY, Shima H. Integração Docente Assistencial como referencial teórico-metodológico para o ensino e a pesquisa da assistência em enfermagem em saúde coletiva. In: Universidade de São Paulo. Integração Docente Assistencial. São Paulo: Escola de Enfermagem da USP; 1992, p. 75-155.

Egry EY. Saúde Coletiva: construindo um novo método em enfermagem. São Paulo: Ícone; 1996.

Emmanuel M, Campbell M. Commentary: a comparative review of involuntary admission of people with mental illness in China and Barbados. J Am Acad Psychiatry Law. 2015;43(1):45-7.

Ferrannini L, Peloso PF. The Closure of the Psychiatric Hospital as an Original Feature of Rehabilitation in Italy. Int J Ment Health. 2016;45(1)1-6. 
Ferronatto A. O ministério público e a curatela dos interditos: atuação em rede na saúde mental e atenção psicossocial. Revista do Ministério Público do RS. 2012;(71):25-33.

Figueirêdo MLR, Delevati DM, Tavares MG. Entre loucos e manicômios: história da loucura e a reforma psiquiátrica no Brasil. Ciências Humanas e Sociais. 2014;2(2):121-36.

Fleury MJ, Grenier G, Vallé C, Aubé D, Farand L, Bamvita JM, et al. Implementation of the Quebec mental health reform (2005-2015). BMC Health Serv Res. 2016;16(1):586.

Flick U. Introdução à Pesquisa Qualitativa. 3 ed. Porto Alegre: Artmed; 2009.

Fórum de Luta Antimanicomial de Sorocaba - FLAMAS. Dossiê dos Manicômios Levantamento de indicadores sobre os manicômios de Sorocaba e região[Internet]. Setembro 2011. [citado 5 ago. 2017]. Disponível em: https://flamasorocaba.wordpress.com/dossie-dosmanicomios.

Fórum de Luta Antimanicomial de Sorocaba - FLAMAS. Levantamento de indicadores sobre os manicômios de Sorocaba e região. Sorocaba: SinPsi; 2011.

Fund ação Seade. Portal de Estatísticas do Estado de São Paulo[Internet]. [citado 4 nov. 2019]. Disponível em: http://www.seade.gov.br/

Gadelha Junior O. Hospital psiquiátrico: (re)afirmação da exclusão. Psicologia \& Sociedade. 2002;14(1):87-102.

Gil AC. Como elaborar projetos de pesquisa. 4 ed. São Paulo: Atlas; 2002.

Goffman E. Manicômios, Prisões e Conventos. 7 ed. São Paulo: Perspectiva; 2003.

Guljor AP. Não vamos aceitar retrocesso na Reforma Psiquiátrica. [Depoimento a Maíra Mathias] Escola Politécnica de Saúde Joaquim Venâncio/Fiocruz. 2016 maio 18. [citado 2017 maio 18] Disponível em: http://www.epsjv.fiocruz.br/noticias/entrevista/nao-vamos-aceitarretrocesso-na-reforma-psiquiatrica

Hazelton M. Mental health reform, citizenship and human rights in four countries. Health Sociology Review. 2005;14(3):1-6.

Kinoshita RT. O outro na reforma: contribuições da teoria da autopoiese para a problemática da cronicidade no contexto das reformas psiquiátricas [tese]. Campinas: Faculdade de Ciências Médicas, Universidade Estadual de Campinas; 2001. 
Leonardis O, Mauri D, Rotelli F. Deinstitutionalization, another way: the Italian mental health reform. Health Promot. 1986;1(2):151-65.

Lüchmann LHH, Rodrigues J. O movimento antimanicomial no Brasil. Cien Saude Colet. 2007;12(2):399-407.

Machado CV, Baptista TWF, Lima LD, organizadores. Políticas de saúde no Brasil: continuidades e mudanças. 1 reimp. Rio de Janeiro: Fiocruz; 2014.

Marcon SR, Oliveira AGB. Família e Transtorno Mental: Reflexões Teórico-Práticas. In: Oliveira AGB, organizador. Ensino de Enfermagem: temas e estratégias interdisciplinares. Cuiabá: UFTM; 2006.

Marconi MA, Lakatos EM. Fundamentos de metodologia científica. 7 ed. São Paulo: Atlas; 2010.

Marx KH, Engels F. Manifesto do Partido Comunista. São Paulo: Cortez; 1997.

McCrone P, Becker T. Limits of deinstitutionalization: experience in England. Psychiatr Prax. 2000;(2):S68-71.

Mendes JDV, Cruz RMF, Portas SLC, organizadores. Plano Estadual de Saúde - Pes 20162019. São Paulo: Secretaria de Estado de São Paulo; 2015.

Mendes JDV, Osiano VLRL. Situação dos Centros de Atenção Psicossocial no SUS nas regiões do Estado de São Paulo em 2015. Boletim eletrônico do grupo técnico de avaliação e informações de Saúde [Internet]. 2016 [citado 2019 nov. 7];8(53). Disponível em: http://portal.saude.sp.gov.br/resources/ses/perfil/profissional-da saude/destaques//gais_jornal_53.pdf

Mendes JDV, Takahashi F. Situação dos Centros de Atenção Psicossocial no SUS nas regiões de saúde do Estado de São Paulo em 2012. Boletim eletrônico do grupo técnico de avaliação e informações de Saúde [Internet]. 2013. [citado 2019 nov. 4];5(23). Disponível em: http://portal.saude.sp.gov.br/resources/ses/perfil/gestor/homepage//gaisinforma/gais_jornal_23.pdf

Mfoafo-M'Carthy M, Huls S. Human Rights Violations and Mental Illness: Implications for Engagement and Adherence. SAGE Open. 2014;1-18.

Minayo MCS. Análise qualitativa: teoria, passos e fidedignidade. Cien Saude Colet. 2012;17(3):621-6. 
Minayo MCS. O desafio do conhecimento: pesquisa qualitativa em saúde. 11 ed. São Paulo: Hucitec; 2008.

Minayo MCS. O desafio do conhecimento: pesquisa qualitativa em saúde. 12 ed. São Paulo: Hucitec; 2010.

Mitre ANM. A loucura em diferentes épocas: a convivência da família com o portador de transtorno mental. Mental [Internet]. 2017 [citado 2019 out. 2]; 11(20):4-28. Disponível em: http://pepsic.bvsalud.org/scielo.php?script=sci_arttext\&pid=S1679.

$44272017000100002 \& \operatorname{lng}=$ pt\&nrm=iso

Morzycka-Markowska M, Drozdowicz E, Nasierowski T. Deinstitutionalization in Italian psychiatry - the course and consequences Part I. The course of deinstitutionalization - the activity of Basaglia's group. Psychiatr Pol. 2015a;49(2):391-401.

Morzycka-Markowska M, Drozdowicz E, Nasierowski T. Deinstitutionalization in Italian psychiatry - the course and consequences Part II. The consequences of deinstitutionalization. Psychiatr Pol. 2015b;49(2):403-12.

Moscovici S. Representações Sociais: investigações em psicologia social. 3 ed. Petrópolis: Vozes; 2003.

Mota LA, organizador. Capitalismo contemporâneo: olhares multidisciplinares. Campina Grande: Eduepb; 2014.

Nicácio F, Campos GWS. A complexidade da atenção às situações de crise - contribuições da desinstitucionalização para a invenção de práticas inovadoras em saúde mental. Rev Ter Ocup Univ São Paulo. 2004;15(2):71-81.

Oliveira JP. A transversalidade do encontro: da desinstitucionalização em Trieste à Sorocaba, (re)fazeres? [dissertação]. Assis: Faculdade de Ciências e Letras de Assis, Universidade Estadual Paulista; 2017.

Oliveira WF, Martinhago F, Moraes RSA. M. Entendendo a Reforma Psiquiátrica - A Construção da Rede de Atenção à Saúde Mental. Florianópolis: ABRASME; 2009.

Pádua EMM. Metodologia da pesquisa: abordagem teórico prática. 2 ed. Campinas: Papirus; 1997.

Pereira EC. Ensaio de intercessão institucional em um CAPS - Centro de Atenção Psicossocial [dissertação]. Assis: Faculdade de Ciências e Letras de Assis, Universidade Estadual Paulista; 2011. 
Perron A, Rudge T, Holmes D. Citizen minds, citizen bodies: the citizenship experience and the government of mentally ill persons. Nurs Philos. 2010;11(2):100-11.

Pitta AMF. Um balanço da reforma psiquiátrica brasileira: instituições, atores e políticas. Cien Saude Colet. 2011;16(12):4579-89.

Rotelli F. et al. Desinstitucionalização. São Paulo: Hucitec; 1990.

Roza Junior JÁ, Loffredo AM. Residências Terapêuticas e a cidade: enfrentamentos de normas sociais vigentes. Saúde debate. 2018;42(116):287-95.

Santos BS, organizador. Reconhecer para libertar: os caminhos do cosmopolitanismo multicultural. Rio de Janeiro: Civilização Brasileira; 2003.

Santos BS. Se Deus Fosse um Ativista dos Direitos Humanos. São Paulo: Cortez; 2013.

São Paulo (Estado). Defensoria Pública do Estado de São Paulo. Defensoria Pública do Estado de São Paulo [Internet]. São Paulo [citado 19 ago. 2019c]. Disponível em: https://www.defensoria.sp.def.br/dpesp/Default.aspx?idPagina=2868

São Paulo (Estado). Deliberação CIB 87, de 3 de dezembro de 2012. Termo de Referência para a implantação das Redes Regionais de Atenção Psicossocial no âmbito das CIR/CGR, conforme Anexos I e II. Diário Oficial do Estado de São Paulo. São Paulo, 29 jun. 2009.

São Paulo (Estado). Ministério Público. Conselho Regional de Psicologia. Termo de Cooperação Técnica N. ${ }^{\circ}$ 10/2016. [Internet]. São Paulo, 2016 [citado 19 ago. 2017]. Disponível em: http://www.mpsp.mp.br/portal/page/portal/Saude_Publica/hd_sp_tct/ Termo\%20MPSP\%20-\%20CRPsicologia\%20SP.pdf

São Paulo (Estado). Ministério Público. Procuradoria Geral da Justiça. Termo de Ajuste e Conduta (TAC) [Internet]. São Paulo, 18 dez. 2012. [citado 15 nov. 2017]. Disponível em: http://pfdc.pgr.mpf.mp.br/temas-de-atuacao/saude-mental/atuacao-do-mpf/tacdesinstitucionalizacao-de-hospitais-psiquiatricos-2012

São Paulo (Estado). Ministério Público. Termo de Cooperação Técnica $n^{\circ}$ 002/2014 [Internet]. São Paulo, 2014 [citado 2 ago. 2018]. Disponível em: http://www.mpsp.mp.br/ portal/page/portal/Portal_da_Transparencia/Licitacoes_Contratos_Convenios/Licitacoes_Con venios/Lista_de_convenios/Lista_de_convenios_ate2016/20140225141233697.pdfmunicipais

São Paulo (Estado). Ministério Público. Termo de Cooperação Técnica N. ${ }^{\circ}$ 017/2015 Termo de Cooperação Técnica que entre si celebram o Ministério Público do Estado de São Paulo e a Associação Brasileira de Psiquiatria[Internet]. São Paulo, 2015. [citado em 2 ago. 2018]. 
Disponível em: http://www.mpsp.mp.br/portal/page/portal/Saude_Publica/hd_sp_tct/Termo\% 20de\%20Coopera\%C3\%A7\%C3\%A3o\%20n\%20017-15\%20-\%20MPSP\%20-\%20ABP.pdf

São Paulo (Estado). Ministério Público. Termo De Cooperação Técnica no 00/2013-MPSP. Termo de Cooperação Técnica que entre si celebram o Ministério Público do Estado de São Paulo e a Secretaria Estadual de Saúde[Internet]. São Paulo, 2013. [citado 2 ago 2018. Disponível em: http://www.saude.sp.gov.br/resources/ses/perfil/profissional-da-saude/ homepage/grupo-tecnico-de-acoes-estrategicas-gtae/saude-mental-alcool-e-drogas/parceriases-e-mp/minuta_termo_de_cooperacao_tecnica_mp_ses.pdf

São Paulo (Estado). Resolução SS no 114, de 28 de julho de 2009 que constitui o Grupo de Trabalho para a elaboração do plano estratégico de ação para o cuidado de pessoas idosas e/ou com deficiências, moradoras de hospitais psiquiátricos do Estado de São Paulo. Diário Oficial do Estado de São Paulo. São Paulo, 29 jun. 2009.

São Paulo (Estado). Resolução SS no 294 de 29 de agosto de 2007. Institui Grupo de Trabalho para construção de proposta de desinstitucionalização de pacientes de longa permanência dos hospitais psiquiátricos do Estado de São Paulo. Diário Oficial do Estado de São Paulo. São Paulo, 30 ago. 2007. Seção 1, p. 27.

São Paulo (Estado). Secretaria de Estado da Saúde. BVS - Biblioteca Virtual em Saúde. BIREME/OPAS/OMS. AMVISA/VISALEGIS. LEGSES-SP - Texto Completo de Legislação em Saúde[Internet]. São Paulo [citado4 ago. 2017b]. Disponível em: http://tclegis2.bvs.br/leisref/public/home.php

São Paulo (Estado). Secretaria de Estado da Saúde. Conselho Estadual de Saúde. Deliberação CES/SP n ${ }^{\circ}$ 12, de 17 de setembro de 2004. Aprova o Regimento Interno do Conselho Estadual de Saúde. Diário Oficial do Estad o de São Paulo. São Paulo, 16 out. 2004.

São Paulo (Estado). Secretaria de Estado da Saúde. Nota Técnica Conjunta Orientações para Desinstitucionalização a Serem realizadas pelos Hospitais Psiquiátricos/ Especializados em Psiquiatria no Estado de São Paulo[Internet]. São Paulo [citado19 ago. 2017c]. Disponível em: http://www.saude.sp.gov.br/ses/perfil/profissional-da-saude/areas-tecnicas-da-sessp/ saude-mental-alcool-e-d rogas/nota-tecnica-conjunta-orientacoes-para-desinstitucionalizacao-a serem-realizadas-pelos-hospitais-psiquiatricos-especializados-em-psiquiatria-no-estado-de-sp

São Paulo (Estado). Secretaria de Estado da Saúde. Nota técnica para subsidiar a desinstitucionalização dos pacientes psiquiátricos[Internet]. São Paulo [citado19 ago. 2017s/d]. Disponível em: http://www.saude.sp.gov.br/ses/perfil/profissional-da-saude/areastecnicas-da-sessp/saude-mental-alcool-e-d rogas/nota-tecnica-para-subsidiar-adesinstitucionalizacao-dos-pacientes-psiquiatricos 
São Paulo (Estado). Secretaria de Estado da Saúde. Regionais de saúde[Internet]. São Paulo [citado 19 ago. 2017a]. Disponível em: http://www.saude.sp.gov.br/ses/institucional/ departamentos-regionais-de-saude/regionais-de-saude

São Paulo (Estado). Secretaria de Estado da Saúde. Resolução SS nº 84, de 29 de maio de 2009. Institui Grupo de Trabalho para coordenar as ações de regularização de Registro Civil de nascimento dos pacientes de longa permanência dos hospitais psiquiátricos do Estado de São Paulo- Diário Oficial do Estado de São Paulo. São Paulo, 30 mai. 2009.

Saraceno B. Libertando identidades: da reabilitação psicossocial à cidadania possível. Rio de Janeiro: Instituto Franco Basaglia; Belo Horizonte: Te Corá; 1999.

Saraceno B. Libertando identidades: da reabilitação psicossocial à cidadania possível. 2. ed. Rio de Janeiro: Instituto Franco Basaglia; Belo Horizonte: Te Corá; 2001.

Saraceno B. Reabilitação psicossocial: uma estratégia para a passagem do milênio. In: Pitta AMF, organizadora. Reabilitação psicossocial no Brasil. São Paulo: Hucitec; 1996. p. 13-18.

Sarlet IW. Internação obrigatória não pode ser utilizada de modo generalizado [Internet]. ConJur 9 dez. 2016. [citado 2018 jun. 2]. Disponível em: https://www.conjur.com.br/2016dez-09/d ireitos-fundamentais-internacao-obrigatoria-nao-utilizada-modo-generalizado

Shao Y, Xie B. Approaches to involuntary admission of the mentally ill in the People's Republic of China: changes in legislation from 2002 to 2012. J Am Acad Psychiatry Law. 2015;43(1):35-44.

Silva AG, Mota LA, Dornelas CSM, Lacerda AV. A relação entre Estado e políticas públicas: uma análise teórica sobre o caso brasileiro. Revista Debates. 2017;11(1):25-42.

Silva DAB, Vicentin MCG. Cotidiano de uma residência terapêutica e a produção de subjetividade. Revista Distúrbios da Comunicação. 2017;29:197.

Silva EKB, Rosa LC. Desinstitucionalização Psiquiátrica no Brasil: riscos de desresponsabilização do Estado? Rev Katálysis. 2014;17(2):252-60.

Souza ECF, Vilar RLA, Rocha NSPD, Uchoa AC, Rocha PM. Acesso e acolhimento na atenção básica: uma análise da percepção dos usuários e profissionais de saúde. Cad. Saúde Pública. 2008b;24(Supl. 1):100-10.

Souza RR, Mendes JDV, Portas SLC, Barros S, Vallim S, organizadores. Plano estadual de saúde 2008 - 2011. São Paulo: Secretaria da Saúde;2008a. 
Taylor ST, Killaspy H, King M. The relationship between deinstitutionalization and quality of care in longer-term psychiatric and social care facilities in Europe: A cross-sectional study. Eur Psychiatry. 2017;42:95-102.

Teixeira JMC, Portas SLC, Vallim S, Mendes JDV, Rodrigues EL, organizadores. Plano estadual 2012-2015. São Paulo: Secretaria da Saúde; 2012.

Thornicroft G. Evaluation of the closure of large psychiatric hospitals in England. Rev Epidemiol Sante Publique. 1993;41(4):292-7.

Turner J, Hayward R, Angel K, Fulford B, Hall J, Millard C, et al. The History of Mental Health Services in Modern England: Practitioner Memories and the Direction of Future Research. Med Hist. 2015 Oct;59(4):599-624.

Vasconcelos EM, organizador. Saúde mental e serviço social: o desafio da subjetividade e da interdisciplinaridade. São Paulo: Cortez; 2014.

Veloso LUP, Carlos KPT. A nova política de saúde mental no Estado do Piauí: mudanças e perspectivas. In: Rosa LCS, Guimarães LDA, Carvalho MEB, organizadores. Cenários de práticas em saúde mental: a atenção psicossocial no Piauí. Teresina: UFPI; 2009, p. 98-111.

Ventura CAA. Saúde Mental e Direitos Humanos: o processo de construção da cidadania das pessoas portadoras de transtornos mentais [tese de livre-docência]. Ribeirão Preto: Escola de Enfermagem de Ribeirão Preto, Universidade de São Paulo; 2011.

Yasui S. Rupturas e encontros: desafios da reforma psiquiátrica brasileira. Rio de Janeiro: Editora Fiocruz; 2010. (Coleção Loucura \& Civilização). 
APÊNDICES 


\title{
APÊNDICES
}

\section{APÊNDICE A - INSTRUMENTO GUIA PARA ENTREVISTA}

\author{
"Políticas Públicas de Desinstitucionalização no Estado de São Paulo e as
}

Recomendações do Censo Psicossocial (2008) de Moradores de Hospitais Psiquiátricos"

\section{DADOS DE IDENTIFICAÇÃO}

Iniciais:

Endereço:

Telefone:

E-mail:

Idade:

Escolaridade:

Raça/cor: ( )branco ( )pardo ( )preto ( )amarelo ( )indígena

Sexo: ( )Feminino ( ) Masculino

Profissão:

Vínculo empregatício:

Nome do cargo que ocupa:

Local de atuação profissional:

Tempo de atuação no cargo atual:

Cidade onde atua:

\section{QUESTÕES ABERTAS}

Questão 1 - Como se dá o planejamento das ações de saúde da SES-SP em relação a Política Estadual de Saúde Mental?

Questão 2 - Na sua opinião, como devem ser cuidadas as pessoas com transtornos mentais considerados graves?

Questão 3 - Vossa Senhoria tem conhecimento do Censo Psicossocial dos Moradores dos Hospitais Psiquiátricos do Estado de São Paulo realizado no ano de 2008? Retomando naquela ocasião, o Censo encontrou a realidade do expressivo número de 6.349 pessoas com longo tempo de internação em hospitais psiquiátricos no Estado de São Paulo e, que 70 \% destes foram internados há mais de dez anos. A partir dos resultados do Censo, foram 
propostas entre as páginas 124-130 da obra, 17 recomendações para a desinstitucionalização daquelas pessoas dos hospitais psiquiátricos do Estado de São Paulo.

Pergunta: Poderia me informar, o que foi feito para atender as recomendações, ou seja, que ações foram propostas ou implementadas em Saúde Mental para a construção de políticas públicas de desinstitucionalização?

Questão 4 - Na sua opinião, quais as dificuldades ou impasses em relação à desinstitucionalização das pessoas com transtornos mentais internadas em hospitais psiquiátricos?

Questão 5 - Vossa Senhoria, junto a instituição que representa, pretende propor, articular ou implementar ações para a construção de políticas públicas estadual de desinstitucionalização das pessoas com transtornos mentais internadas em hospitais psiquiátricos no Estado de São Paulo?

Se sim, quais?

Se não, por quê?

Questão 6 - Qual o propósito da Política de Saúde Mental no Estado de São Paulo? Quais suas principais características?

\section{COMENTÁRIOS E SUGESTÕES:}




\section{APÊNDICE B - TERMO DE CONSENTIMENTO LIVRE E ESCLARECIDO}

\section{(Resolução 466/2012 do CNS)}

O(A) senhor(a) está sendo convidado(a) para participar da pesquisa "Políticas Públicas de Desinstitucionalização no Estado de São Paulo e as Recomendações do Censo Psicossocial (2008) de Moradores de Hospitais Psiquiátricos", desenvolvida pela Sra. Lara Simone Messias Floriano, pós-graduanda da Escola de Enfermagem da Universidade de São Paulo (EEUSP), sob orientação da Prof. . Dr. ${ }^{a}$ Sônia Barros.

A pesquisa tem como objetivos: Analisar as políticas públicas de direitos e cidadania e reabilitação psicossocial efetivamente implementadas no Estado de São Paulo, derivadas do conjunto de recomendações propostas na obra resultante do Censo Psicossocial dos moradores em hospitais psiquiátricos (2008), para contribuir com a (re) formulação das políticas públicas de direitos e cidadania e reabilitação psicossocial; Identificar as ações propostas e implementadas pela Secretaria de Estado da Saúde de São Paulo (SES-SP) para efetivar políticas públicas de desinstitucionalização, após o Censo Psicossocial (2008) de moradores em hospitais psiquiátricos do Estado de São Paulo; Caracterizar a existência, ou não, de políticas públicas de desinstitucionalização das pessoas com transtornos mentais internadas em hospitais psiquiátricos no Estado de São Paulo.

Para alcançar esses objetivos precisamos que o senhor (a) responda algumas perguntas de entrevista semi estruturada. Isto poderá ser feito em vários encontros, os quais agendaremos de acordo com sua disponibilidade. Os encontros serão realizados no seu local de serviço ou se preferir em uma sala reservada pela pesquisadora na Escola de Enfermagem da USP e nesse caso, não acarretará nenhuma despesa de transporte para o senhor (a). $\mathrm{O}$ tempo de duração da entrevista será de no mínimo 30 minutos.

A entrevista não oferece risco imediato ao (a) senhor (a), porém considera-se a possibilidade de um risco subjetivo, pois algumas perguntas podem remeter algum desconforto ou levar a um leve cansaço após respondê-las. Caso algumas dessas possibilidades ocorram, o(a) senhor (a) poderá optar pela suspensão imediata da entrevista.

O senhor (a) NÃO terá custo ou compensação financeira ao participar do estudo.

A sua participação é voluntária e seu consentimento pode ser retirado a qualquer momento, sem prejuízos. A sua recusa não trará nenhum prejuízo na sua relação com o pesquisador ou com a instituição sobre a qual forneceu os dados.

Suas respostas serão tratadas de forma anônima e confidencial, ou seja, seu nome não será divulgado em qualquer fase do estudo. Quando for necessário exemplificar determinada situação, sua privacidade será assegurada. Os dados coletados poderão ter seus resultados divulgados em eventos, revistas e/ou trabalhos científicos.

Essa pesquisa pretende contribuir para a desinstitucionalização de pessoas com transtornos mentais há longo tempo internadas em hospitais psiquiátricos no Estado de São Paulo, na busca do resgate aos direitos humanos, da cidadania, da autonomia, da dignidade da pessoa humana e para a discussão e elaboração de ações e diretrizes que possam ser aplicadas pelos Estados e municípios no Brasil, para a construção de políticas públicas de direitos e cidadania e reabilitação psicossocial das pessoas com transtornos mentais.

Comunico que o (a) senhor (a) deverá rubricar todas as páginas do Termo e assinar as duas vias do mesmo em local indicado, isso se concordar em participar da pesquisa. Logo após rubricar e assinar os termos, o (a) senhor (a) receberá uma via - também rubricada e assinada pelo pesquisador responsável pela pesquisa - no qual consta o telefone e o endereço do mesmo, podendo tirar suas dúvidas sobre a pesquisa e sua participação, agora ou em qualquer etapa do estudo. 
Para esclarecimentos sobre a pesquisa você pode entrar em contato com:

- Lara Simone Messias Floriano, pesquisador principal, na Escola de Enfermagem da USP, situada na Av. Enéas de Carvalho Aguiar, 419, Departamento de Enfermagem Materno-Infantil e Psiquiátrica (ENP), ou pelo e-mail laramessias@ig.com.br / larasmessias@gmail.com- Telefone: (42) 99106-3222.

Esclareço que o Comitê de Ética em Pesquisa é responsável pela avaliação e acompanhamento dos aspectos éticos de todas as pesquisas envolvendo os seres humanos. Caso tenha alguma consideração ou dúvida sobre ética em pesquisa, entre em contato com o seguinte Comitê de Ética em Pesquisa:

- O Comitê de Ética em Pesquisa da Escola de Enfermagem da USP, na Escola de Enfermagem da USP, situada na Av. Enéas de Carvalho Aguiar, 419, ou pelo e-mail: cepee@usp.br e telefone: (11) 3061-8858.

Afirmo que esta pesquisa atende todas as especificações da Resolução 466, de 12 de dezembro de 2012 que aprova as diretrizes e normas regulamentadoras de pesquisas envolvendo seres humanos.

De antemão, agradeço a sua colaboração.

\author{
Lara Simone Messias Floriano \\ (Pesquisador Principal) \\ Escola de Enfermagem da Universidade de São Paulo (EEUSP) \\ Telefone: (42) 99106-3222. E-mail: laramessias@ig.com.br
}

Assinatura do participante da pesquisa

Nome completo do participante da pesquisa

São Paulo - SP, de de 201 


\section{APÊNDICE C - MODELO DE PEDIDO DE AUTORIZAÇÃO INSTITUCIONAL PARA REALIZAÇÃO DE PESQUISA CIENTÍFICA}

Il. ${ }^{\text {mo }} \mathrm{Sr}$.

Dr. David Everson Uip

Secretário Estadual de Saúde do Estado de São Paulo - SES/SP

Prezado Senhor,

Eu, Lara Simone Messias Floriano, Doutoranda do Programa Interunidades da Escola de Enfermagem da Universidade de São Paulo, sob orientação da Prof. ${ }^{a}$ Dr. ${ }^{a}$ Sônia Barros, estou desenvolvendo o estudo intitulado: "Políticas Públicas de Desinstitucionalização no Estado de São Paulo e as Recomendações do Censo Psicossocial (2008) de Moradores de Hospitais Psiquiátricos".

A pesquisa tem como objetivos: Analisar as políticas públicas de direitos e cidadania e reabilitação psicossocial efetivamente implementadas no Estado de São Paulo, derivadas do conjunto de recomendações propostas na obra resultante do Censo Psicossocial dos moradores em hospitais psiquiátricos (2008), para contribuir com a (re) formulação das políticas públicas de direitos e cidadania e reabilitação psicossocial; Identificar as ações propostas e implementadas pela Secretaria de Estado da Saúde de São Paulo (SES-SP) para efetivar políticas públicas de desinstitucionalização, após o Censo Psicossocial (2008) de moradores em hospitais psiquiátricos do Estado de São Paulo; Caracterizar a existência, ou não, de políticas públicas de desinstitucionalização das pessoas com transtornos mentais internadas em hospitais psiquiátricos no Estado de São Paulo.

Solicito autorização para a aplicação do instrumento de coleta de dados (Entrevista semi estruturada) na instituição sob sua responsabilidade. Para atingir os objetivos propostos, pretendo entrevistar o Secretário Estadual de Saúde do Estado de São Paulo - SES-SP e a Coordenadora Técnica da Área de Saúde Mental da SES-SP.

Esta pesquisa será submetida ao Comitê de Ética em Pesquisa da Escola de Enfermagem da Universidade de São Paulo - CEP-EEUSP como instituição proponente para avaliação das questões éticas em pesquisa e só será realizada após a aprovação do mesmo.

Agradeço antecipadamente sua atenção e reitero votos de estima e apreço.

São Paulo - SP, 25 de outubro de 2017.

Lara Simone Messias Floriano

Doutoranda do Programa Interunidades em Enfermagem da Universid ade de São Paulo$\mathrm{EE} / \mathrm{USP}$

Contato: (42) 99106-3222/3028-7050 
ANEXOS

"




\title{
ANEXOS
}

\section{ANEXO A - CARTA DE AUTORIZAÇÃO INSTITUCIONAL SES/SP}

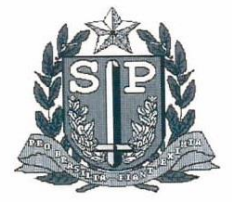

\author{
SECRETARIA DE ESTADO DA SAÚDE \\ GABINETE DO SECRETÁRIO
}

$\underline{\text { Autorização Institucional para Realização de Pesquisa Científica }}$

Eu, Nilson Ferraz Paschoa, Chefe de Gabinete da Secretaria da Saúde do Estado de São Paulo, autorizo a pesquisadora Lara Simone Messias Floriano, Doutoranda do Programa Interunidades da Escola de Enfermagem da Universidade de São Paulo, sob orientação da Profa Dra Sônia Barros, a aplicar o instrumento de coleta de dados (entrevista semi estruturada) nesta instituição, exclusivamente para o desenvolvimento do estudo intitulado: "Políticas Públicas de Desinstitucionalização no Estado de São Paulo e as Recomendações do Censo Psicossocial (2008) de Moradores de Hospitais Psiquiátricos". A Assessora Técnica de Gabinete responsável pela Área Técnica de Saúde Mental, Álcool e Drogas, sra. Rosangela Elias, tem minha anuência para ser entrevistada respondendo por esta Pasta.

Declaro estar ciente que o estudo tem como objetivos: Analisar as políticas públicas de direitos e cidadania e reabilitação psicossocial efetivamente implementadas no Estado de São Paulo, derivadas do conjunto de recomendações propostas na obra resultante do Censo Psicossocial dos moradores em hospitais psiquiátricos (2008), para contribuir com a (re) formulação das políticas públicas de direitos e cidadania e reabilitação psicossocial; Identificar as ações propostas e implementadas pela Secretaria de Estado da Saúde de São Paulo (SES-SP) para efetivar políticas públicas de desinstitucionalização, após o Censo Psicossocial (2008) de moradores em hospitais psiquiátricos do Estado de São Paulo; Caracterizar a existência, ou não, de políticas públicas de desinstitucionalização das pessoas com transtornos mentais internadas em hospitais psiquiátricos no Estado de São Paulo.

São Paulo, 20 de fevereiro de 2018.

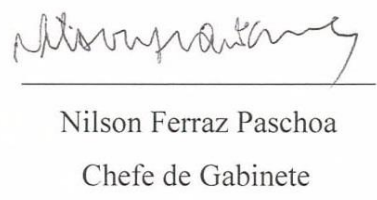




\section{ANEXO B - AUTORIZAÇÃO INSTITUCIONAL - CES/SP}

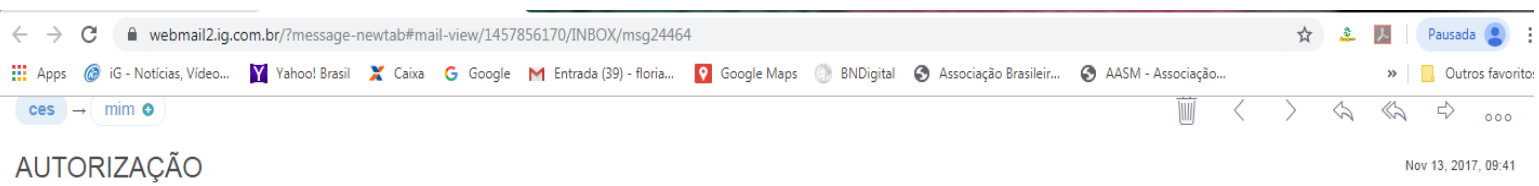

Doutoranda do Programa Interunidades em Enfermagem da Universidade de São Paulo- EE/USP

Cara Professora,

Em resposta à sua solicitação para colher dados com entrevistas aos Coordenadores de Comissões do Conselho Estadual de Saúde, informamos que está, sim, autorizado, porém, com Parecer do Comitê de Ética em Pesquisa da Escola de Enfermagem da Universidade de São Paulo - CEP-EEUSP.

À disposição para eventuais esclarecimentos, SECRETARIA EXECUTIVA

\footnotetext{
Conselho Estadual de Saúde de são Paulo Tel: (11) 3066-871 CONSELHO ESTADUAL
DESAUDEE DE SAO PAULO

E-mail: ces@saude.sp.gov.br
} 


\title{
ANEXO C - AUTORIZAÇÃO INSTITUCIONAL - COSEMS/SP
}

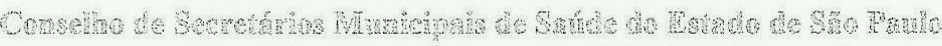 \\ wDr. Sebastita de Mirnes" - COSEMS/GP

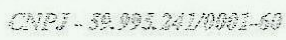

$\sin$

São Pavio, 22 de margo de 2018

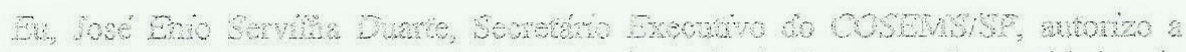

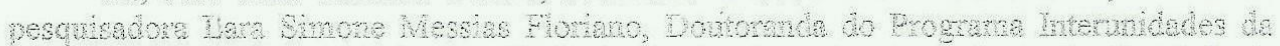
Escola de Enfemagem da Univerbidude de Sho Pavio, sob onemaca da Prof Dra Sonia

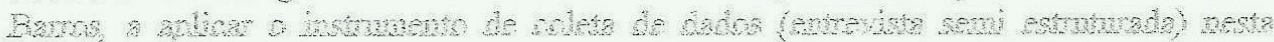
inotituigio, exclusivamente para o desenvolvmento do estudo intiniado: wpoltioas

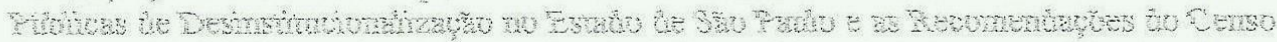

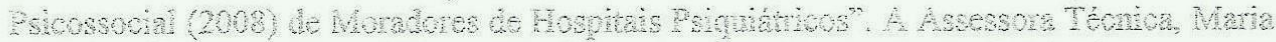

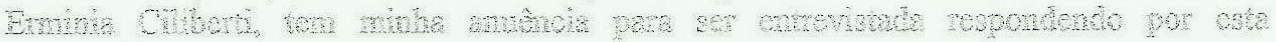
instivicso.

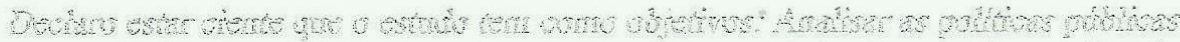

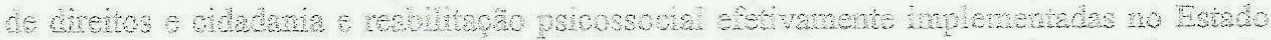
de Sä Faulo, dervadas do conjunto de recomendaposes proposins na obra resulante do

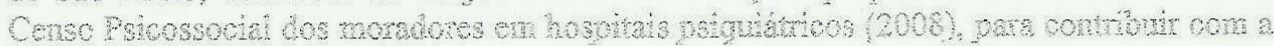

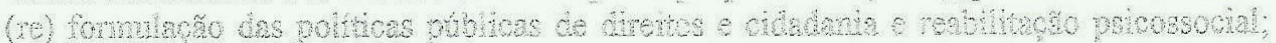

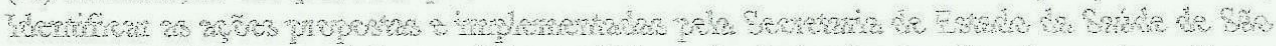

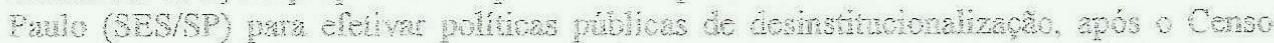

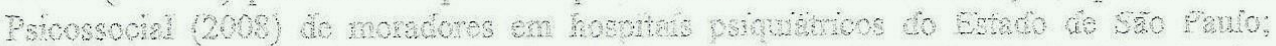

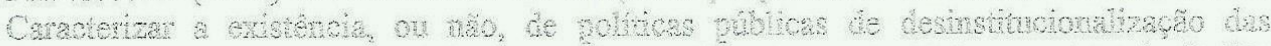
pessoas con trmstomos hembis inemedas an hospitais priquámicos no Estado do Sa Pewio.

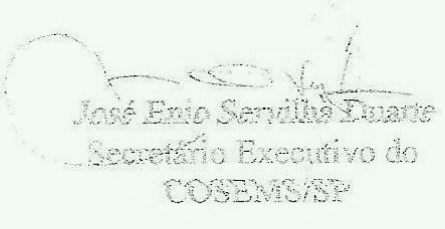

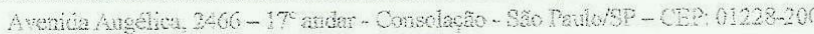

S-mail:

Site:

Fone: (11) $3013-7225$ 


\title{
ANEXO D - AUTORIZAÇÃO INSTITUCIONAL - MPSP
}

\author{
MINISTÉRIO PÚBLICO DO ESTADO DE SÃO PAULO \\ PROCURADORIA GERAL DE JUSTIÇA
}

\section{AUTORIZAÇÃO INSTITUCIONAL PARA REALIZAÇÃO DE PESQUISA CIENTÍFICA}

Eu, Tiago Cintra Zarif, Procurador de Justiça, Coordenador-Geral do Centro de Apoio Cível e de Tutela Coletiva, do Ministério Público do Estado de São Paulo, autorizo a pesquisadora Lara Simone Messias Floriano, Doutoranda do Programa Interunidades da Escola de Enfermagem da Universidade de São Paulo, sob orientação da Profa Dra Sônia Barros, a aplicar o instrumento de coleta de dados (entrevista semi estruturada) nesta instituição, exclusivamente para o desenvolvimento do estudo intitulado: "Políticas Públicas de Desinstitucionalização no Estado de São Paulo e as Recomendações do Censo Psicossocial (2008) de Moradores de Hospitais Psiquiátricos!". O Coordenador do Centro de Apoio de Direitos Humanos e Direitos Sociais, Dr. Roberto de Campos Andrade, tem minha anuência para ser entrevistado respondendo por este setor.

Declaro estar ciente que o estudo tem como objetivos: Analisar as políticas públicas de direitos e cidadania e reabilitação psicossocial efetivamente implementadas no Estado de São Paulo, derivadas do conjunto de recomendações propostas na obra resultante do Censo Psicossocial dos moradores em hospitais psiquiátricos (2008), para contribuir com a (re) formulação das políticas públicas de direitos e cidadania e reabilitação psicossocial; Identificar as ações propostas e implementadas pela Secretaria de Estado da Saúde de São Paulo (SES-SP) para efetivar políticas públicas de desinstitucionalização, após o Censo Psicossocial (2008) de moradores em hospitais psiquiátricos do Estado de 


\section{MINISTÉRIO PÚBLICO DO ESTADO DE SÃO PAULO PROCURADORIA GERAL DE JUSTIÇA}

São Paulo; Caracterizar a existência, ou não, de políticas públicas de desinstitucionalização das pessoas com transtornos mentais internadas em hospitais psiquiátricos no Estado de São Paulo.

São Paulo, 26 de março de 2018.

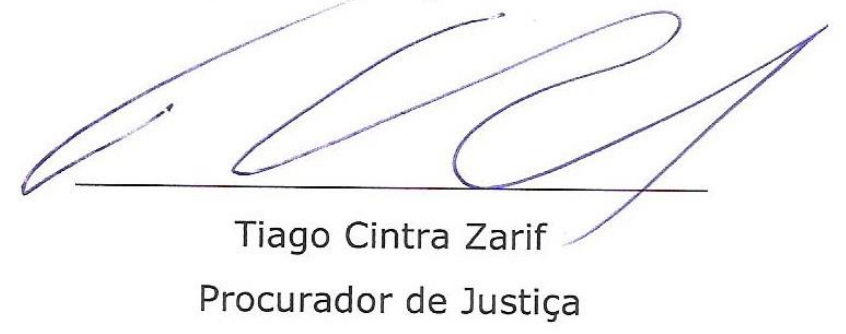

Coordenador-Geral do CAO Cível e de Tutela Coletiva 


\section{ANEXO E - PARECER COMITÊ DE ÉTICA DA EEUSP}

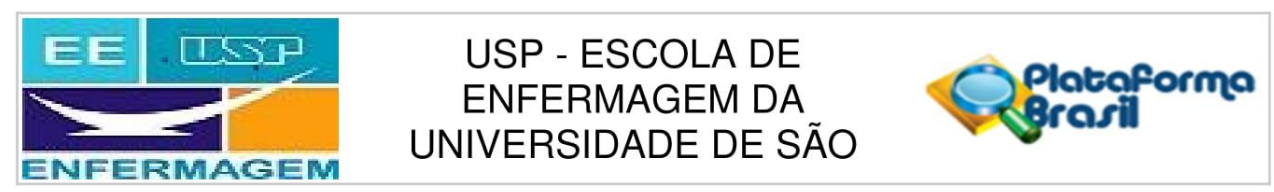

\section{PARECER CONSUBSTANCIADO DO CEP}

\section{DADOS DO PROJETO DE PESQUISA}

Título da Pesquisa: POLÍTICAS PÚBLICAS DE DESINSTITUCIONALIZACÃO NO ESTADO DE SÃO PAULO E AS RECOMENDAÇÕES DO CENSO PŞICOSSOCIAL (2008) DE MORADORES DE HOSPITAIS PSIQUIÁTRICOS

Pesquisador: LARA SIMONE MESSIAS FLORIANO

Área Temática:

Versão: 1

CAAE: 79446417.7 .0000 .5392

Instituição Proponente: Escola de Enfermagem da Universidade de São Paulo - EEUSP

Patrocinador Principal: Financiamento Próprio

\section{DADOS DO PARECER}

Número do Parecer: 2.384 .307

Apresentação do Projeto:

Trata-se de um projeto vinculado ao Programa Interunidades de Doutoramento em Enfermagem da Escola de Enfermagem da Universidade de São Paulo e Escola de Enfermagem de Ribeirão Preto.

A pesquisadora toma como objeto de estudo, a análise das recomendações e diretrizes das políticas públicas de desinstitucionalização conduzidas pela Secretaria de Estado da Saúde de São Paulo (SES-SP), após a publicação em 2008 do Censo Psicossocial de moradores de Hospitais Psiquiátricos do Estado de São Paulo.

Trata-se de um estudo de abordagem qualitativa, baseado em pesquisa documental e na realização de 10 entrevistas semi-estruturadas com gestores. 0 cenário do estudo será a SES-SP. Serão entrevistados o Secretário Estadual de Saúde da época da realização do Censo Psicossocial de 2008 e das gestões posteriores; o Coordenador da Área Técnica Saúde Mental, Álcool e Drogas da SES-SP da época de realização dos dois Censos Psicossociais (2008 e 2014) e das gestões posteriores; o Presidente ou representante do Conselho de Secretários Municipais de Saúde do Estado de São Paulo; o Coordenador ou representante da Comissão de Saúde Mental, Álcool e outras Drogas do Conselho Estadual de Saúde; o Coordenador ou representante do Centro de Apoio Operacional Cível e de Tutela Coletiva - CAO Direitos Humanos e Direitos Sociais do Ministério Público de São Paulo; e o Coordenador ou representante do Núcleo Especializado de Cidadania e Direitos Humanos da Defensoria Pública de São Paulo.

Endereço: Av. Dr. Enéas de Carvalho Aguiar, 419

Bairro: Cerqueira Cesar

UF: SP Município: SAOPAULO

CEP: $05.403-000$

Telefone: (11)3061-8858

E-mail: cepee@usp.br 


\section{USP - ESCOLA DE
ENFERMAGEM DA
UNIVERSIDADE DE SÃO}

Continuação do Parecer: 2.384.307

As entrevistas serão gravadas, transcritas e analisadas com base no "Método de Análise de Discurso". O roteiro para condução das entrevistas consta do protocolo da pesquisa. Apresenta ainda, o cronograma de execução do projeto com término previsto para dezembro de 2018. O orçamento totaliza $R \$ 950,00$ e será custeado pela própria pesquisadora.

\section{Objetivo da Pesquisa:}

Objetivo geral:

Analisar as políticas públicas de direitos e cidadania e reabilitação psicossocial efetivamente implementadas no Estado de São Paulo, derivadas do conjunto de recomendações propostas na obra resultante do Censo Psicossocial dos moradores em hospitais psiquiátricos (2008), para contribuir com a (re) formulação das políticas públicas de direitos e cidadania e reabilitação psicossocial.

Objetivos específicos:

1-Identificar as ações propostas e implementadas pela Secretaria de Estado da Saúde de São Paulo (SESSP) para efetivar políticas públicas de desinstitucionalização, após o Censo Psicossocial (2008) de moradores em hospitais psiquiátricos do Estado de São Paulo.

2-Caracterizar a existência, ou não, de políticas públicas de desinstitucionalização das pessoas com transtornos mentais internadas em hospitais psiquiátricos no Estado de São Paulo.

\section{Avaliação dos Riscos e Benefícios:}

A pesquisadora informou que a entrevista poderá gerar algum desconforto em função das perguntas ou mesmo do cansaço em função do tempo despendido pelo participante. Caso isso ocorra, o participante poderá suspender a entrevista. Quanto aos benefícios, o estudo poderá contribuir no aperfeiçoamento das políticas e das ações de Saúde Mental em curso na SES-SP para a desinstitucionalização dos moradores com longa internação nos hospitais psiquiátricos do estado.

\section{Comentários e Considerações sobre a Pesquisa:}

O projeto está redigido adequadamente, apresenta coerência interna e detalha os aspectos éticos. Constam do protocolo de pesquisa, os modelos de cartas de solicitação de autorização institucional para a realização do estudo.

De acordo com o cronograma apresentado, a coleta dos dados será iniciada em 02/01/2018.

Endereço: Av. Dr. Enéas de Carvalho Aguiar, 419

Bairro: Cerqueira Cesar

UF: SP Município: SAO PAULO

CEP: $05.403-000$

Telefone: (11)3061-8858

E-mail: cepee@usp.br 


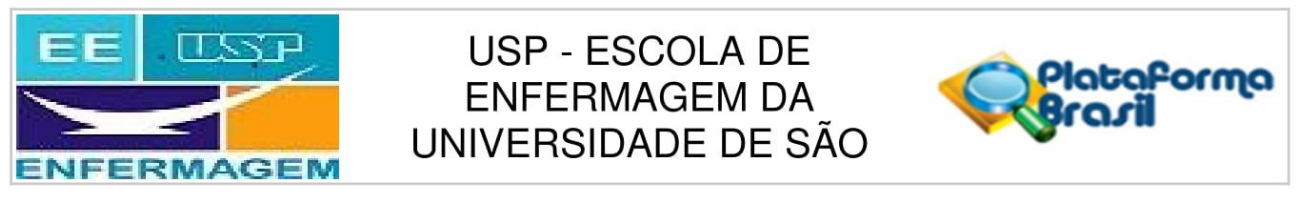

Continuação do Parecer: 2.384.307

Considerações sobre os Termos de apresentação obrigatória:

O Termo de Consentimento Livre e Esclarecido (TCLE), dirigido aos gestores que serão entrevistados, atende todos os requisitos da resolução 466/2012 da Conep.

Recomendações:

Recomenda-se, incluir no TCLE que a entrevista será gravada, conforme consta dos procedimentos metodológicos do projeto.

Conclusões ou Pendências e Lista de Inadequações:

O projeto não apresenta óbices éticos que impeçam a sua realização.

Considerações Finais a critério do CEP:

- Este CEP informa a necessidade de registro dos resultados parciais e finais na Plataforma Brasil;

- Esta aprovação não substitui a autorização da instituição coparticipante, antes do início da coleta de dados.

Este parecer foi elaborado baseado nos documentos abaixo relacionados:

\begin{tabular}{|c|c|c|c|c|}
\hline Tipo Documento & Arquivo & Postagem & Autor & Situação \\
\hline $\begin{array}{l}\text { Informações Básicas } \\
\text { do Projeto }\end{array}$ & $\begin{array}{l}\text { PB_INFORMAÇÖES_BÁSICAS_DO_P } \\
\text { ROJETO 1020681.pōdf }\end{array}$ & $\begin{array}{c}30 / 10 / 2017 \\
12: 56: 40 \\
\end{array}$ & & Aceito \\
\hline $\begin{array}{l}\text { TCLE / Termos de } \\
\text { Assentimento / } \\
\text { Justificativa de } \\
\text { Ausência } \\
\end{array}$ & tcleLara.docx & $\begin{array}{c}30 / 10 / 2017 \\
12: 56: 07\end{array}$ & $\begin{array}{l}\text { LARA SIMONE } \\
\text { MESSIAS } \\
\text { FLORIANO }\end{array}$ & Aceito \\
\hline $\begin{array}{l}\text { Projeto Detalhado / } \\
\text { Brochura } \\
\text { Investigador }\end{array}$ & projetoqualificacaolarafinal30102017.dod & $\begin{array}{c}30 / 10 / 2017 \\
12: 55: 47\end{array}$ & $\begin{array}{l}\text { LARA SIMONE } \\
\text { MESSIAS } \\
\text { FLORIANO }\end{array}$ & Aceito \\
\hline Folha de Rosto & lara__20171030103616.pdf & $\begin{array}{c}30 / 10 / 2017 \\
11: 36: 47\end{array}$ & $\begin{array}{l}\text { LARA SIMONE } \\
\text { MESSIAS }\end{array}$ & Aceito \\
\hline
\end{tabular}

Situação do Parecer:

Aprovado

Necessita Apreciação da CONEP:

Não

Endereço: Av. Dr. Enéas de Carvalho Aguiar, 419

Bairro: Cerqueira Cesar

UF: SP Município: SAO PAULO

CEP: $\quad 05.403-000$

Telefone: (11)3061-8858

E-mail: cepee@usp.br 


USP - ESCOLA DE
ENFERMAGEM DA
ENIVERSIDADE DE SÃO

SAO PAULO, 16 de Novembro de 2017

Assinado por:

Lisabelle Mariano Rossato

(Coordenador)

Endereço: Av. Dr. Enéas de Carvalho Aguiar, 419

Bairro: Cerqueira Cesa

CEP: $\quad 05.403-000$

UF: SP

Município: SAO PAULO

Telefone: (11)3061-8858

E-mail: cepee@usp.br 